Portland State University

PDXScholar

Spring 1-1-2012

\title{
An Empirical Study of Particulate Matter Exposure for Transit Users at Bus Stop Shelters
}

Adam Moore

Portland State University

Follow this and additional works at: https://pdxscholar.library.pdx.edu/open_access_etds

Part of the Environmental Design Commons, Environmental Engineering Commons, and the Structural Engineering Commons

Let us know how access to this document benefits you.

\section{Recommended Citation}

Moore, Adam, "An Empirical Study of Particulate Matter Exposure for Transit Users at Bus Stop Shelters" (2012). Dissertations and Theses. Paper 870.

https://doi.org/10.15760/etd.870

This Thesis is brought to you for free and open access. It has been accepted for inclusion in Dissertations and Theses by an authorized administrator of PDXScholar. Please contact us if we can make this document more accessible: pdxscholar@pdx.edu. 
An Empirical Study of Particulate Matter Exposure for Transit Users at Bus Stop Shelters

by

Adam Moore

A thesis submitted in partial fulfillment of the requirements for the degree of

Master of Science

in

Civil and Environmental Engineering

Thesis Committee:

Miguel Figliozzi, Chair

Christopher Monsere

Kelly Clifton

Portland State University

(C) 2012 


\begin{abstract}
Congested traffic corridors in dense urban areas are key contributors to the degradation of urban air quality. While waiting at bus stops, transit patrons may be exposed to greater amounts of vehicle-based pollution, including particulate matter, due to their proximity to the roadway. Current guidelines for the location and design of bus stops do not take into account air quality or exposure considerations.

This thesis provides a unique contribution to roadside air quality studies and presents an innovative method for the consideration of bus shelter placement. Exposure to roadside pollutants is estimated for transit riders waiting at three-sided bus stop shelters that either: 1) face roadway traffic, or 2) face away from roadway traffic. Shelters were instrumented with particulate matter monitoring equipment, sonic anemometers for wind speed and direction, and vehicle counters capable of categorizing vehicles by length. Temperature and relative humidity were gathered from a nearby monitoring station. Data were collected for two different days at three shelters during both the morning and afternoon peak periods for a total of eleven data periods.

Bus shelter orientation is found to significantly affect concentration of four sizes of particulate matter: ultrafine particles, $\mathrm{PM}_{1}, \mathrm{PM}_{2.5}$, and $\mathrm{PM}_{10}$. Shelters with an opening oriented towards the roadway were observed to have significantly higher concentrations inside the shelter than outside the shelter. In contrast, shelters oriented away from the roadway were observed to have significantly lower concentrations inside the shelter than outside the shelter. The differences in average particulate matter concentrations are statistically significant across all four sizes of particulate matter studied.
\end{abstract}


Additional correlation and linear regression investigation reveals interactions between particulate concentrations and built environment characteristics, vehicle flow, and weather conditions. Temperature and relative humidity played a large role in the diurnal variation of average concentration levels. In all instances, particulate concentrations were greater during the morning period, often substantially so. Particulate concentrations are shown to vary based on both wind speed and direction. Vehicle flow is correlated with particulate levels, though significance is not consistent. Lagged vehicle flow is demonstrated to be more consistently significant. Regression analysis suggests weather factors such as wind, temperature, and relative humidity explain roughly $70 \%$ of particulate variation, while vehicle flow explains less than $6 \%$. 


\section{ACKNOWLEDGEMENTS}

This master's thesis has been a long time coming, and at times it has proven to be the stereotypical thorn-in-side to both myself and my advisor. Yet, it has provided invaluable experiences in project management, scientific investigation, academic writing, and perseverance. At its most basic, this thesis is a manifestation of my graduate student experience and demonstrates my potential and desire for conducting research relating to transportation air quality issues. I consider myself fortunate to have found my way into this topic area almost by chance. I entered graduate school with only a vague research area in mind. Through the helpful guidance of my advisor, Dr. Miguel Figliozzi, I became involved in several projects investigating air quality along near-road environments. Without Dr. Figliozzi's guidance, I'm not sure I would have been so fortunate. This thesis has been built upon a solid foundation of guidance not only from Dr. Figliozzi, but also from others at Portland State and beyond. I have had help from numerous other academic "mentors," including Dr. Christopher Monsere and Dr. Kelly Clifton. My family and friends have provided essential patience and support and, on late nights in front of the computer, an occasional bottle of good Oregon beer. Finally, this project would have been considerably more difficult were it not for the help of two of my peers, Eric Albright and Courtney Slavin, who selflessly assisted in my cumbersome data collections and helped haul ever-multiplying monitoring devices over the course of three months. 


\section{TABLE OF CONTENTS}

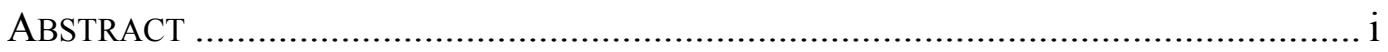

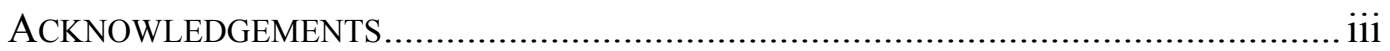

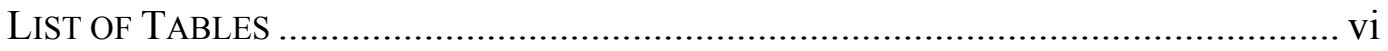

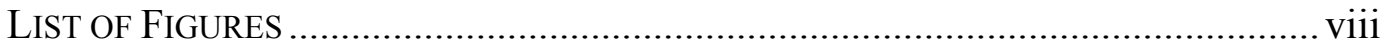

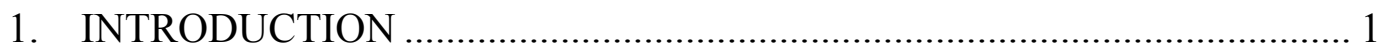

2. BACKGROUND AND LITERATURE REVIEW …................................... 3

2.1. Particulate Matter................................................................................... 3

2.2. Exposure to Particulate Matter ............................................................ 4

2.3. Mobile Particulate Matter Sources ....................................................... 5

2.4. Monitoring Particulate Matter Levels ..................................................... 6

2.5. Particulate Matter Exposure by Mode of Travel .................................. 7

2.6. Particulate Matter Exposure at Bus Stops............................................ 12

3. EXPERIMENTAL DESIGN AND DATA COLLECTION ....................... 22

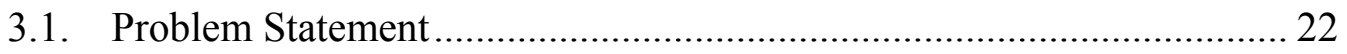

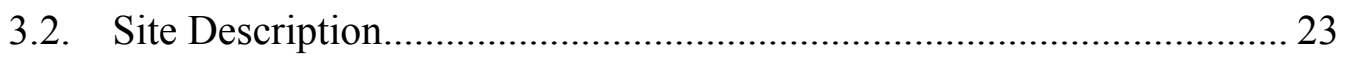

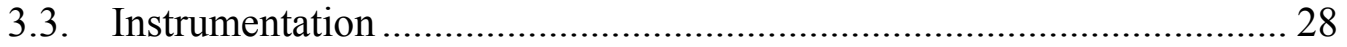

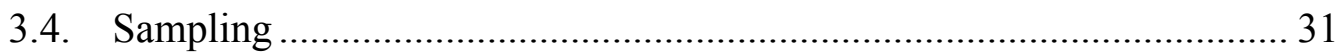

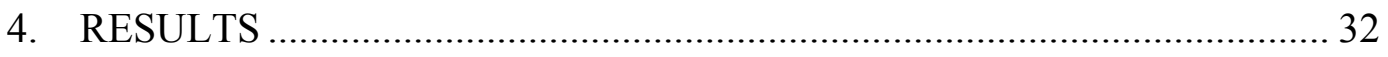

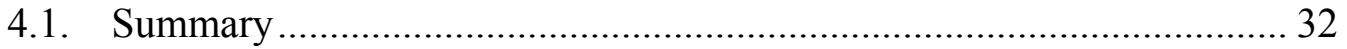

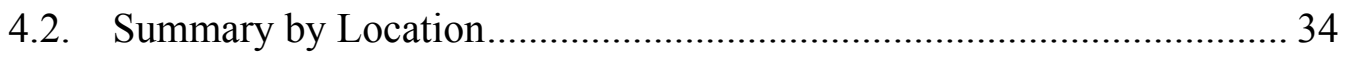

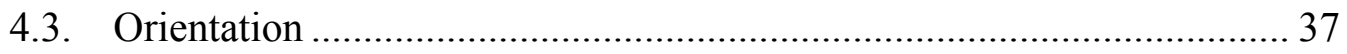

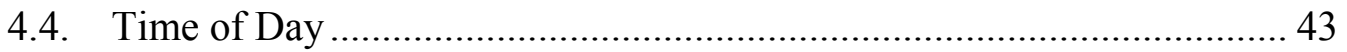

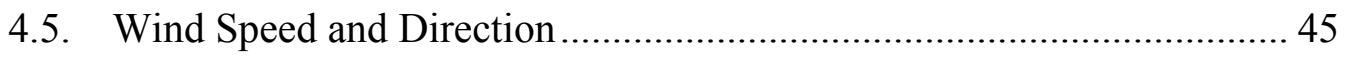

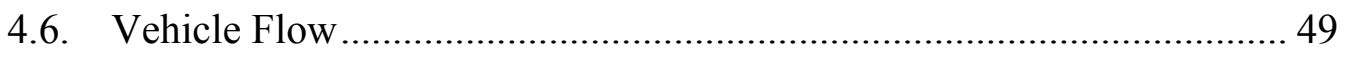

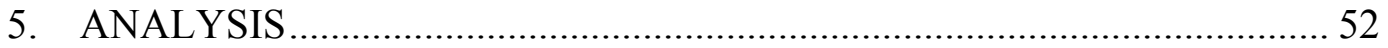

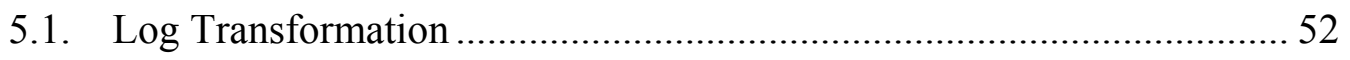

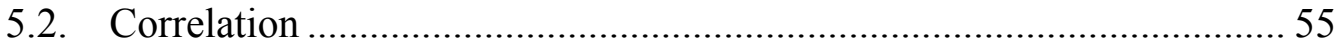

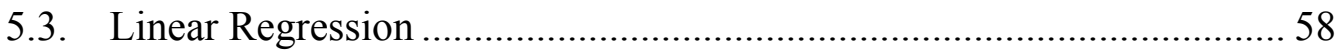

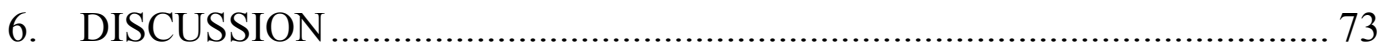




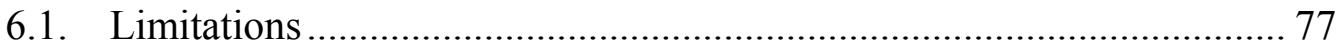

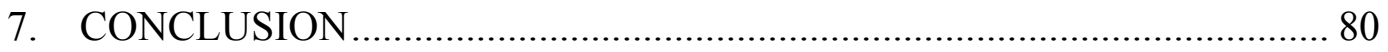

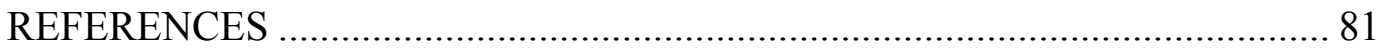

APPENDIX A - CORRELATION......................................................... 88

Pearson Correlations by Location (log-transformed) ................................... 88

Pearson Correlations by Location (not log-transformed) .............................. 94

APPENDIX B - Linear Regression ............................................................... 100

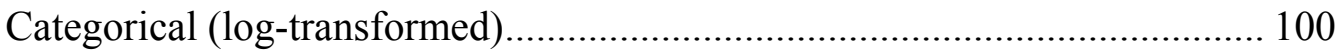

Comprehensive (log-transformed) ..................................................... 104

Categorical (not log-transformed) ........................................................ 108

Comprehensive (not log-transformed) ................................................. 112

APPENDIX C - Shelter Orientation Time Series Plots .................................. 114

Morning Particulate Measurements .......................................................... 114

Evening Particulate Measurements ......................................................... 118

APPENDIX D - Wind Effects on Particulate Concentration............................ 122

UFP - Wind Measurements......................................................................... 122

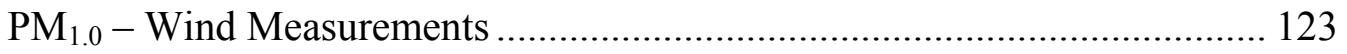

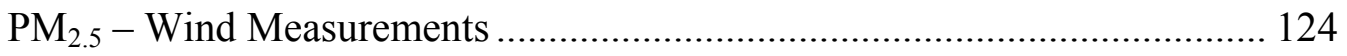

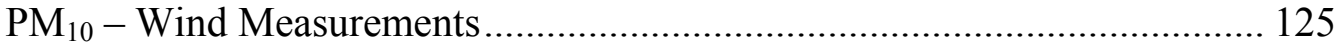

APPENDIX E - Vehicle and Particulate Interactions .................................... 126

Morning Vehicle Measurements............................................................ 126

Evening Vehicle Measurements ............................................................... 130 


\section{LiST OF TABLES}

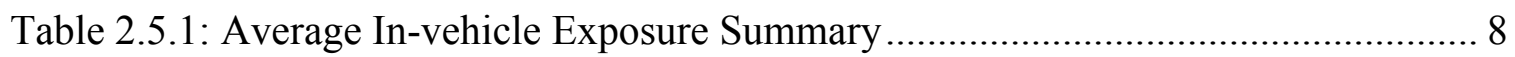

Table 2.5.2: Average Pedestrian Exposure Summary ........................................................ 9

Table 2.5.3: Average Cyclist Exposure Summary ............................................................. 10

Table 2.5.4: Average Transit Exposure Summary ........................................................... 11

Table 2.6.1: Advantages and Disadvantages of Bus Stop Locations .............................. 13

Table 2.6.2: Bus Stop Exposure Summary ………………………………………........ 18

Table 2.6.3: Summary of PM Exposure Concentration Studies on Different Transportation Modes in the Urban Environment ........................................................ 19

Table 3.1.1: Study Hypotheses .............................................................................. 22

Table 3.2.1: Bus Stop Shelter Characteristics along Powell Boulevard........................... 24

Table 3.2.2: Detailed Roadside Environment Characteristics of Study Locations........... 25

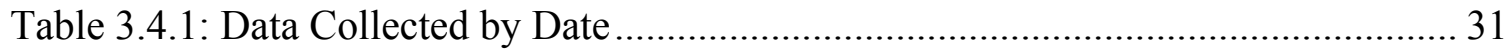

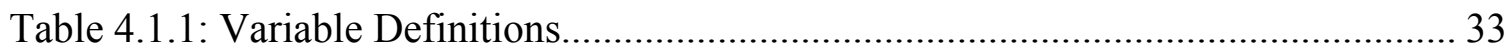

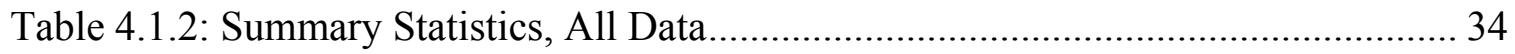

Table 4.2.1: Summary Statistics, Location 1 ................................................................ 35

Table 4.2.2: Summary Statistics, Location 2 ……………........................................... 35

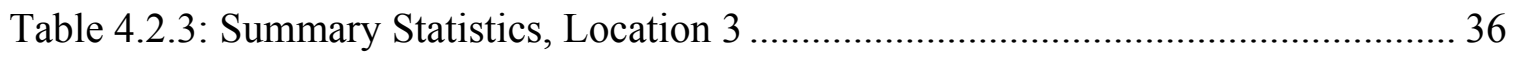

Table 4.2.4: Student t-test Results for Location 1 ....................................................... 36

Table 4.3.1: Summary Statistics, Location 1 .............................................................. 37

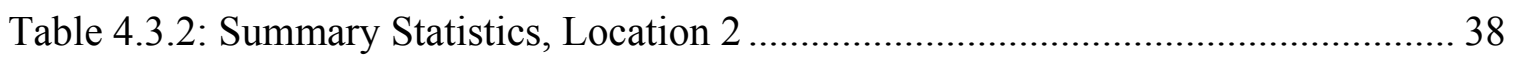

Table 4.3.3: Summary Statistics, Location 3 ………..................................................... 39

Table 4.3.4: Student t-test Results for Statistical Significance ………………………..... 41

Table 4.4.1: Comparative Average Time of Day Concentrations ..................................... 44

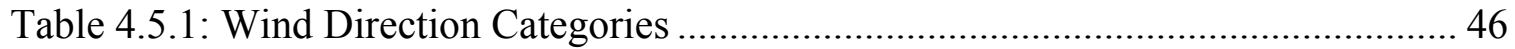

Table 5.2.1: Association Correlation Test (UFP and $\mathrm{PM}_{2.5}$ ) ………………………...... 56

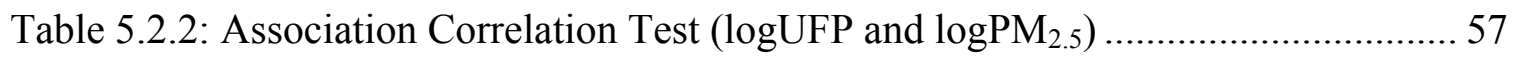

Table 5.3.1: Expected Coefficient Signs for Regression Analysis .................................... 59

Table 5.3.2: Comprehensive Linear Regression Model (logUFP Inside)......................... 64

Table 5.3.3: Comprehensive Linear Regression Model (logUFP Outside)....................... 64 
Table 5.3.4: Comprehensive Linear Regression Model $\left(\log \mathrm{PM}_{2.5}\right.$ Inside) ...................... 65

Table 5.3.5: Comprehensive Linear Regression Model $\left(\log \mathrm{PM}_{2.5}\right.$ Outside) ................... 65

Table 5.3.6: Final logUFP Linear Regression Model, Inside Shelter.............................. 66

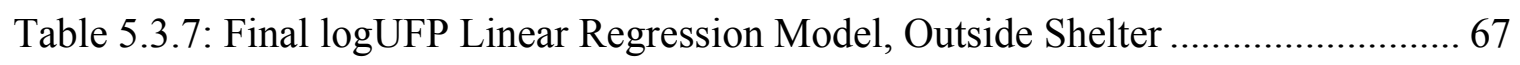

Table 5.3.8: Final $\log \mathrm{PM}_{2.5}$ Linear Regression Model, Inside Shelter ........................... 67

Table 5.3.9: Final $\log \mathrm{PM}_{2.5}$ Linear Regression Model, Outside Shelter ......................... 68

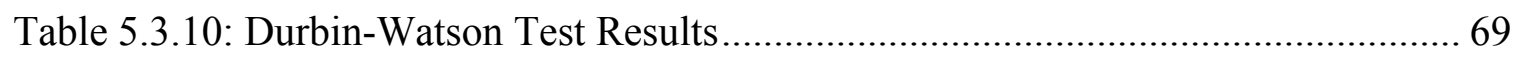

Table 5.3.11: Final UFP Model + Autoregresive Term, Inside Shelter........................... 70

Table 5.3.12: Final UFP Model + Autoregresive Term, Outside Shelter ....................... 71

Table 5.3.13: Final $\mathrm{PM}_{2.5}$ Model + Autoregresive Term, Inside Shelter ........................ 71

Table 5.3.14: Final $\mathrm{PM}_{2.5}$ Model + Autoregresive Term, Outside Shelter ...................... 72

Table 5.3.15: Durbin-Watson Test Results for Autoregressive Term ........................... 72 


\section{LIST OF FIGURES}

Figure 2.6.1: Bus stop locations on city corridors................................................... 14

Figure 2.6.2: Minimum shelter design dimensions for ADA compliance......................... 16

Figure 2.6.3: Shelter clearance distances .................................................................... 16

Figure 3.2.1: Shelter facing towards roadway. ……………………………………... 24

Figure 3.2.2: Shelter facing away from roadway.......................................................... 24

Figure 3.2.3: Shelter location overview, courtesy Google.com....................................... 26

Figure 3.2.4: Built environment characteristics for (a) Location 1, (b) Location 2, and (c) Location 3. Aerial photography courtesy Google.com .................................................... 27

Figure 4.3.1: Morning (a) UFP and (b) $\mathrm{PM}_{2.5}$ concentrations inside and outside the bus

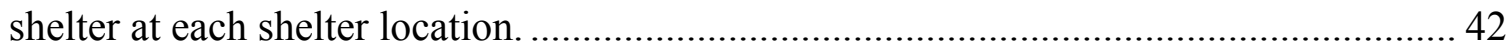

Figure 4.5.1: Bivariate polar plots illustrating wind speed and direction effects on UFP

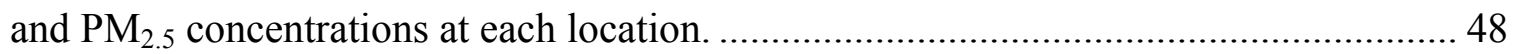

Figure 4.6.1: Morning UFP (a) and evening $\mathrm{PM}_{2.5}$ (b) concentrations at each bus shelter location overlaid with hourly vehicle flow................................................................. 51

Figure 5.1.1: Sample comparisons of UFP distributions, shelter facing roadway............ 53

Figure 5.1.2: Sample comparisons of UFP distributions, shelter facing away from

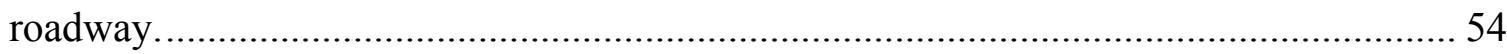

Figure 5.3.1: Model residuals for each particualte size. .................................................. 69 


\section{INTRODUCTION}

This thesis uses original air quality samples to analyze the impacts of semienclosed bus stop shelters on transit user exposure. Such shelters are common in urban areas and have traditionally been placed on high-ridership routes to provide a convenience to waiting passengers. Little research has been conducted to determine whether orientation of bus shelters significantly affects exposure to roadside air pollution, and no published study has examined the variables considered in this paper simultaneously. This research lays a framework for investigating shelter orientation while examining other variables including wind speed and direction and vehicle flow as they pertain to particulate matter concentration levels.

Environmental concerns constitute a rising trend among the general public, demanding focused research to best understand the impact we have on our surroundings, be it a natural or metropolitan setting. It is important to understand impacts to human health in the built environment of some of our most populated (and polluted) urban areas to mitigate risks and raise quality of life. Arterial corridors are a vital component of the urban fabric and are traveled daily by thousands using a variety of modes. Commuters choose public transportation for a variety of reasons, one of which may be to reduce their impact on the environment. Ironically, those waiting at bus stops may be standing in a microenvironment with substandard air quality, exposed to elevated levels of air pollution because of a close proximity to high volumes of motor vehicles.

Commuters in the United States spend an average of 45 minutes of their day commuting to and from work (Pisarski 2006), giving rise to concerns over traffic congestion, public health factors, and environmental deterioration. These concerns have 
fostered a push to shift from single-occupancy vehicle use to non-automotive or public transport modes of travel in an effort to reduce congestion and improve public and environmental health while maintaining mobility. Exposure to air pollution on and near the roadway varies with mode choice - single-occupancy vehicle, carpool, public transportation, walking, or bicycling. Public transportation users contribute relatively little to total vehicle-based pollution levels compared to motorists yet may be exposed to greater amounts of pollution, including particulate matter, as a result of waiting for buses near busy corridors. 


\section{BACKGROUND AND LITERATURE REVIEW}

\subsection{Particulate Matter}

Particulate matter $(\mathrm{PM})$ is one of six common air pollutants regulated by the National Ambient Air Quality Standards (NAAQS), established by the US Environmental Protection Agency (EPA) as part of the Clean Air Act (EPA 1990). PM is a complex mixture of solid and liquid material, made up of carbon particles, hydrocarbons and inorganics. PM is unsafe at any exposure level, meaning there is no particle concentration threshold below which human health is not jeopardized (Morawska et al. 2004). Despite being relatively nonreactive, PM is highly variable in composition and often contains chemically reactive substances on the particle surface (Vallero 2008).

PM is generally classified into four categories based on aerodynamic diameter of the particles. $\mathrm{PM}_{10}$ (coarse particles), $\mathrm{PM}_{2.5}$ (fine particles) and $\mathrm{PM}_{1.0}$ (very fine particles) are defined as having aerodynamic diameters less than $10 \mu \mathrm{m}, 2.5 \mu \mathrm{m}$ and $1.0 \mu \mathrm{m}$, respectively. $\mathrm{PM}_{0.1}$, more commonly known as ultrafine particles (UFP), have a diameter less than $0.1 \mu \mathrm{m}$ and are the smallest particles yet classified. UFP dominate the particulate number spectrum yet make up a very small percentage of total particulate mass; as a result, UFP are characterized by particle number (particles $/ \mathrm{cm}^{3}$, or $\mathrm{pt} / \mathrm{cc}$ ) as opposed to particle mass $\left(\mathrm{mg} / \mathrm{m}^{3}\right.$ or $\left.\mu \mathrm{g} / \mathrm{m}^{3}\right)$ for $\mathrm{PM}_{1.0}$ and larger.

Ambient urban $\mathrm{PM}_{10}$ background concentrations, unaffected by roadway sources, range from 17-61 $\mu \mathrm{g} / \mathrm{m}^{3}$ (Ballester et al. 2008). Ambient urban $\mathrm{PM}_{2.5}$ background concentrations are generally below $16 \mu \mathrm{g} / \mathrm{m}^{3}$ (Bedada et al. 2007). Studies examining ambient $\mathrm{PM}_{1.0}$ background concentrations are not as common as those for the other particulate sizes in this paper, but it is generally agreed that levels are below $20 \mathrm{ug} / \mathrm{m}^{3}$ 
(Yin and Harrison 2008). Ambient urban UFP background concentrations range from a few thousand to 20,000 particles $/ \mathrm{cm}^{3}$ (Morawska et al. 2004). NAAQS exposure standards were most recently revised in 2006 to tighten the 24-hour $\mathrm{PM}_{2.5}$ standard to 35 $\mu \mathrm{g} / \mathrm{m}^{3}$, while the 24-hour $\mathrm{PM}_{10}$ standard has remained at $150 \mu \mathrm{g} / \mathrm{m}^{3}$ since 1997. $\mathrm{PM}_{1.0}$ and UFP exposure standards have not yet been established by the EPA. While the EPA bases its air quality standards on annual and 24-hour exposures, it is thought that peak exposures (one hour or less in duration) are most relevant to human health and exacerbation of existing symptoms (Michaels and Kleinman 2000).

\subsection{Exposure to Particulate Matter}

Much attention has been given to the epidemiological association between exposure to PM and adverse health outcomes (Møller et al. 2008; Vinzents et al. 2005; Morawska et al. 2004; Pope III et al. 2004). Also referred to as soot, black carbon, black smoke and fine particle pollution, PM exhibits gas-like properties and inhalation brings the particles deep into the lungs. The body's natural defenses, such as nasal hair filtering and cilia in the lungs, are unable to capture PM due to the small size of the particles (Vallero 2008). PM has been linked to aggravation of asthma, chronic bronchitis and decreased lung function (Vallero 2008). Many studies have documented negative cardiovascular effects from exposure to $\mathrm{PM}_{10}$ and $\mathrm{PM}_{2.5}$ (Chuang et al. 2007; Samet et al. 2000), while $\mathrm{PM}_{1.0}$ and UFP have been shown to increase cardiorespiratory symptoms for elderly patients (Chuang et al. 2005).

Individuals traveling within transport microenvironments (that is, an extremely small-scale environment comprised of the roadway and its immediate surroundings) may 
be exposed to higher levels of pollution, comprising a substantial percentage of their daily total exposure within a short amount of time (Kaur et al. 2007; Gulliver and Briggs 2004). Elevated concentrations of particulate matter near roads in excess of ambient urban concentrations indicate a direct relationship to vehicle emissions (Kittelson 1998). Those waiting for buses are often waiting along busy corridors at peak hours, increasing the likelihood of elevated exposure. "Hot spots" of PM concentration can occur near multilane intersections in urban environments (Vallero 2008), and buildings can restrict air movement and limit the volume of air in which the pollution is contained, exacerbating the problem (Vardoulakis et al. 2003). Lung et al. (2005) found $\mathrm{PM}_{2.5}$ concentrations to be nearly double at intersections located near buildings versus intersections in open space. Bus stops are likely to be placed at intersections to allow patrons ease of access to transfer points.

\subsection{Mobile Particulate Matter Sources}

Motor vehicles are the primary source of fine and ultrafine particles along transportation corridors (Hitchins et al. 2000). The majority of particle numbers are in the 0.02-0.13 $\mu \mathrm{m}$ range for diesel engines (Morawska et al. 1998) and 0.02-0.06 $\mu \mathrm{m}$ for gasoline engines (Ristovski et al. 1998). Among motor vehicles, diesel vehicles are commonly understood to emit substantially more PM than gasoline vehicles. Diesel engines are regulated by fuel flow only, differing from gasoline engines in that air flow remains constant with engine speed (Vallero 2008). Such a setup allows for more available power, but also results in more exhaust. PM is a primary emission from diesel engines, and at times diesel engines may emit 10 to 100 times more PM mass than 
gasoline engines (Vallero 2008; Wayne et al. 2004; Kittelson 1998). As such, diesel vehicles are often singled out as significant sources of particulate matter (EPA 1990). PM emissions from diesel engines are regulated by the EPA, most recently set at a maximum of $0.01 \mathrm{~g} / \mathrm{bhp}-\mathrm{hr}$ (EPA 2007).

In singling out diesel vehicles (often referred to as "heavy vehicles" in recognition of virtually all heavy vehicles being powered by diesel engines), it is important to understand pollution mitigation techniques. Although recent EPA standards have targeted diesel engines and mandated more stringent PM emission standards, existing diesel vehicles are likely to remain in operation for some years to come due to the longevity and durability of diesel engines. Diesel PM emissions reduction efforts involve either new engine replacements or retrofitting existing engines with more advanced emission control equipment (Schimek 2001). Emissions are partially mitigated without modification through fuel and maintenance; lower sulfur fuels burn cleaner, and overfueling can be prevented by tuning the engine correctly (Vallero 2008). Alternative fuels can provide PM control; many transit agencies have shifted their fleet to a blend of diesel and biodiesel fuel, which is refined from plant-based hydrocarbons such as used cooking oils and is estimated to reduce PM emissions by as much as 25 percent using a B35 blend (65 percent diesel, 35 percent biodiesel) (Pinto et al. 2005).

\section{4. $\quad$ Monitoring Particulate Matter Levels}

Exposure to pollutants in transportation microenvironments is often more complex than ambient conditions from a fixed monitoring station may describe (Adams et al.2001a). Fixed monitoring stations have traditionally been used for the establishment 
of air quality guidelines and policy (including EPA guidelines) over broad areas such as metro regions, but these stations are not designed to represent exposure on a scale small enough for a transport microenvironment, and as a result may not adequately describe small-scale conditions in close proximity to traffic (Gulliver and Briggs 2004; Adams et al. 2001a). Gulliver and Briggs (2004) found a fixed monitoring station to be a poor marker for $\mathrm{PM}_{10}$ concentrations one kilometer away from their sampling location.

UFP concentrations in particular decrease significantly with distance due to dispersion and coagulation into larger particles, returning to background levels around 300 meters downwind from the roadway (Zhu et al. 2002). A fixed monitoring station would be expected to underestimate UFP concentration levels for a roadway located outside this range. Micro-scale exposure measurements present a more accurate picture of roadway air quality conditions by resolving coagulation problems, in which particles combine to form larger particles over distance, leading to a misrepresentation of particle size concentrations at a given location if the monitoring device is several hundred meters away (Kaur et al.2007).

\subsection{Particulate Matter Exposure by Mode of Travel}

Several studies have used micro-scale measurements of near-roadway environments to investigate commuter exposure to $\mathrm{PM}_{10}, \mathrm{PM}_{2.5}$ and $\mathrm{PM}_{1.0}$ among different commuting modes including private vehicle, bicycle, walking, and public transportation. The general consensus is that particulate exposure is greatly affected by the mode of transport chosen (Briggs et al. 2008; Kaur, Nieuwenhuijsen, and Colvile 2007; Kaur 2006; Chan et al. 2002). 
Adams et al. (2001b) explored in-vehicle exposure to $\mathrm{PM}_{2.5}$ as part of a larger multi-mode exposure investigation conducted over multiple three-week periods in the winter and in the summer in London, UK, and found in-vehicle $\mathrm{PM}_{2.5}$ exposure to be greater in the summer $\left(37.7 \mu \mathrm{g} / \mathrm{m}^{3}\right)$ than the winter $\left(33.7 \mu \mathrm{g} / \mathrm{m}^{3}\right)$ using both diesel- and gasoline-fueled vehicles ranging from six to eight years old. Gulliver and Briggs (2004) found in-vehicle $\mathrm{PM}_{10}, \mathrm{PM}_{2.5}$ and $\mathrm{PM}_{1.0}$ to average $43.16 \mu \mathrm{g} / \mathrm{m}^{3}, 15.54 \mu \mathrm{g} / \mathrm{m}^{3}$ and 7.03 $\mu \mathrm{g} / \mathrm{m}^{3}$, respectively, using a 5-year-old vehicle in Northampton, UK. Briggs et al. (2008) found in-vehicle exposure in London, UK to average $5.87 \mu \mathrm{g} / \mathrm{m}^{3}, 3.01 \mu \mathrm{g} / \mathrm{m}^{3}, 1.82 \mu \mathrm{g} / \mathrm{m}^{3}$ and 21,639 $\mathrm{pt} / \mathrm{cm}^{3}$ for $\mathrm{PM}_{10}, \mathrm{PM}_{2.5}, \mathrm{PM}_{1.0}$ and UFP, respectively; these averages are lower than the literature would expect and are attributed by the author to the in-vehicle air vent filtration system. These data are summarized in Table 2.5.1.

Table 2.5.1: Average In-vehicle Exposure Summary

\begin{tabular}{|c|c|c|c|c|}
\hline & \multicolumn{4}{|c|}{ Exposure } \\
\hline & UFP $\left(\mathrm{pt} / \mathrm{cm}^{3}\right)$ & $\mathrm{PM}_{1.0}\left(\mu \mathrm{g} / \mathrm{m}^{3}\right)$ & $\mathrm{PM}_{2.5}\left(\mu \mathrm{g} / \mathrm{m}^{3}\right)$ & $\mathrm{PM}_{10}\left(\mu \mathrm{g} / \mathrm{m}^{3}\right)$ \\
\hline $\begin{array}{c}\text { (Adams et al. } \\
\text { 2001b) }\end{array}$ & - & - & $\begin{array}{c}37.7(\operatorname{summer}) \\
33.7(\text { winter })\end{array}$ & - \\
\hline $\begin{array}{c}\text { (Gulliver and } \\
\text { Briggs 2004) }\end{array}$ & - & 7.03 & 15.54 & 43.16 \\
\hline $\begin{array}{c}\text { (Briggs et al. } \\
\text { 2008) }\end{array}$ & 21,639 & 1.82 & 3.01 & 5.87 \\
\hline
\end{tabular}

Kaur et al. (2005) found pedestrian exposure along a major road in London, UK to average $37.7 \mu \mathrm{g} / \mathrm{m}^{3}$ and $80,009 \mathrm{pt} / \mathrm{cm}^{3}$ for $\mathrm{PM}_{2.5}$ and UFP, respectively. $\mathrm{PM}_{2.5}$ levels in the morning were significantly higher than in the afternoon. UFP levels were significantly lower when walking building side in comparison to curbside on the 
sidewalk, attributed to proximity from the roadway. Gulliver and Briggs (2004) observed average $\mathrm{PM}_{10}, \mathrm{PM}_{2.5}$ and $\mathrm{PM}_{1.0}$ levels to be $38.18 \mu \mathrm{g} / \mathrm{m}^{3}, 15.06 \mu \mathrm{g} / \mathrm{m}^{3}$ and $7.14 \mu \mathrm{g} / \mathrm{m}^{3}$, respectively, while walking within a few feet of the curb along one of the main commuter routes in town. These data were collected simultaneously with the vehicle data previously mentioned, and the comparisons show a $16 \%$ increase in $\mathrm{PM}_{10}$ levels inside the vehicle versus walking, but show no change for $\mathrm{PM}_{2.5}$ and $\mathrm{PM}_{1.0}$ levels. Briggs et al. (2008) found average pedestrian exposure in London, UK to be $27.56 \mu \mathrm{g} / \mathrm{m}^{3}, 6.59 \mu \mathrm{g} / \mathrm{m}^{3}, 3.37$ $\mu \mathrm{g} / \mathrm{m}^{3}$ and $30,334 \mathrm{pt} / \mathrm{cm}^{3}$ for $\mathrm{PM}_{10}, \mathrm{PM}_{2.5}, \mathrm{PM}_{1.0}$ and UFP, respectively. These exposures are in excess of the in-vehicle exposure levels found by Briggs et al. (2008) by a factor of 4.7 for $\mathrm{PM}_{10}, 2.2$ for $\mathrm{PM}_{2.5}, 1.9$ for $\mathrm{PM}_{1.0}$ and 1.4 for UFP. These data are summarized in Table 2.5.2.

Table 2.5.2: Average Pedestrian Exposure Summary

\begin{tabular}{|c|c|c|c|c|}
\hline & \multicolumn{4}{|c|}{ Exposure } \\
\hline & UFP $\left(\mathrm{pt} / \mathrm{cm}^{3}\right)$ & $\mathrm{PM}_{1.0}\left(\mu \mathrm{g} / \mathrm{m}^{3}\right)$ & $\mathrm{PM}_{2.5}\left(\mu \mathrm{g} / \mathrm{m}^{3}\right)$ & $\mathrm{PM}_{10}\left(\mu \mathrm{g} / \mathrm{m}^{3}\right)$ \\
\hline $\begin{array}{c}\text { (Kaur, } \\
\text { Nieuwenhuijsen, } \\
\text { and Colvile 2005) }\end{array}$ & 80,009 & - & 37.7 & - \\
\hline $\begin{array}{c}\text { (Gulliver and } \\
\text { Briggs 2004) }\end{array}$ & - & 7.14 & 15.06 & 38.18 \\
\hline $\begin{array}{c}\text { (Briggs et al. } \\
\text { 2008) }\end{array}$ & 30,334 & 3.37 & 6.59 & 27.56 \\
\hline “_“= Not Applicable
\end{tabular}

The multi-mode study conducted by Adams et al. (2001b) found average cyclist $\mathrm{PM}_{2.5}$ exposure was greater in the summer $\left(34.5 \mu \mathrm{g} / \mathrm{m}^{3}\right)$ than in the winter $\left(23.5 \mu \mathrm{g} / \mathrm{m}^{3}\right)$. In a separate, cycle-specific study, Adams et al. (2001b) observed similar results: average cyclist exposure to $\mathrm{PM}_{2.5}$ was $34.2 \mu \mathrm{g} / \mathrm{m}^{3}$. Kendrick et al. (2011) conducted a UFP 
exposure comparison study between a traditional bicycle lane and a "cycle track" buffered from moving vehicles by a lane of parallel parking. UFP concentrations were consistently greater in the bicycle lane than the cycle track, with a mean difference ranging from $3,309 \mathrm{pt} / \mathrm{cm}^{3}$ to $21,043 \mathrm{pt} / \mathrm{cm}^{3}$ (Kendrick et al. 2011).

Table 2.5.3: Average Cyclist Exposure Summary

\begin{tabular}{|c|c|c|c|c|}
\hline & \multicolumn{4}{|c|}{ Exposure } \\
\hline & $\mathrm{UFP}\left(\mathrm{pt} / \mathrm{cm}^{3}\right)$ & $\mathrm{PM}_{1.0}\left(\mu \mathrm{g} / \mathrm{m}^{3}\right)$ & $\mathrm{PM}_{2.5}\left(\mu \mathrm{g} / \mathrm{m}^{3}\right)$ & $\mathrm{PM}_{10}\left(\mu \mathrm{g} / \mathrm{m}^{3}\right)$ \\
\hline $\begin{array}{c}\text { (Adams et al. } \\
\text { 2001) }\end{array}$ & - & - & $\begin{array}{c}34.5(\text { summer }) \\
23.5(\text { winter })\end{array}$ & - \\
\hline $\begin{array}{c}\text { (Adams, } \\
\text { Nieuwenhuijsen, } \\
\text { and Colvile 2001) }\end{array}$ & - & - & 34.2 & - \\
\hline $\begin{array}{c}\text { Kendrick et al. } \\
\text { 2011) }\end{array}$ & $\begin{array}{c}3309-21,043 \\
\text { (mean difference } \\
\text { range between bike } \\
\text { lane and cycle } \\
\text { track) }\end{array}$ & - & - & - \\
\hline “-“= Not Applicable & & & & \\
\hline
\end{tabular}

Transit network exposure studies commonly focus on diesel buses, the backbone of most transit agencies. Transit buses have repeatedly been singled out as significant sources of PM in urban areas (Jackson and Holmén 2009; Kaur et al. 2007; Holmén and Ayala 2002; Schimek 2001). A common study design involving diesel buses focuses on in-cabin bus driver and bus patron exposure. In their multi-modal study, Adams et al. (2001b) observed consistent mean in-cabin $\mathrm{PM}_{2.5}$ concentrations in the summer (39.0 $\left.\mu \mathrm{g} / \mathrm{m}^{3}\right)$ and the winter $\left(38.9 \mu \mathrm{g} / \mathrm{m}^{3}\right)$. Levy et al. (2002) measured $\mathrm{PM}_{2.5}$ levels in a bus with open windows in Boston, finding the median value to be $105 \mu \mathrm{g} / \mathrm{m}^{3}$. Hill et al. (2005) tested retrofitted emissions controls in school buses in several cities for effectiveness in reducing interior UFP exposure. In Atlanta, mean UFP exposure ranged 
from $7,381 \mathrm{pt} / \mathrm{cm}^{3}$ to $50,230 \mathrm{pt} / \mathrm{cm}^{3}$; in Chicago, mean UFP exposure was $29,868 \mathrm{pt} / \mathrm{cm}^{3}$ - 74,466 pt/ $\mathrm{cm}^{3}$; in Ann Arbor, MI, mean UFP exposure was 9,570 pt/ $\mathrm{cm}^{3}-53,040$ $\mathrm{pt} / \mathrm{cm}^{3}$ (Hill et al. 2005). The authors note that implementation of diesel particulate filters and ultra-low sulfur fuel reduced in-cabin UFP concentrations. Zhu et al. (2010) examined the micro-environmental conditions in Harvard University shuttle system buses in Cambridge, MA. Concentration levels of $\mathrm{PM}_{10}$ ranged from 11-18 $\mu \mathrm{g} / \mathrm{m}^{3}$ depending on the sample date. Likewise, concentration levels of $\mathrm{PM}_{2.5}$ and UFP ranged from 11-15 $\mu \mathrm{g} / \mathrm{m}^{3}$ and 40,000-57,000 pt/ $\mathrm{cm}^{3}$, respectively. Zhu et al. (2010) note that $\mathrm{PM}_{2.5}$ concentrations were an order of magnitude higher during peak hours, attributed by the authors to high traffic conditions.

Table 2.5.4: Average Transit Exposure Summary

\begin{tabular}{|c|c|c|c|c|}
\hline & \multicolumn{4}{|c|}{ Exposure } \\
\hline & $\mathrm{UFP}\left(\mathrm{pt} / \mathrm{cm}^{3}\right)$ & $\mathrm{PM}_{1.0}\left(\mu \mathrm{g} / \mathrm{m}^{3}\right)$ & $\mathrm{PM}_{2.5}\left(\mu \mathrm{g} / \mathrm{m}^{3}\right)$ & $\mathrm{PM}_{10}\left(\mu \mathrm{g} / \mathrm{m}^{3}\right)$ \\
\hline $\begin{array}{l}\text { (Adams et al. } \\
\text { 2001) }\end{array}$ & - & - & $\begin{array}{c}39.0 \text { (summer) } \\
38.9 \text { (winter) }\end{array}$ & - \\
\hline (Hill et al. 2005) & $\begin{array}{c}7,381-50,230 \\
\text { (Atlanta) } \\
\text { 29-868-74,466 } \\
\text { (Chicago) } \\
9,570-53,040 \\
\text { (Ann Arbor) }\end{array}$ & - & 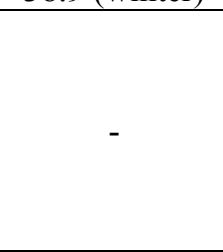 & - \\
\hline $\begin{array}{l}\text { (Levy, Dumyahn, } \\
\text { and Spengler } \\
\text { 2002) }\end{array}$ & - & - & 105 (median) & - \\
\hline $\begin{array}{c}\text { (S. Zhu, } \\
\text { Demokritou, and } \\
\text { Spengler 2010) }\end{array}$ & $40,000-57,000$ & - & $11-15$ & $11-18$ \\
\hline
\end{tabular}

"“" = Not Applicable 


\subsection{Particulate Matter Exposure at Bus Stops}

Most reviewed air quality study designs, particularly transit-oriented studies, fail to capture the exposure for a transit patron waiting at a bus stop. Yet, bus stop location is considered to be one of the most important aspects to transit route design, determining transit system performance, traffic flow, safety, and security (Fitzpatrick et al. 1996).

Bus stops are located in one of three configurations, each relative to the closest intersection: near-side, far-side, and mid-block (Figure 2.6.1). Near-side bus stops are located immediately before an intersection in the direction of travel. Far-side bus stops are located immediately after an intersection in the direction of travel. Mid-block bus stops are located within the block. Locating the bus stop in any of these configurations comes with distinct advantages and disadvantages. Fitzpatrick et al. (1996) summarize these advantages and disadvantages in Table 2.6.1. 
Table 2.6.1: Advantages and Disadvantages of Bus Stop Locations (Fitzpatrick et al. 1996)

\begin{tabular}{|c|c|c|}
\hline & Advantages & Disadvantages \\
\hline 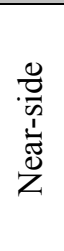 & $\begin{array}{l}\text { Allows passengers to access bus } \\
\text { while it is stopped at a red light } \\
\text { - Allows passengers to access buses } \\
\text { closest to crosswalk } \\
\text { - Intersection is available for driver } \\
\text { to pull away from curb }\end{array}$ & $\begin{array}{l}\text { - Increases right-turn vehicle conflicts } \\
\text { - Increases sight distance problems for crossing } \\
\text { pedestrians } \\
\text { - May obscure curbside traffic control devices and } \\
\text { crossing pedestrians }\end{array}$ \\
\hline 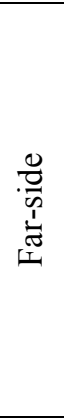 & $\begin{array}{ll}\text { - } & \text { Minimizes right-turn vehicle } \\
\text { conflicts } \\
\text { - }\end{array}$ & $\begin{array}{l}\text { - Stopping buses may queue into the intersection } \\
\text { - Traffic may queue behind a bus into the } \\
\text { intersection } \\
\text { - Bus may stop far side after stopping for a red } \\
\text { light, which interferes with bus operations and all } \\
\text { other traffic } \\
\text { - May obscure sight distance for crossing vehicles }\end{array}$ \\
\hline $\begin{array}{l}\frac{y}{0} \\
\frac{0}{0} \\
\frac{1}{0} \\
\frac{1}{2}\end{array}$ & $\begin{array}{ll}- & \text { Passenger waiting areas may } \\
\text { experience less pedestrian } \\
\text { congestion }\end{array}$ & $\begin{array}{ll}- & \text { Requires additional no-parking restrictions } \\
\text { - } & \text { Encourages jaywalking }\end{array}$ \\
\hline
\end{tabular}




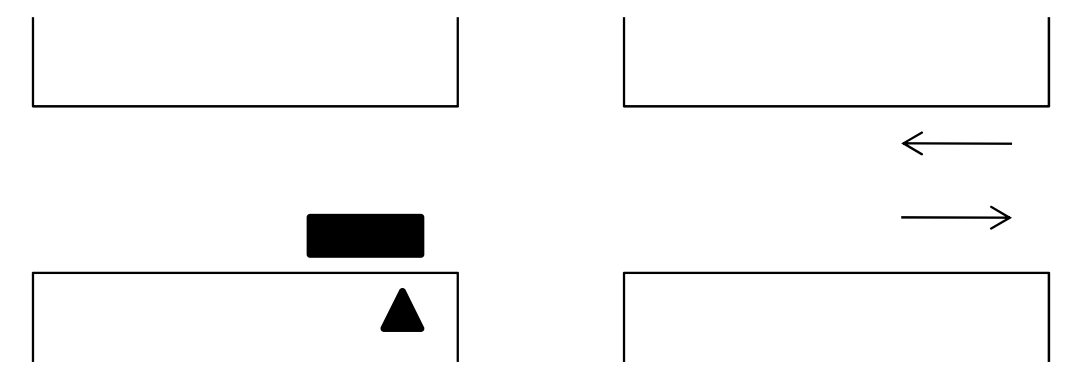

(a) Near-side: bus stop is immediately before the intersection in the direction of travel
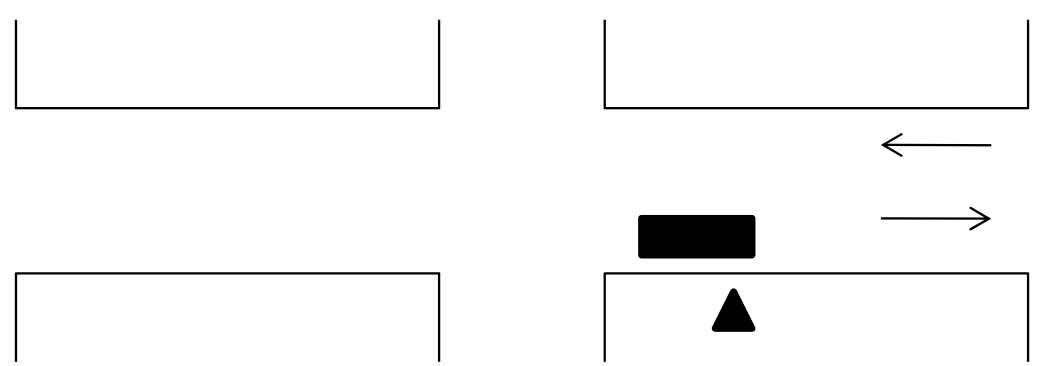

(b) Far-side: bus stop is immediately after the intersection in the direction of travel
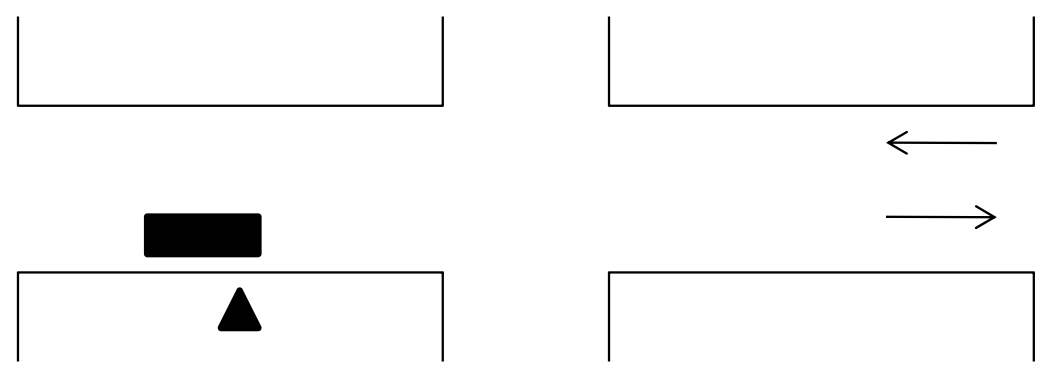

(c) Mid-block: bus stop is within the block

Figure 2.6.1: Bus stop locations on city corridors. 
Bus stops are placed to give direct access to transit from the intersection or nearby land use (Fitzpatrick et al. 1996). In urban areas, stops are placed next to sidewalks; in rural areas, it is not uncommon for stops to be placed in grass or dirt. When placing a stop next to a sidewalk, a concrete pad is laid to provide visual cues, convenience, and protection from puddles and mud. The pad can contain such amenities as a bench, a shelter, a trash receptacle, or bike racks. The size of the pad varies depending on amenities present at the stop. Transit agencies typically have a primary pad configuration and one or two accessory-pad variations for use when space constraints apply. When possible, the pad is placed such that the waiting patrons will not interfere with at least three feet of sidewalk right-of-way for passersby (Fitzpatrick et al. 1996). The pad can be located on either side of the sidewalk so long as space is available.

Bus stop shelters are constructed at bus stops for many reasons, most notably for protection from the elements. They also attract riders, provide information, give visual cues for route layouts, and support the pedestrian network (Law and Taylor 2001; Project for Public Spaces, Inc 1997). Shelter designs can vary widely between transit agencies, though according to the Americans with Disabilities Act (ADA) of 1990, they are required to have a vertical clearance of at least 6' 8 ', entrances at least $28^{\prime \prime}$ ' wide, and enclose a minimum clear area of 2'6" wide by 4'0" deep, as shown in Figure 2.6.2 (U.S. Architectural and Transportation Barriers Compliance Board 2002). Typical shelter width is 10 feet wide (Fitzpatrick et al. 1996). Shelters may have up to a six inch clearance between the ground and the bottom of the panels for ventilation and debris management (Fitzpatrick et al. 1996). Within the confines of the concrete pad, the shelter is limited in its placement to avoid interference with nearby buildings, arriving buses, and ADA 
compliance. Shelters must be at least 12" from a building, and at least 2'0" from the roadway to avoid conflicts with a bus's side-view mirror, as shown in Figure 2.6.3.

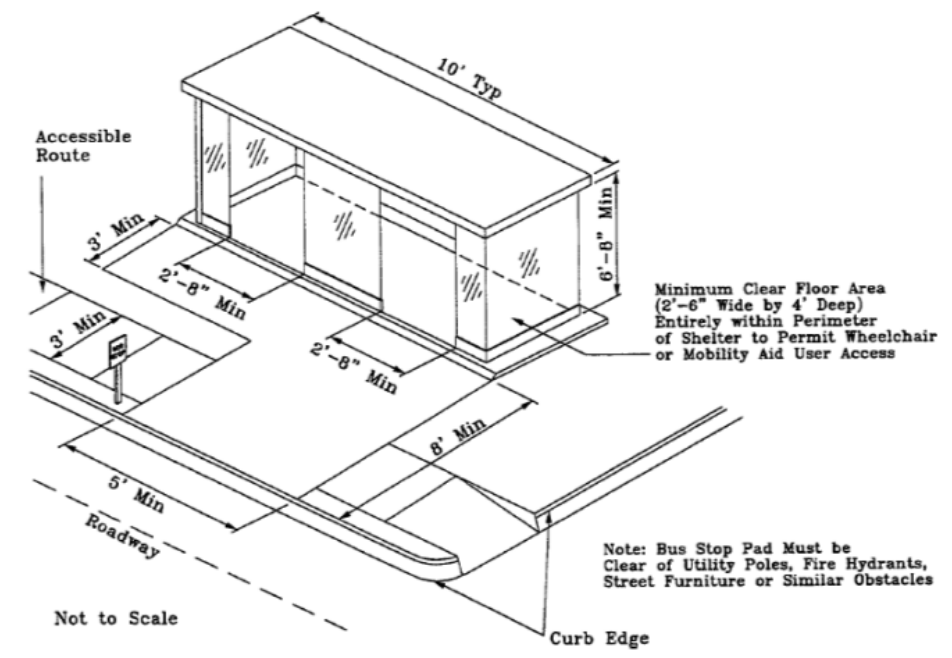

Figure 2.6.2: Minimum shelter design dimensions for ADA compliance. (Fitzpatrick et al. 1996).
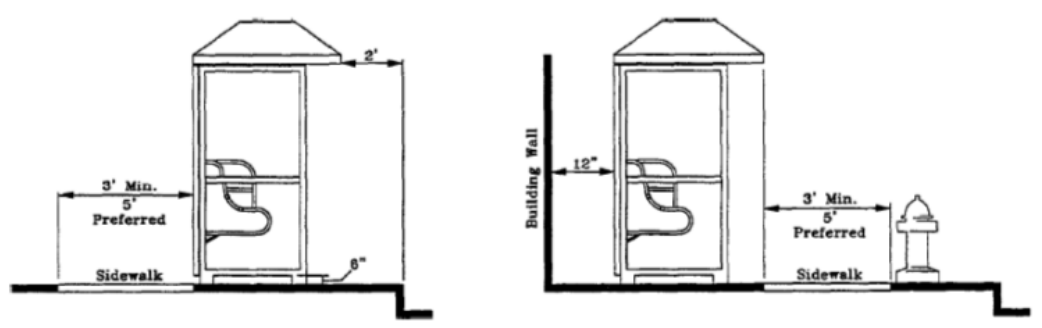

Figure 2.6.3: Shelter clearance distances. (Fitzpatrick et al. 1996).

Shelters are commonly made of Plexiglas panels with metal support frames. The arrangement of panels can be used to characterize the shelter. For instance, shelters may be grouped according to the number of panels used to construct the walls. Orientation of a shelter is characterized by the direction in which the opening faces, and is at the 
discrepancy of the transit agency. Fitzpatrick et al. (1996) recommend considering environmental characteristics when orienting shelters, to either block or contain the sun's heat and prevailing winds.

Shelters are often installed at a stop on the basis of meeting an established minimum threshold of boardings. Three principal factors affect placement of shelters at bus stops: 1) number of boardings and alightings, 2) major origins and destinations, and 3) major transfer points (Law and Taylor 2001). Prevailing practice suggests a minimum threshold of 50 to 100 daily boardings to justify the installation of a bus stop shelter in urban environments (Fitzpatrick et al. 1996). Shelters, then, denote bus stops where high volumes of passengers are waiting in close proximity to traffic.

Bus stops present a unique exposure scenario in which transit patrons are routinely waiting in close proximity to vehicles, including large diesel buses. Wang et al. (2010) developed a model to examine exposure levels at a bus station, modeling both diesel and compressed natural gas (CNG) buses and taking into account various driving conditions including cruising, deceleration, idling and accelerating. It was found that acceleration distance was a key factor involved in estimating PM levels, and no significant emissions increases were observed at idling locations (Wang et al. 2010).

Only one study has evaluated air quality specifically at and within bus stop shelters. Hess et al. (2010) evaluated commuter exposure to $\mathrm{PM}_{2.5}$ for passengers waiting at seven bus stop shelters in Buffalo, NY, finding that time of day, passenger waiting location, land use and presence of cigarette smoke have a statistically significant effect on PM concentrations. Inside the bus shelter, $\mathrm{PM}_{2.5}$ levels were measured at $16.24 \mu \mathrm{g} / \mathrm{m}^{3}$, and outside, levels were measured at $14.72 \mu \mathrm{g} / \mathrm{m}^{3}$. A statistical model developed for the 
study suggests an 18 percent increase in $\mathrm{PM}_{2.5}$ inside a bus shelter versus outside the shelter. The study design, however, leaves room for further investigation. Sample durations were short (30 minute) and traffic data were not collected; Hess et al. (2010) observed morning levels that are higher than evening levels but do not indicate if this may be due to temperature or directional flow of commuter traffic. Longer sample durations could provide insights into morning/evening peak hour fluctuations. Only one type of shelter design is studied: shelters that face towards the roadway. This literature review was unable to find a published study that has examined differences in shelter orientation with a focus on air quality concerns.

Table 2.6.2: Bus Stop Exposure Summary

\begin{tabular}{|c|c|c|c|c|}
\hline & \multicolumn{4}{|c|}{ Exposure } \\
\hline & UFP $\left(\mathrm{pt} / \mathrm{cm}^{3}\right)$ & $\mathrm{PM}_{1.0}\left(\mu \mathrm{g} / \mathrm{m}^{3}\right)$ & $\mathrm{PM}_{2.5}\left(\mu \mathrm{g} / \mathrm{m}^{3}\right)$ & $\mathrm{PM}_{10}\left(\mu \mathrm{g} / \mathrm{m}^{3}\right)$ \\
\hline & & & 16.24 \\
(Hess et al. 2010) & - & - & $\begin{array}{c}14.72 \\
\text { (outside shelter) }\end{array}$ & - \\
& & & & \\
\hline
\end{tabular}

"-“= Not Applicable 


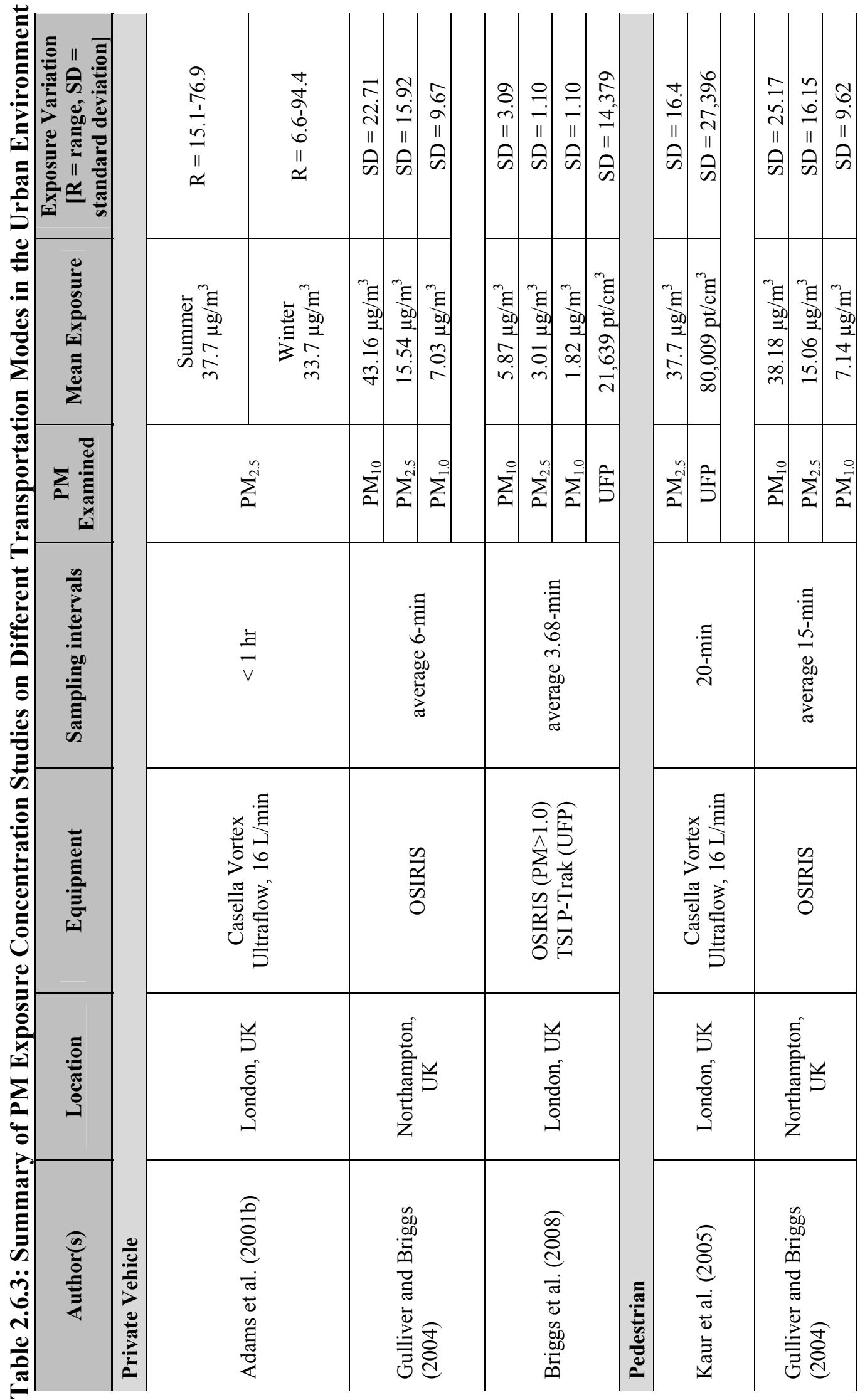




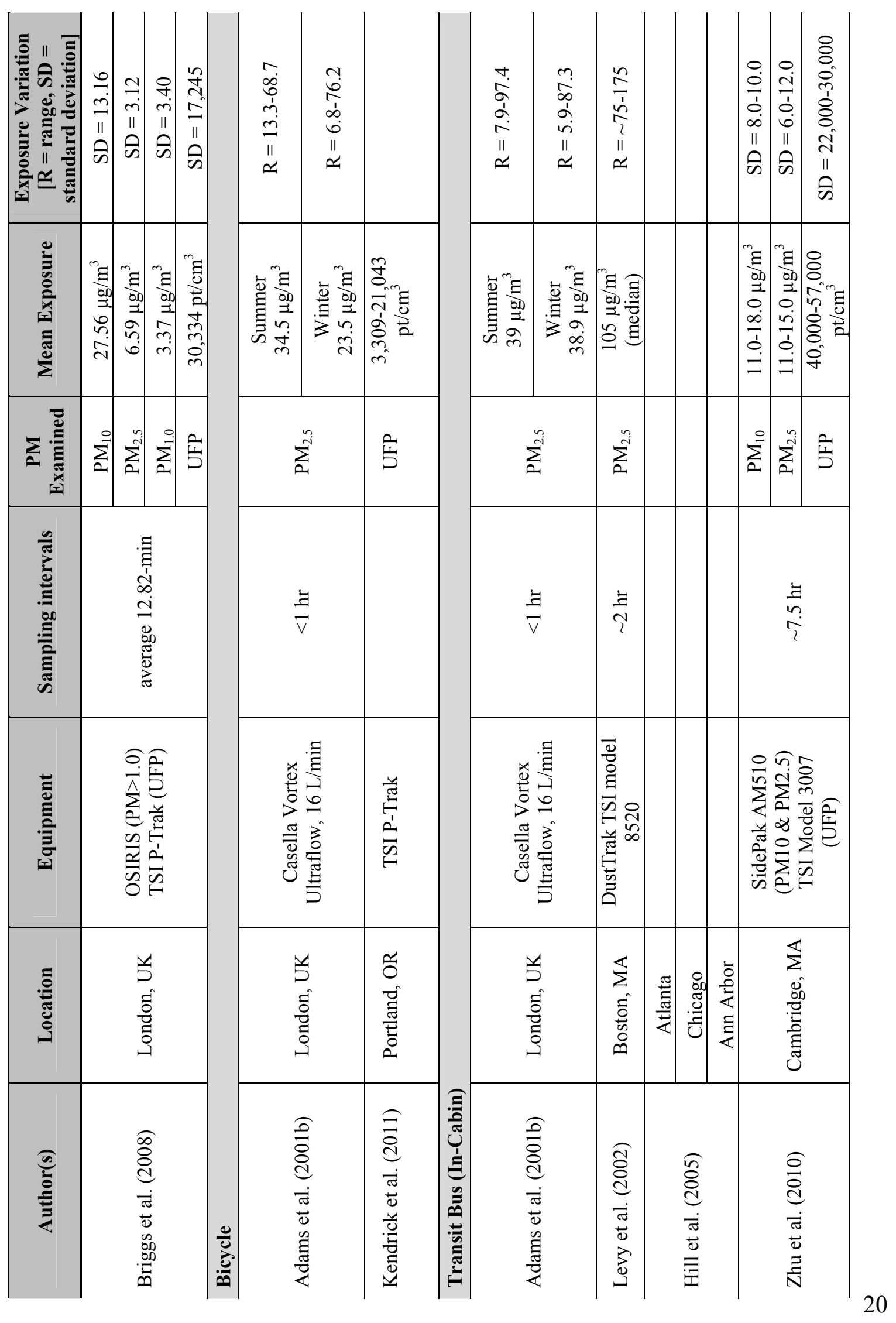




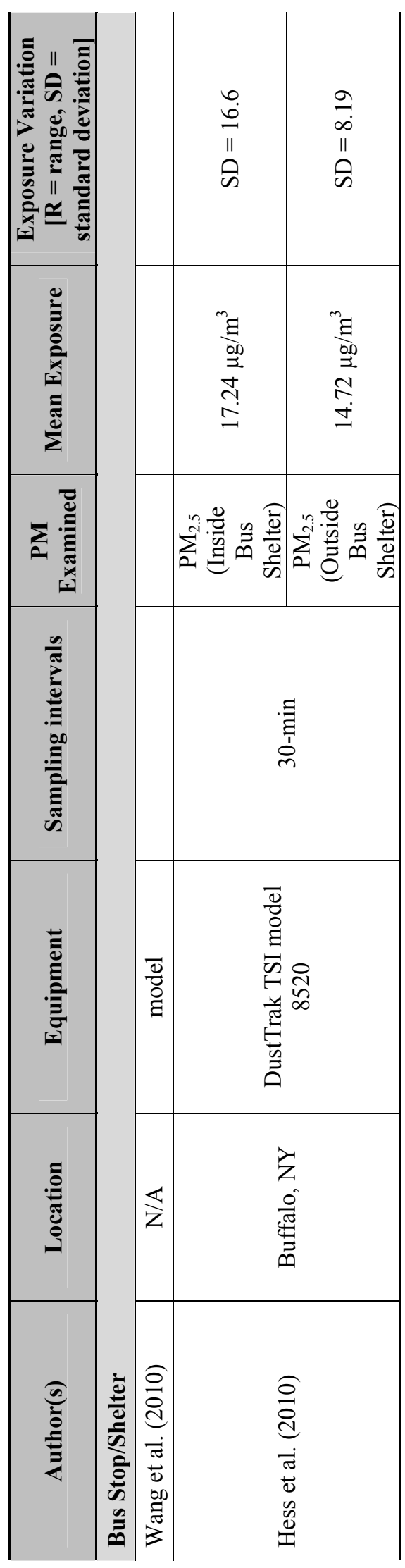




\section{EXPERIMENTAL DESIGN AND DATA COLLECTION}

\subsection{Problem Statement}

This thesis aims to answer three hypotheses arising from the previous literature review. As shown, particulate levels are affected by one specific type of bus stop shelter design. Hess et al. (2010) have already shown that particulate levels are significantly different inside and outside a shelter facing the roadway. The first hypothesis of this thesis expands upon the findings by Hess et al. (2010) and examines whether particulate levels are affected by a different type of shelter design (that is, whether particulate levels are the same inside and outside the new type of shelter). The second and third hypotheses go further and ask whether orienting a shelter differently with respect to the roadway increases or decreases particulate exposure inside the shelter.

Concepts for each of these hypotheses are summarized in Table 3.1.1 and discussed in the remaining sections of this chapter.

Table 3.1.1: Study Hypotheses

\begin{tabular}{|c|c|c|}
\hline Hypothesis & $\mathbf{H}_{\mathbf{0}}$ & $\mathbf{H}_{\mathbf{1}}$ \\
\hline $\begin{array}{c}\text { When a shelter faces away from } \\
\text { the roadway, average particulate } \\
\text { levels are different inside than } \\
\text { outside the shelter } \\
\text { (two-tailed) }\end{array}$ & $\begin{array}{c}\text { Average particulate } \\
\text { concentrations are the same } \\
\text { inside and outside the shelter }\end{array}$ & $\begin{array}{c}\text { Average particulate levels are not } \\
\text { the same inside and outside the } \\
\text { shelter }\end{array}$ \\
\hline $\begin{array}{c}\text { Average particulate levels are less } \\
\text { inside than outside for a shelter } \\
\text { facing away from the roadway } \\
\text { (one-tailed) }\end{array}$ & $\begin{array}{c}\text { Average particulate levels inside } \\
\text { the shelter are greater than or } \\
\text { equal to the outside }\end{array}$ & $\begin{array}{c}\text { Average particulate levels are less } \\
\text { inside the shelter than outside }\end{array}$ \\
$\begin{array}{c}\text { Average particulate levels are } \\
\text { greater inside than outside for a } \\
\text { shelter facing towards the } \\
\text { roadway } \\
\text { (one-tailed) }\end{array}$ & $\begin{array}{c}\text { Average particulate levels inside } \\
\text { the shelter are less than or equal } \\
\text { to the outside }\end{array}$ & $\begin{array}{c}\text { Average particulate levels are } \\
\text { greater inside the shelter than } \\
\text { outside }\end{array}$ \\
\hline
\end{tabular}




\subsection{Site Description}

Bus shelters selected for monitoring are located along Powell Boulevard, a major east-west arterial located approximately two miles southeast of the central business district (CBD) of Portland, OR. Powell Boulevard serves as a commuter thoroughfare for the outlying suburbs, with high inbound morning traffic volumes and high outbound evening traffic volumes. Land use along the corridor is primarily one- and two-story commercial buildings.

There are 31 bus stops along the two-mile stretch of roadway selected for analysis. Of these 31 stops, 17 feature shelters. Shelters are characterized according to the number of panels in their design, the depth of the shelter, and the orientation of the shelter. Shelters are primarily placed near-side and far-side, with only two placed in midblock locations.

There are four shelter layouts, characterized in Table 3.2.1 as Shelter A, B, C, or D. The panels of the shelter determine its layout. Panels that form an opening facing the roadway are described as oriented towards the roadway (Figure 3.2.1). Similarly, panels that form an opening facing away from the roadway are described as oriented away from the roadway (Figure 3.2.2). Shelter type A is the most predominant type of shelter layout, placed at 12 locations. The next most predominant shelter types are Shelter B and Shelter C, each placed at two locations. It appears the four locations of Shelter B and Shelter C are spatially constrained, hence the absence of Shelter A, which is larger than either Shelter B or Shelter C.

This study focuses on three shelters on Powell Boulevard (Figure 3.2.3). Shelters were chosen primarily for their orientation. The shelter at Location 1 is oriented away 
from the roadway while the shelters at Locations 2 and 3 are oriented towards the roadway. Shelters facing the roadway were chosen due to their prevalence along the corridor, and Shelter A was chosen over Shelter B for its use as the primary shelter layout. Shelter $\mathrm{C}$ was chosen for its unique orientation away from the roadway, despite being shallower in depth than Shelter A.

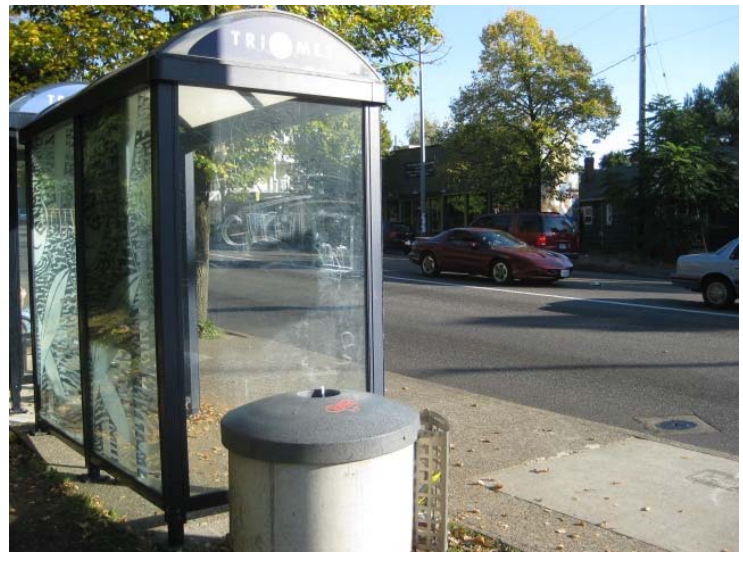

Figure 3.2.1: Shelter facing towards roadway.

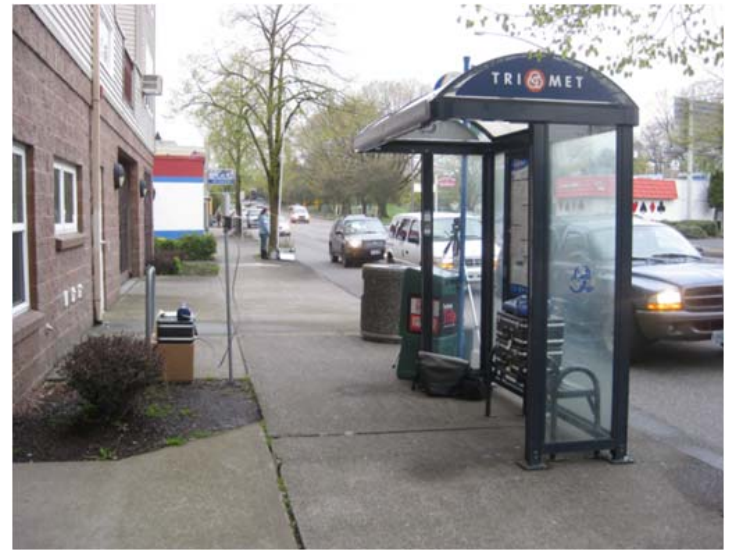

Figure 3.2.2: Shelter facing away from roadway.

Table 3.2.1: Bus Stop Shelter Characteristics along Powell Boulevard

\begin{tabular}{|c|c|c|c|c|c|c|}
\hline \multicolumn{2}{|c|}{ Shelter Layout } & A & B & $\mathrm{C}$ & D & $\mathbf{E}$ \\
\hline \multicolumn{2}{|c|}{ Number of Panels } & 3 & 3 & 3 & 4 & $\begin{array}{c}\text { No } \\
\text { Shelter }\end{array}$ \\
\hline \multicolumn{2}{|c|}{ Depth } & $4^{\prime} 3^{\prime \prime}$ & $2 ' 3 \prime$ & $23^{\prime \prime}$ & 4'3"' & - \\
\hline \multicolumn{2}{|c|}{$\begin{array}{l}\text { Orientation to } \\
\text { Roadway }\end{array}$} & Toward & Toward & Away & Both & - \\
\hline \multicolumn{2}{|c|}{ Layout } & & & & & - \\
\hline \multirow{3}{*}{$\begin{array}{l}\vec{\Xi} \\
\vec{\Xi} \\
\vec{\Xi} \\
\frac{\tilde{\Xi}}{2}\end{array}$} & $\begin{array}{l}\text { Near- } \\
\text { side }\end{array}$ & 4 & 1 & 1 & 1 & 0 \\
\hline & Far-side & 6 & 1 & 1 & 0 & 2 \\
\hline & $\begin{array}{l}\text { Mid- } \\
\text { block }\end{array}$ & 2 & 0 & 0 & 0 & 12 \\
\hline \multicolumn{2}{|l|}{ Total } & 12 & 2 & 2 & 1 & 14 \\
\hline
\end{tabular}


The chosen shelters have similar surrounding built environments, taking into consideration similar building heights behind the shelters to control for wind characteristic effects. Table 3.2.1 and Table 3.2.2 summarize characteristics of the shelters and the roadway. Figure 3.2.4 shows the built environment surrounding the shelters.

Table 3.2.2: Detailed Roadside Environment Characteristics of Study Locations

\begin{tabular}{|c|c|c|c|}
\hline $\begin{array}{l}\text { Shelter } \\
\text { Characteristics }\end{array}$ & $\begin{array}{c}\text { Location } 1 \\
\text { (facing away from } \\
\text { roadway) }\end{array}$ & $\begin{array}{c}\text { Location } 2 \\
\text { (facing toward } \\
\text { roadway) }\end{array}$ & $\begin{array}{c}\text { Location } 3 \\
\text { (facing towards } \\
\text { roadway) }\end{array}$ \\
\hline Shelter Type & $\mathrm{C}$ & $\mathrm{A}$ & $\mathrm{A}$ \\
\hline Near-side/Far-side & Near-side & Near-side & Far-side \\
\hline $\begin{array}{l}\text { Eastbound/Westbound } \\
\text { on Powell }\end{array}$ & $\begin{array}{l}\text { Westbound } \\
\text { (Inbound) }\end{array}$ & $\begin{array}{l}\text { Westbound } \\
\text { (Inbound) }\end{array}$ & $\begin{array}{l}\text { Eastbound } \\
\text { (Outbound) }\end{array}$ \\
\hline Cross Street & $21^{\text {st }}$ Ave & $26^{\text {th }}$ Ave & $39^{\text {th }}$ Ave \\
\hline Distance to Curb & $2 ’ 0 "$ & 9'0" & $12^{\prime} 6^{\prime \prime}$ \\
\hline $\begin{array}{l}\text { Distance to } \\
\text { Intersection }\end{array}$ & $24^{\prime} 0 "$ & $12^{\prime} 0^{\prime \prime}$ & 70’0" \\
\hline $\begin{array}{l}\text { Built Environment } \\
\text { Behind Shelter }\end{array}$ & $\begin{array}{l}\text { Multi-story building, } \\
12{ }^{\prime} 0 \text { " behind shelter }\end{array}$ & $\begin{array}{l}\text { Multi-story building, } \\
20^{\prime} 0 \text { " behind shelter }\end{array}$ & $\begin{array}{l}\text { Multi-story building, } \\
\text { 3'6" behind shelter }\end{array}$ \\
\hline $\begin{array}{l}\text { Annual Average Daily } \\
\text { Traffic }(2009)^{*}\end{array}$ & 35,300 & 31,500 & 34,100 \\
\hline $\begin{array}{l}\text { Percent Trucks, } \\
\text { Morning }{ }^{\ddagger} \text { (Powell) }\end{array}$ & $12.4 \%$ & $18.6 \%$ & $4.5 \%$ \\
\hline $\begin{array}{l}\text { Percent Trucks, } \\
\text { Evening (Powell) }\end{array}$ & $9.7 \%$ & $17.1 \%$ & $5.5 \%$ \\
\hline $\begin{array}{l}\text { Approximate Morning } \\
\text { Bus Headway }\end{array}$ & 8 minutes & 8 minutes & 20 minutes \\
\hline $\begin{array}{l}\text { Approximate Evening } \\
\text { Bus Headway }\end{array}$ & 15 minutes & 15 minutes & 7 minutes \\
\hline $\begin{array}{l}\text { Average Boardings } \\
\text { per hour, Morning }\end{array}$ & 1.2 & 1.0 & 1.9 \\
\hline $\begin{array}{l}\text { Average Boardings } \\
\text { per hour, Evening }\end{array}$ & 1.6 & 1.9 & 2.8 \\
\hline
\end{tabular}




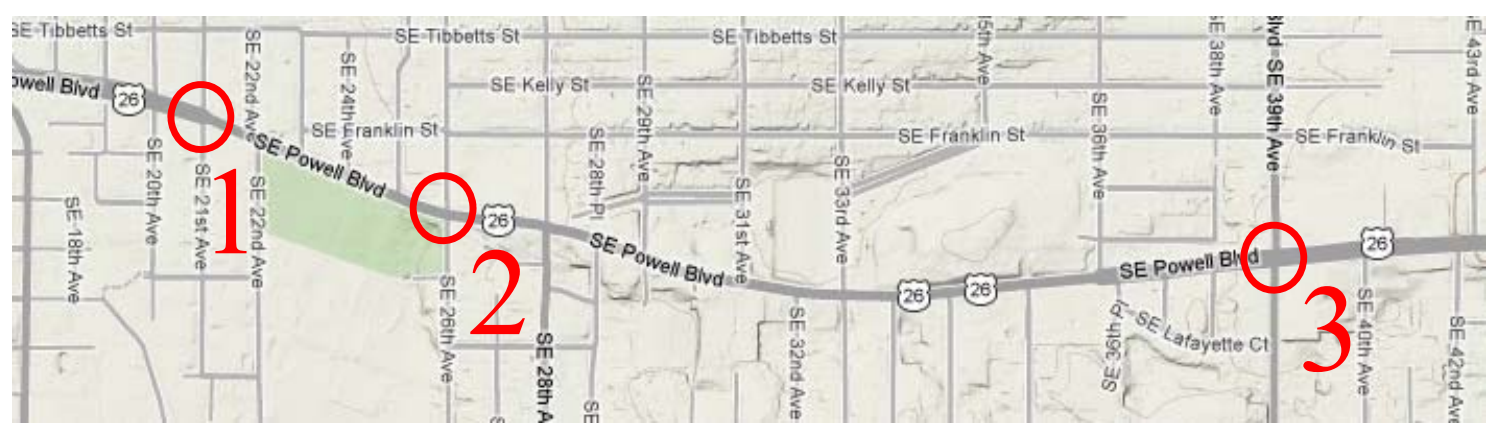

Figure 3.2.3: Shelter location overview, courtesy Google.com. (North towards top of page.) 


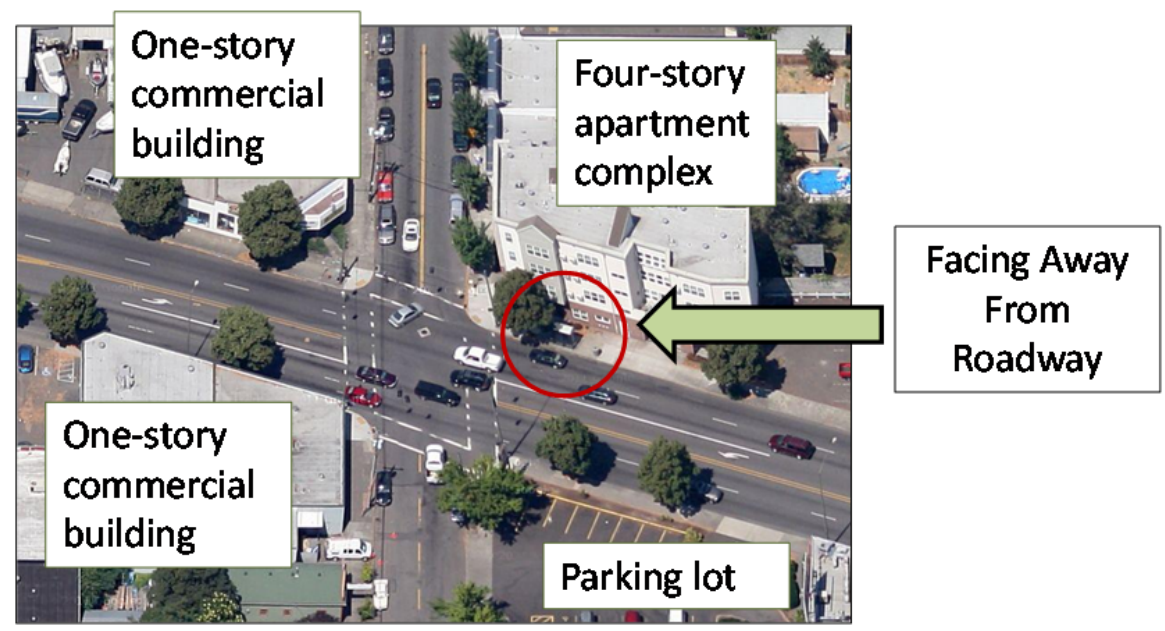

(a)

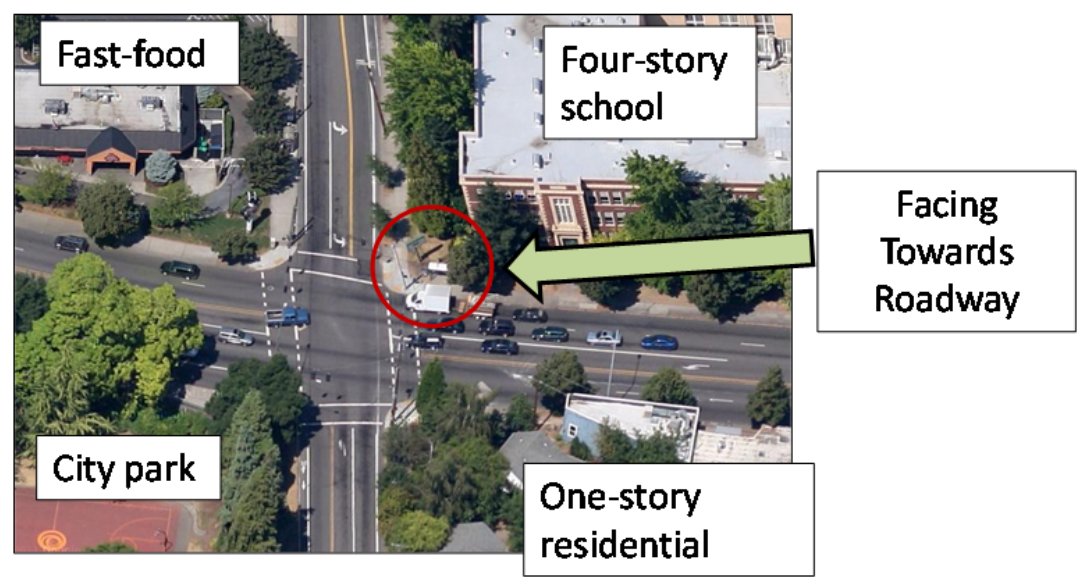

(b)

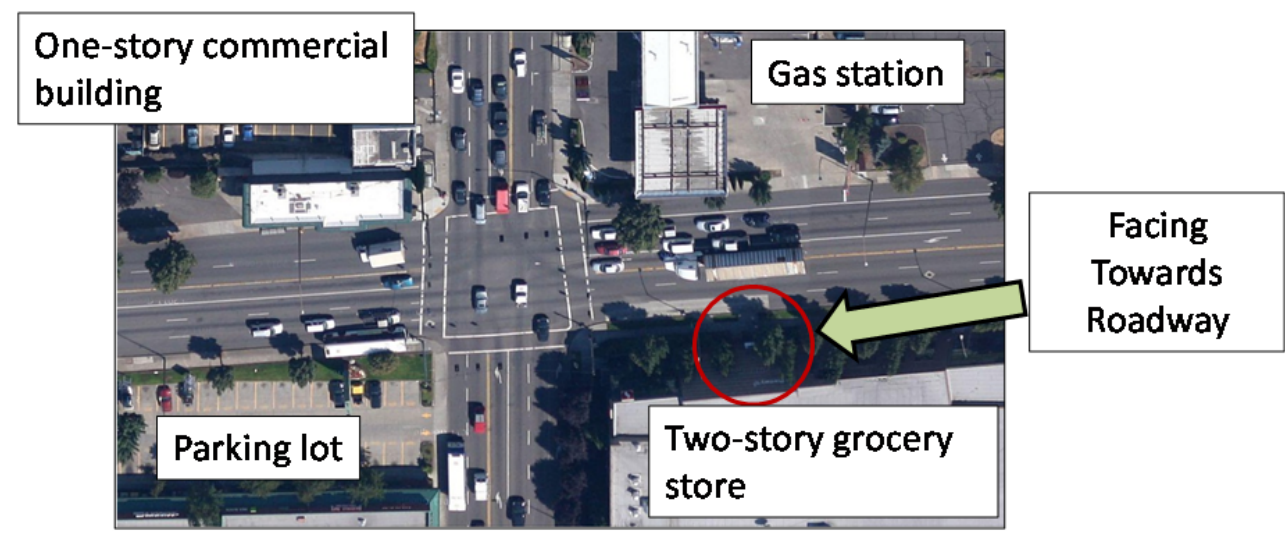

(c)

Figure 3.2.4: Built environment characteristics for (a) Location 1, (b) Location 2, and (c) Location 3. Aerial photography courtesy Google.com. (North towards top of page.) 


\subsection{Instrumentation}

Particulate matter concentrations were monitored both inside and outside the shelter simultaneously to control for any changes in environmental conditions. $\mathrm{PM}_{1.0}$, $\mathrm{PM}_{2.5}$, and $\mathrm{PM}_{10}$ measurements were made using two DustTrak DRX Aerosol Monitors (TSI Model 8533). DustTrak monitors are capable of measuring concentrations between $1 \mu \mathrm{g} / \mathrm{m}^{3}$ and $150,000 \mu \mathrm{g} / \mathrm{m}^{3}$, and have a resolution of $\pm 0.1 \%$ of reading or $0.001 \mathrm{mg} / \mathrm{m}^{3}$, whichever is greater. Both units were calibrated to a zero filter prior to each use. UFP measurements were made using two P-Trak Ultrafine Particle Counters (TSI Model 8525 ), capable of measuring concentrations between zero particles $/ \mathrm{cm}^{3}$ and $5 \times 10^{5}$ particles $/ \mathrm{cm}^{3}$ and particle sizes between $0.02 \mu \mathrm{m}$ to $1 \mu \mathrm{m}$ in diameter. The DustTraks and P-Traks were started simultaneously and operated continuously at one-second resolutions for the entirety of the sampling period. Before data collection, both sets of instruments were run side-by-side in the laboratory to ensure that measurements were highly correlated $\left(r^{2}=0.996\right)$.

Device intake points were set at five feet above the ground, following standard practice observed in similar studies (Hess et al. 2010; Kaur, Nieuwenhuijsen, and Colvile 2005; Gulliver and Briggs 2004; Adams et al. 2001). Inside the shelter, intake points were placed in the center of the shelter, approximately six inches from the rear panel (referenced as "inside monitor"). Outside the shelter (referenced as "outside monitor"), intake points were placed three feet from the shelter, mimicking the distance set by Hess et al. (2010), at the same distance from the curb as the inside monitor. Devices were randomly rotated between inside and outside locations at the beginning of each sampling period (morning and afternoon periods). 
Placement of the outside monitor required an assumption about where patrons would most likely congregate while waiting for bus arrivals. Location 3 set the precedent for other locations due to the presence of a concrete pad next to one side of the shelter, providing patrons an additional place to stand while waiting for the bus. The other side of the shelter is unpaved and laid with mulch. Assuming patrons would most likely choose to wait on the paved side rather than the unpaved side, monitoring the paved side would replicate exposure. The concrete pad is located upstream (against the flow of traffic) of the Location 1 shelter. To maintain consistency, the outside location was then placed upstream at Location 1 and Location 2. For near-side shelters (Locations 1 and 2), this setup results in the outside monitor being farther from the intersection than the monitor inside the shelter; for the far-side shelter (Location 3), the outside monitor is closer to the intersection than the monitor inside the shelter.

Wind speed and direction were measured using an RM Young Ultrasonic Anemometer (Young Model 81000), placed next to the outside location particulate monitors. The wind speed sensor has a range of $0-40 \mathrm{~m} / \mathrm{s}$, and an accuracy of $\pm 1 \% \mathrm{rms}$ for wind speeds up to $30 \mathrm{~m} / \mathrm{s}$ and $\pm 3 \% \mathrm{rms}$ for wind speeds $30-40 \mathrm{~m} / \mathrm{s}$. The wind direction sensor has an accuracy of \pm 2 degrees for wind speeds up to $30 \mathrm{~m} / \mathrm{s}$ and \pm 5 degrees for wind speeds $30-40 \mathrm{~m} / \mathrm{s}$. The anemometer was placed as close to the outside particulate monitors as possible, slightly upstream from the shelter.

Traffic data were collected using an RTMS G4 unit (ISS Model K4-LV-CAM). The RTMS (Remote Traffic Microwave Sensor) unit is a radar sensor capable of providing per-lane presence as well as volume, occupancy, speed and classification information. The RTMS unit is designed for mid-block operation and depends on vehicle 
movement for detection, and does not reliably note vehicles if they come to a stop in its field of view. To counter problems associated with vehicle queuing, the unit was placed approximately 60-70 feet away from the intersection in an effort to avoid stopping vehicles. A major limitation of the RTMS unit is that it was only capable of recording traffic in the direction of travel closest to the bus stop shelter. For instance, at Location 1 traffic data were only collected for the westbound direction of travel. This amounts to three lanes of travel (See Section 3.1 for lanes of travel at each location). In effect, only half of the roadway was captured for each location, and thus only half of traffic.

Temperature and relative humidity data were gathered from a nearby fixed monitoring station. The station is located 1.2 miles, 0.97 miles, and 0.15 miles away from Locations 1, 2, and 3, respectively. Data were available in approximately five-minute intervals, and were interpolated to smaller intervals to match the rest of the data. For reasons discussed in Section 2.4, care must be taken when interpreting temperature and relative humidity analysis given shortcomings associated with fixed monitoring stations in this type of study. 


\subsection{Sampling}

Particulate matter concentration data were collected during morning peak (7:00 am - 9:00 am) and evening peak (4:00 pm - 6:00 pm) periods at each shelter. Data were collected on two different days at each shelter, yielding two morning and two evening sample sets for each location. Data collection occurred primarily on Fridays between late March and mid-May, with one collection on a Tuesday at both Location 1 and Location 3. Collection days were rotated between shelters so as to best account for gradual changes in meteorological conditions as winter progressed to spring. Table 3.4.1 details data collected on each date and at each location.

Data were not collected during one evening period at Location 1 due to poor weather conditions. Data were only partially collected for one morning period at Location 2 due to a power issue when the batteries for one device failed unexpectedly. Wind speed and direction were collected during four sampling periods: morning wind data on April 8 and April 29, evening wind data on March 22 and May 13. Wind data were unable to be collected on other collection dates due to poor weather conditions.

Table 3.4.1: Data Collected by Date

\begin{tabular}{|c|c|c|c|c|c|c|c|}
\hline & & \multicolumn{2}{|c|}{ Location 1} & \multicolumn{2}{|c|}{ Location 2} & \multicolumn{2}{|c|}{ Location 3} \\
\hline & & April 5 & April 29 & April 8 & May 13 & March 22 & April 15 \\
\hline \multirow{4}{*}{ 咲 } & UFP & & & & & & \\
\hline & $\mathrm{PM}_{1.0}-\mathrm{PM}_{10}$ & & & & & & \\
\hline & Wind & & & & & & \\
\hline & Traffic & & & & & & \\
\hline \multirow{4}{*}{ 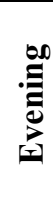 } & UFP & & & & & & \\
\hline & $\mathrm{PM}_{1.0}-\mathrm{PM}_{10}$ & & & & & & \\
\hline & Wind & & & & & & \\
\hline & Traffic & & & & & & \\
\hline
\end{tabular}

$\square \begin{gathered}\text { Data } \\ \text { Collected }\end{gathered} \square \begin{gathered}\text { Outside Shelter Data } \\ \text { Not Collected }\end{gathered} \square \begin{aligned} & \text { Data Not } \\ & \text { Collected }\end{aligned}$




\section{RESULTS}

\subsection{Summary}

Data for each sample date were combined into one data frame for analysis. Data were organized into dependent and independent variables. Table 4.1.1 provides definitions and units for each variable, as well as its classification.

All data were aggregated from five-second intervals to one-minute intervals and all analysis is based on this level of resolution unless otherwise noted. Table 4.1.2 presents summary statistics for all days, discussed further in the remainder of this section.

The mean UFP concentration was $34,815 \mathrm{pt} / \mathrm{cc}$ for all data collected. The mean values of $\mathrm{PM}_{1.0}, \mathrm{PM}_{2.5}$, and $\mathrm{PM}_{10}$ were $21.53,22.02$, and $24.98 \mu \mathrm{g} / \mathrm{m}^{3}$, respectively. These values, shown in Table 4.1.2, are in line with existing literature results for nearroad conditions.

Independent variables investigated include orientation to the roadway, bus stop location (near side or far side), vehicle flow, heavy vehicle flow, wind speed, wind direction, temperature, and relative humidity.

Vehicle flow averaged 1,285 vehicles per hour. Note that this unit of measure is not vehicles per hour per lane. Rather, this is an average of all lanes of travel in the direction closest to the shelter (three lanes at each shelter). 
Table 4.1.1: Variable Definitions

\begin{tabular}{|c|c|c|}
\hline Variables & Definition & Unit \\
\hline \multicolumn{3}{|l|}{ DEPENDENT VARIABLES } \\
\hline UFP & Continuous variable describing concentration & $\mathrm{pt} / \mathrm{cc}$ \\
\hline $\mathrm{PM}_{1.0}$ & Continuous variable describing concentration & $\mu \mathrm{g} / \mathrm{m}^{3}$ \\
\hline $\mathrm{PM}_{2.5}$ & Continuous variable describing concentration & $\mu \mathrm{g} / \mathrm{m}^{3}$ \\
\hline $\mathrm{PM}_{10}$ & Continuous variable describing concentration & $\mu \mathrm{g} / \mathrm{m}^{3}$ \\
\hline \multicolumn{3}{|l|}{ INDEPENDENT VARIABLES } \\
\hline \multicolumn{3}{|l|}{ Location } \\
\hline Location 1 & Dummy variable, $=0$ if Location 2 or $3 ;=1$ otherwise & 0,1 \\
\hline Location 2 & Dummy variable, $=0$ if Location 1 or $3 ;=1$ otherwise & 0,1 \\
\hline Location 3 & Dummy variable, $=0$ if Location 1 or $2 ;=1$ otherwise & 0,1 \\
\hline \multicolumn{3}{|l|}{ Vehicles } \\
\hline Vehicle Flow & $\begin{array}{l}\text { Continuous variable describing number of vehicles } \\
\text { present }\end{array}$ & veh/hour \\
\hline Vehicle Flow - lagged & $\begin{array}{l}\text { Continuous variable describing number of vehicles } \\
\text { present in previous one, two, or three minutes }\end{array}$ & veh/hour \\
\hline Heavy Vehicle (Truck) Flow & $\begin{array}{l}\text { Continuous variable describing number of heavy } \\
\text { vehicles present (defined as length }>6 \mathrm{~m} \text { ) }\end{array}$ & veh/hour \\
\hline Heavy Vehicle Flow - lagged & $\begin{array}{l}\text { Continuous variable describing number of heavy } \\
\text { vehicles present in previous one, two, or three minutes }\end{array}$ & veh/hour \\
\hline \multicolumn{3}{|l|}{ Weather } \\
\hline Wind Speed & Continuous variable describing wind speed & $\mathrm{m} / \mathrm{s}$ \\
\hline Wind Speed - lagged & $\begin{array}{l}\text { Continuous variable describing wind speed in previous } \\
\text { one, two, or three minutes }\end{array}$ & $\mathrm{m} / \mathrm{s}$ \\
\hline $\begin{array}{l}\text { Wind Direction - Towards } \\
\text { Shelter }\end{array}$ & $\begin{array}{l}\text { Percent of wind blowing towards the shelter over a } \\
\text { one-minute interval }\end{array}$ & $\%$ \\
\hline $\begin{array}{l}\text { Wind Direction - Away from } \\
\text { Shelter }\end{array}$ & $\begin{array}{l}\text { Percent of wind blowing away from the shelter over a } \\
\text { one -minute interval }\end{array}$ & $\%$ \\
\hline $\begin{array}{l}\text { Wind Direction - With the } \\
\text { Direction of Traffic }\end{array}$ & $\begin{array}{l}\text { Percent of wind blowing in the direction of traffic } \\
\text { closest to the shelter over a one-minute interval }\end{array}$ & $\%$ \\
\hline $\begin{array}{l}\text { Wind Direction - Against the } \\
\text { Direction of Traffic }\end{array}$ & $\begin{array}{l}\text { Percent of wind blowing against the direction of traffic } \\
\text { closest to the shelter over a one-minute interval }\end{array}$ & $\%$ \\
\hline Wind Direction - lagged & $\begin{array}{l}\text { Percent of wind blowing in each direction over the } \\
\text { previous one, two, or three-minute interval }\end{array}$ & $\%$ \\
\hline Temperature & Continuous variable describing temperature & $\begin{array}{l}\text { degrees } \\
\text { Celsius }\end{array}$ \\
\hline Relative Humidity & Continuous variable describing relative humidity & $\%$ \\
\hline
\end{tabular}


Table 4.1.2: Summary Statistics, All Data

\begin{tabular}{lc|c|c|c|c|c}
\hline Variable & Mean & Median & Minimum & Maximum & SD & N \\
\hline DEPENDENT VARIABLES & \multicolumn{7}{|c}{} \\
\hline UFP $(\mathrm{pt} / \mathrm{cc})$ & 34,815 & 28,497 & 4,508 & 256,243 & 25,223 & 2,462 \\
$\mathrm{PM}_{1.0}\left(\mathrm{ug} / \mathrm{m}^{3}\right)$ & 21.53 & 14.80 & 3.96 & 171.83 & 19.46 & 2,286 \\
$\mathrm{PM}_{2.5}\left(\mathrm{ug} / \mathrm{m}^{3}\right)$ & 22.02 & 15.16 & 4.02 & 178.69 & 19.89 & 2,286 \\
$\mathrm{PM}_{10}\left(\mathrm{ug} / \mathrm{m}^{3}\right)$ & 24.98 & 18.19 & 4.53 & 308.65 & 22.13 & 2,286 \\
\hline INDEPENDENT VARIABLES & & & & & \\
\hline Vehicles & 1,285 & 1,200 & 60 & 3,180 & 624 & 2,378 \\
Vehicle Flow (veh/hr) & 107 & 60 & 0 & 600 & 122 & 2,378 \\
Heavy Vehicle Flow (veh/hr) & & & & & & \\
Weather & 48.82 & 47.40 & 31.80 & 73.00 & 10.34 & 2,462 \\
Temperature $\left({ }^{\circ} \mathrm{C}\right)$ & 70.57 & 85.00 & 26.00 & 94.00 & 24.06 & 2,462 \\
Relative Humidity $(\%)$ & 0.83 & 0.77 & 0.16 & 1.96 & 0.31 & 890 \\
Wind Speed (m/s) & & & & & & \\
\hline
\end{tabular}

Temperature averaged $49^{\circ} \mathrm{C}$ over a wide range, $31^{\circ} \mathrm{C}-73^{\circ} \mathrm{C}$, indicative of changing conditions between morning and evening sampling times. Similarly, relative humidity ranged from $26 \%$ to $94 \%$, averaging $71 \%$.

Wind speed averaged less than $1 \mathrm{~m} / \mathrm{s}$. Wind direction statistics were not collected but are further discussed in Section 4.5.

\subsection{Summary by Location}

To further investigate the summary statistics and elicit differences between each sampling location, data were divided by location. These data are shown in Table 4.2.1, Table 4.2.2, and Table 4.2.3 for Location 1, 2, and 3, respectively.

Generally, average particulate levels were different between inside and outside locations. This phenomenon is discussed further in Section 4.3. Average vehicle flow was roughly the same at Locations 1 and 2, and slightly less at Location 3. The same follows for average heavy vehicle flow. 
Table 4.2.1: Summary Statistics, Location 1

\begin{tabular}{|c|c|c|c|c|c|c|}
\hline \multicolumn{2}{|c|}{ Variable } & Mean & Median & Minimum & Maximum & SD \\
\hline \multicolumn{7}{|c|}{ DEPENDENT VARIABLES } \\
\hline \multirow{2}{*}{$\mathrm{UFP}(\mathrm{pt} / \mathrm{cc})$} & Inside & 30,226 & 21,803 & 7,344 & 162,242 & 23,798 \\
\hline & Outside & 36,862 & 28,078 & 8,064 & 157,374 & 25,970 \\
\hline \multirow{2}{*}{$\mathrm{PM}_{1.0}\left(\mathrm{ug} / \mathrm{m}^{3}\right)$} & Inside & 16.50 & 15.80 & 3.96 & 68.39 & 9.32 \\
\hline & Outside & 16.62 & 14.80 & 6.07 & 87.00 & 9.18 \\
\hline \multirow{2}{*}{$\mathrm{PM}_{2.5}\left(\mathrm{ug} / \mathrm{m}^{3}\right)$} & Inside & 17.13 & 16.71 & 4.02 & 70.77 & 9.72 \\
\hline & Outside & 17.22 & 15.27 & 6.19 & 89.14 & 9.55 \\
\hline \multirow{2}{*}{$\mathrm{PM}_{10}\left(\mathrm{ug} / \mathrm{m}^{3}\right)$} & Inside & 20.86 & 20.39 & 4.53 & 82.52 & 11.82 \\
\hline & Outside & 18.94 & 16.89 & 7.11 & 91.61 & 9.79 \\
\hline \multicolumn{7}{|c|}{ INDEPENDENT VARIABLES } \\
\hline \multicolumn{2}{|c|}{ Vehicle Flow (veh/hr) } & 1,374 & 1,320 & 240 & 2,580 & 509 \\
\hline \multicolumn{2}{|c|}{ Heavy Vehicle Flow (veh/hr) } & 121 & 120 & 0 & 480 & 104 \\
\hline \multicolumn{2}{|c|}{ Temperature $\left({ }^{\circ} \mathrm{C}\right)$} & 46 & 42 & 40 & 57 & 7 \\
\hline \multicolumn{2}{|c|}{ Relative Humidity (\%) } & 76 & 86 & 52 & 91 & 16 \\
\hline \multicolumn{2}{|c|}{ Wind Speed $(\mathrm{m} / \mathrm{s})$} & 0.90 & 0.84 & 0.35 & 1.62 & 0.30 \\
\hline
\end{tabular}

Table 4.2.2: Summary Statistics, Location 2

\begin{tabular}{|c|c|c|c|c|c|c|}
\hline \multicolumn{2}{|c|}{ Variable } & Mean & Median & Minimum & Maximum & SD \\
\hline \multicolumn{7}{|c|}{ DEPENDENT VARIABLES } \\
\hline \multirow{2}{*}{$\mathrm{UFP}(\mathrm{pt} / \mathrm{cc})$} & Inside & 27,549 & 17,359 & 4,508 & 256,243 & 25,590 \\
\hline & Outside & 27,365 & 16,083 & 5,406 & 153,094 & 23,782 \\
\hline \multirow{2}{*}{$\mathrm{PM}_{1.0}\left(\mathrm{ug} / \mathrm{m}^{3}\right)$} & Inside & 24.56 & 14.95 & 4.69 & 82.56 & 21.10 \\
\hline & Outside & 12.09 & 12.98 & 4.58 & 27.13 & 3.85 \\
\hline \multirow{2}{*}{$\mathrm{PM}_{2.5}\left(\mathrm{ug} / \mathrm{m}^{3}\right)$} & Inside & 24.89 & 15.30 & 4.81 & 83.24 & 21.20 \\
\hline & Outside & 12.28 & 13.26 & 4.63 & 27.48 & 3.89 \\
\hline \multirow{2}{*}{$\mathrm{PM}_{10}\left(\mathrm{ug} / \mathrm{m}^{3}\right)$} & Inside & 27.84 & 18.40 & 5.64 & 88.22 & 22.01 \\
\hline & Outside & 15.75 & 17.29 & 5.81 & 51.10 & 5.27 \\
\hline \multicolumn{7}{|c|}{ INDEPENDENT VARIABLES } \\
\hline \multicolumn{2}{|c|}{ Vehicle Flow (veh/hr) } & 1,312 & 1,320 & 60 & 2,820 & 591 \\
\hline \multicolumn{2}{|c|}{ Heavy Vehicle Flow (veh/hr) } & 151 & 120 & 0 & 600 & 144 \\
\hline \multicolumn{2}{|c|}{ Temperature $\left({ }^{\circ} \mathrm{C}\right)$} & 53 & 60 & 32 & 73 & 14 \\
\hline \multicolumn{2}{|c|}{$\begin{array}{l}\text { Relative Humidity (\%) } \\
\text { Wind Sneed }(\mathrm{m} / \mathrm{s})\end{array}$} & 55 & 35 & 26 & 91 & 27 \\
\hline Wind Speed $(\mathrm{m}$ & & 0.88 & 0.84 & 0.16 & 1.96 & 0.33 \\
\hline
\end{tabular}


Table 4.2.3: Summary Statistics, Location 3

\begin{tabular}{|c|c|c|c|c|c|c|}
\hline \multicolumn{2}{|c|}{ Variable } & Mean & Median & Minimum & Maximum & SD \\
\hline \multicolumn{7}{|c|}{ DEPENDENT VARIABLES } \\
\hline \multirow{2}{*}{$\mathrm{UFP}(\mathrm{pt} / \mathrm{cc})$} & Inside & 49,040 & 43,497 & 13,602 & 161,844 & 25,586 \\
\hline & Outside & 38,515 & 34,639 & 7,389 & 121,753 & 18,764 \\
\hline \multirow{2}{*}{$\mathrm{PM}_{1.0}\left(\mathrm{ug} / \mathrm{m}^{3}\right)$} & Inside & 28.65 & 18.00 & 4.73 & 171.83 & 27.19 \\
\hline & Outside & 25.86 & 16.65 & 4.31 & 87.24 & 21.82 \\
\hline \multirow{2}{*}{$\mathrm{PM}_{2.5}\left(\mathrm{ug} / \mathrm{m}^{3}\right)$} & Inside & 29.54 & 18.74 & 4.84 & 178.69 & 28.39 \\
\hline & Outside & 26.19 & 17.14 & 4.39 & 87.45 & 21.81 \\
\hline \multirow{2}{*}{$\mathrm{PM}_{10}\left(\mathrm{ug} / \mathrm{m}^{3}\right)$} & Inside & 32.76 & 20.57 & 5.13 & 308.65 & 35.28 \\
\hline & Outside & 28.90 & 20.75 & 5.12 & 89.18 & 21.41 \\
\hline \multicolumn{7}{|c|}{ INDEPENDENT VARIABLES } \\
\hline \multicolumn{2}{|c|}{ Vehicle Flow (veh/hr) } & 1,194 & 990 & 60 & 3,180 & 713 \\
\hline \multicolumn{2}{|c|}{ Heavy Vehicle Flow (veh/hr) } & 49 & 0 & 0 & 480 & 77 \\
\hline \multicolumn{2}{|c|}{ Temperature $\left({ }^{\circ} \mathrm{C}\right)$} & 46 & 45 & 40 & 53 & 5 \\
\hline \multicolumn{2}{|c|}{ Relative Humidity (\%) } & 83 & 94 & 49 & 94 & 16 \\
\hline \multicolumn{2}{|c|}{ Wind Speed $(\mathrm{m} / \mathrm{s})$} & 0.64 & 0.61 & 0.24 & 1.24 & 0.21 \\
\hline
\end{tabular}

Turning to the hypotheses stated in Section 3.1, data from Location 1 was used to address the first hypothesis statement: Particulate levels are different inside a shelter than outside a shelter facing away from the roadway. A standard two-tailed, paired student ttest was run with the alternative hypothesis that average particulate concentrations inside the shelter are not equal to average particulate concentrations outside the shelter. The results are presented in Table 4.2.4. The mean of the difference was consistently different across all four particulate sizes, though only significant for three: UFP, $\mathrm{PM}_{1.0}$, and $\mathrm{PM}_{2.5}$.

Table 4.2.4: Student t-test Results for Location 1

\begin{tabular}{|c|c|c|c|c|}
\hline Particulate & $\begin{array}{l}\text { Mean of the } \\
\text { Differences }\end{array}$ & t-value & p-value & $\begin{array}{c}\text { Significant at } \\
\alpha=0.05\end{array}$ \\
\hline & \multicolumn{4}{|c|}{ Location $1\left(\mathrm{H}_{1}\right.$ : Inside has a different mean than outside) } \\
\hline UFP $(p t / c c)$ & $-6,636$ & -10.51 & 0.000 & Yes \\
\hline $\mathrm{PM}_{1.0}\left(\mu \mathrm{g} / \mathrm{m}^{3}\right)$ & -1.02 & -4.92 & 0.000 & Yes \\
\hline $\mathrm{PM}_{2.5}\left(\mu \mathrm{g} / \mathrm{m}^{3}\right)$ & -1.05 & -5.04 & 0.000 & Yes \\
\hline $\mathrm{PM}_{10}\left(\mu \mathrm{g} / \mathrm{m}^{3}\right)$ & 1.02 & 3.67 & 0.999 & No \\
\hline
\end{tabular}

The null hypothesis is rejected for the three significant particulate sizes, providing enough evidence that the difference in particulate concentrations between the inside and 
outside of the shelter is significant. These results are in line with literature and compliment the findings of Hess et al. (2010). There was not enough evidence to reject the null hypothesis for $\mathrm{PM}_{10}$.

\subsection{Orientation}

The primary investigation of this study was to determine whether particulate concentrations were statistically different inside a bus stop shelter than outside the shelter conditional on the orientation of the shelter. To this end, the results are divided by "inside shelter" or "outside shelter" classifications. Results are presented in Table 4.3.1, Table 4.3.2, and Table 4.3.3.

Table 4.3.1: Summary Statistics, Location 1

\begin{tabular}{|c|c|c|c|c|c|c|}
\hline \multicolumn{2}{|l|}{ Variable } & Mean & Median & Minimum & Maximum & SD \\
\hline \multicolumn{7}{|c|}{ SHELTER FACING AWAY FROM ROADWAY (N=670) } \\
\hline \multicolumn{7}{|c|}{$U F P(p t / c c)$} \\
\hline \multirow{2}{*}{ Morning } & Inside & 36,704 & 26,774 & 7,493 & 162,242 & 25,994 \\
\hline & Outside & 44,707 & 36,185 & 12,138 & 157,374 & 27,577 \\
\hline \multirow{2}{*}{ Evening } & Inside & 17,153 & 14,280 & 7,344 & 61,434 & 9,590 \\
\hline & Outside & 21,032 & 18,122 & 8,064 & 72,765 & 11,316 \\
\hline \multicolumn{7}{|c|}{$P M_{1.0}\left(\mathrm{ug} / \mathrm{m}^{3}\right)$} \\
\hline \multirow{2}{*}{ Morning } & Inside & 21.41 & 18.79 & 11.76 & 68.39 & 8.19 \\
\hline & Outside & 19.10 & 17.07 & 6.07 & 87.00 & 9.90 \\
\hline \multirow{2}{*}{ Evening } & Inside & 8.63 & 7.49 & 3.96 & 26.77 & 4.21 \\
\hline & Outside & 11.79 & 10.49 & 6.68 & 38.46 & 4.75 \\
\hline \multicolumn{7}{|c|}{$P M_{2.5}\left(\mathrm{ug} / \mathrm{m}^{3}\right)$} \\
\hline \multirow{2}{*}{ Morning } & Inside & 22.37 & 19.82 & 11.83 & 70.77 & 8.41 \\
\hline & Outside & 19.94 & 18.02 & 6.19 & 89.14 & 10.23 \\
\hline \multirow{2}{*}{ Evening } & Inside & 8.72 & 7.64 & 4.02 & 26.85 & 4.21 \\
\hline & Outside & 11.92 & 10.61 & 6.74 & 38.61 & 4.76 \\
\hline \multicolumn{7}{|c|}{$P M_{10}\left(\mathrm{ug} / \mathrm{m}^{3}\right)$} \\
\hline \multirow{2}{*}{ Morning } & Inside & 27.41 & 25.92 & 12.52 & 82.52 & 10.11 \\
\hline & Outside & 21.81 & 19.94 & 7.11 & 91.61 & 10.39 \\
\hline \multirow{2}{*}{ Evening } & Inside & 10.36 & 9.49 & 4.53 & 28.50 & 4.56 \\
\hline & Outside & 13.31 & 12.13 & 7.38 & 39.73 & 4.90 \\
\hline
\end{tabular}


Examining UFP concentrations, average outside concentrations are greater than average inside concentrations at Location 1, the only shelter facing away from the roadway. Results are less consistent for Locations 2 and 3, facing towards the roadway. At Location 2, average morning UFP concentrations are greater outside, but are greater inside in the evening. At Location 3, average morning and evening UFP concentrations are greater inside the shelter. In general, these results match expectations and support the hypothesis that concentrations will be lesser inside the shelter if the shelter is oriented away from the roadway.

Table 4.3.2: Summary Statistics, Location 2

\begin{tabular}{|c|c|c|c|c|c|c|}
\hline \multicolumn{2}{|l|}{ Variable } & Mean & Median & Minimum & Maximum & SD \\
\hline \multicolumn{7}{|c|}{ SHELTER FACING AWAY FROM ROADWAY (N=932) } \\
\hline \multicolumn{7}{|c|}{$U F P(p t / c c)$} \\
\hline \multirow{2}{*}{ Morning } & Inside & 43,545 & 37,508 & 11,190 & 256,243 & 28,978 \\
\hline & Outside & 45,714 & 43,198 & 15,467 & 153,094 & 22,655 \\
\hline \multirow{2}{*}{ Evening } & Inside & 12,742 & 11,792 & 4,508 & 42,914 & 5,339 \\
\hline & Outside & 10,381 & 9,537 & 5,406 & 34,212 & 3,720 \\
\hline \multicolumn{7}{|c|}{$P M_{1.0}\left(\mathrm{ug} / \mathrm{m}^{3}\right)$} \\
\hline \multirow{2}{*}{ Morning } & Inside & 39.73 & 43.82 & 14.22 & 82.56 & 21.63 \\
\hline & Outside & 13.31 & 12.98 & 10.67 & 17.48 & 1.61 \\
\hline \multirow{2}{*}{ Evening } & Inside & 10.52 & 10.64 & 4.69 & 37.46 & 3.77 \\
\hline & Outside & 11.54 & 12.51 & 4.58 & 27.13 & 4.39 \\
\hline \multicolumn{7}{|c|}{$P M_{2.5}\left(\mathrm{ug} / \mathrm{m}^{3}\right)$} \\
\hline \multirow{2}{*}{ Morning } & Inside & 40.19 & 44.11 & 14.61 & 83.24 & 21.65 \\
\hline & Outside & 13.61 & 13.26 & 10.93 & 17.81 & 1.62 \\
\hline \multirow{2}{*}{ Evening } & Inside & 10.73 & 10.86 & 4.81 & 37.66 & 3.80 \\
\hline & Outside & 11.69 & 12.66 & 4.63 & 27.48 & 4.43 \\
\hline \multicolumn{7}{|c|}{$P M_{10}\left(\mathrm{ug} / \mathrm{m}^{3}\right)$} \\
\hline \multirow{2}{*}{ Morning } & Inside & 43.64 & 46.88 & 16.86 & 88.22 & 22.46 \\
\hline & Outside & 17.66 & 17.37 & 13.97 & 24.86 & 2.09 \\
\hline \multirow{2}{*}{ Evening } & Inside & 13.21 & 13.61 & 5.64 & 40.15 & 4.55 \\
\hline & Outside & 14.91 & 17.18 & 5.81 & 51.10 & 5.98 \\
\hline
\end{tabular}


Examining $\mathrm{PM}_{1.0}, \mathrm{PM}_{2.5}$, and $\mathrm{PM}_{10}$ concentrations reveals little in the way of trends for all three locations. For morning conditions, average concentrations for all three particulate sizes are consistently greater inside the shelter at all three locations. While shelters facing towards the roadway would be expected to have higher concentrations inside, this was an unexpected outcome for Location 1, facing away from the roadway.

Evening measurements revealed the opposite trend, in that all three particulate sizes were almost always (with one exception) greater outside the shelter than inside at all three locations.

Table 4.3.3: Summary Statistics, Location 3

\begin{tabular}{|c|c|c|c|c|c|c|}
\hline \multicolumn{2}{|l|}{ Variable } & Mean & Median & Minimum & Maximum & SD \\
\hline \multicolumn{7}{|c|}{ SHELTER FACING AWAY FROM ROADWAY $(\mathbf{N}=\mathbf{8 6 0})$} \\
\hline \multicolumn{7}{|c|}{$U F P(p t / c c)$} \\
\hline \multirow{2}{*}{ Morning } & Inside & 53,672 & 48,697 & 18,287 & 161,844 & 24,171 \\
\hline & Outside & 44,328 & 40,206 & 15,980 & 114,322 & 17,800 \\
\hline \multirow{2}{*}{ Evening } & Inside & 44,097 & 37,698 & 13,602 & 161,267 & 26,180 \\
\hline & Outside & 32,312 & 26,728 & 7,389 & 121,753 & 17,791 \\
\hline \multicolumn{7}{|c|}{$P M_{1.0}\left(u g / m^{3}\right)$} \\
\hline \multirow{2}{*}{ Morning } & Inside & 45.66 & 48.57 & 15.69 & 171.83 & 28.67 \\
\hline & Outside & 41.46 & 52.62 & 14.09 & 87.24 & 20.24 \\
\hline \multirow{2}{*}{ Evening } & Inside & 10.49 & 10.02 & 4.73 & 25.16 & 3.51 \\
\hline & Outside & 9.20 & 8.77 & 4.31 & 21.23 & 2.99 \\
\hline \multicolumn{7}{|c|}{$P M_{2.5}\left(\mathrm{ug} / \mathrm{m}^{3}\right)$} \\
\hline \multirow{2}{*}{ Morning } & Inside & 47.10 & 48.91 & 16.51 & 178.68 & 30.20 \\
\hline & Outside & 41.87 & 52.84 & 14.61 & 87.45 & 20.11 \\
\hline \multirow{2}{*}{ Evening } & Inside & 10.79 & 10.44 & 4.84 & 25.68 & 3.57 \\
\hline & Outside & 9.45 & 9.09 & 4.39 & 21.34 & 3.02 \\
\hline \multicolumn{7}{|c|}{$P M_{10}\left(\mathrm{ug} / \mathrm{m}^{3}\right)$} \\
\hline \multirow{2}{*}{ Morning } & Inside & 51.99 & 50.11 & 18.16 & 308.65 & 40.42 \\
\hline & Outside & 44.39 & 53.84 & 18.03 & 89.18 & 19.38 \\
\hline \multirow{2}{*}{ Evening } & Inside & 12.25 & 12.33 & 5.13 & 28.06 & 4.01 \\
\hline & Outside & 12.36 & 12.80 & 5.12 & 24.26 & 4.06 \\
\hline
\end{tabular}


Examining magnitudes of concentrations reveals additional information about the effects of shelter orientation on particulate concentrations. When the shelter faces the roadway, particulate measurements inside the shelter were, on average across all particulate levels, 29 percent more than measurements outside the shelter. In contrast, when the shelter faces away from the roadway, measurements inside the shelter were one percent less than measurements outside the shelter.

Time series plots were created to show inside and outside particulate concentrations for the duration of each sampling period. Figure 4.3.1 shows morning peak UFP and $\mathrm{PM}_{2.5}$ concentrations inside and outside the shelter at each shelter location for three dates: April 5, May 13, and March 22 for Locations 1, 2, and 3, respectively. Data are aggregated to 5-minute intervals to remove noise and emphasize trends. Shelters facing towards the roadway (Locations 2 and 3) display opposing trends compared to the shelter facing away from the roadway (Location 1). Particulate levels at Location 1 are generally greater outside the shelter, and spikes in concentration levels are more pronounced outside the shelter. Particulate levels at Locations 2 and 3 are generally greater inside the shelter, and spikes in concentration levels are more pronounced inside the shelter. All sampling periods are shown in Appendix C.

To determine the statistical significance of the average particulate concentrations, standard one-tailed, paired student t-tests were used to evaluate whether the mean particulate concentration levels inside the bus shelter were significantly different than mean particulate concentration levels outside the shelter, conditional on the shelter orientation. Establishing an alternative hypothesis was dependent on the conditions outlined in Table 3.1.1. The alternative hypothesis for Location 1 is that average 
concentrations inside the shelter are less than the outside; for Locations 2 and 3, the alternative hypothesis is that average concentrations inside the shelter are greater than the outside.

Table 4.3.4: Student t-test Results for Statistical Significance

\begin{tabular}{|c|c|c|c|c|}
\hline Particulate & $\begin{array}{l}\text { Mean of the } \\
\text { Differences }\end{array}$ & t-value & p-value & $\begin{array}{c}\text { Reject } H_{0} \text { at } \\
\alpha=0.05\end{array}$ \\
\hline & \multicolumn{4}{|c|}{ Location $1\left(\mathrm{H}_{1}\right.$ : Inside has a lesser mean than outside) } \\
\hline UFP $(p t / c c)$ & $-6,636$ & -10.51 & 0.000 & Yes \\
\hline $\mathrm{PM}_{1.0}\left(\mu \mathrm{g} / \mathrm{m}^{3}\right)$ & -1.02 & -4.92 & 0.000 & Yes \\
\hline $\mathrm{PM}_{2.5}\left(\mu \mathrm{g} / \mathrm{m}^{3}\right)$ & -1.05 & -5.04 & 0.000 & Yes \\
\hline \multirow[t]{2}{*}{$\mathrm{PM}_{10}\left(\mu \mathrm{g} / \mathrm{m}^{3}\right)$} & 1.02 & 3.67 & 0.999 & No \\
\hline & \multicolumn{4}{|c|}{ Location 2 ( $\mathrm{H}_{1}$ : Inside has a greater mean than outside) } \\
\hline UFP $(p t / c c)$ & 184 & 0.32 & 0.374 & No \\
\hline $\mathrm{PM}_{1.0}\left(\mu \mathrm{g} / \mathrm{m}^{3}\right)$ & 0.71 & 3.22 & 0.001 & Yes \\
\hline $\mathrm{PM}_{2.5}\left(\mu \mathrm{g} / \mathrm{m}^{3}\right)$ & 0.80 & 3.62 & 0.000 & Yes \\
\hline \multirow[t]{2}{*}{$\mathrm{PM}_{10}\left(\mu \mathrm{g} / \mathrm{m}^{3}\right)$} & -0.10 & -0.42 & 0.661 & No \\
\hline & \multicolumn{4}{|c|}{ Location $3\left(\mathrm{H}_{1}\right.$ : Inside has a greater mean than outside) } \\
\hline $\mathrm{UFP}(p t / c c)$ & 10,525 & 15.91 & 0.000 & Yes \\
\hline $\mathrm{PM}_{1.0}\left(\mu \mathrm{g} / \mathrm{m}^{3}\right)$ & 2.79 & 4.12 & 0.000 & Yes \\
\hline $\mathrm{PM}_{2.5}\left(\mu \mathrm{g} / \mathrm{m}^{3}\right)$ & 3.35 & 4.54 & 0.000 & Yes \\
\hline $\mathrm{PM}_{10}\left(\mu \mathrm{g} / \mathrm{m}^{3}\right)$ & 3.87 & 3.33 & 0.000 & Yes \\
\hline
\end{tabular}

The information in Table 4.3.4 allows a deeper understanding of the mean concentrations presented in the summary statistics. Results were not entirely consistent, but generally, particulate levels were found to be significantly greater $(\alpha=0.05)$ inside the bus shelter when the shelter faces towards the roadway, and significantly greater outside the bus shelter when the shelter faces away from the roadway. 

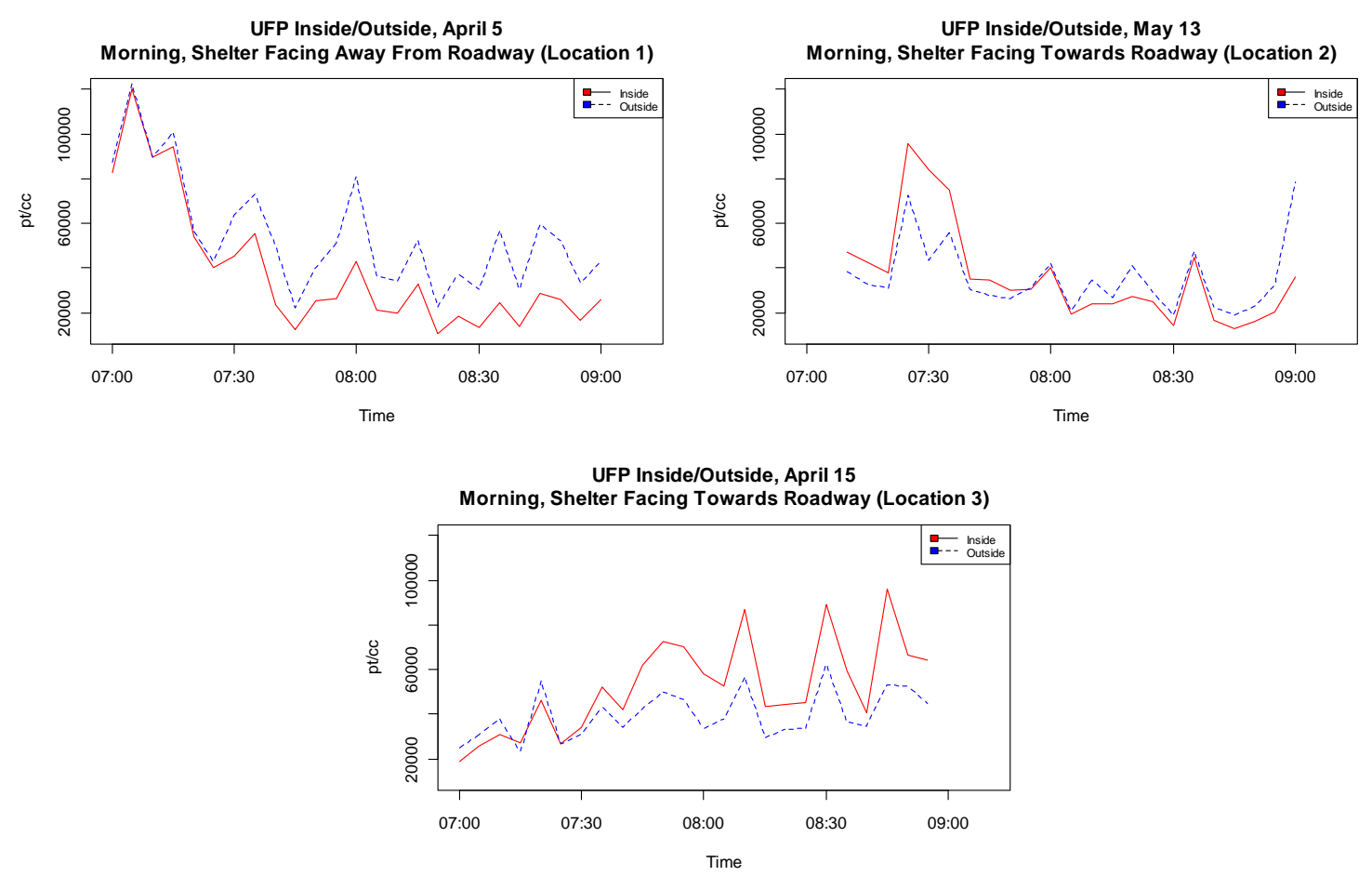

(a)
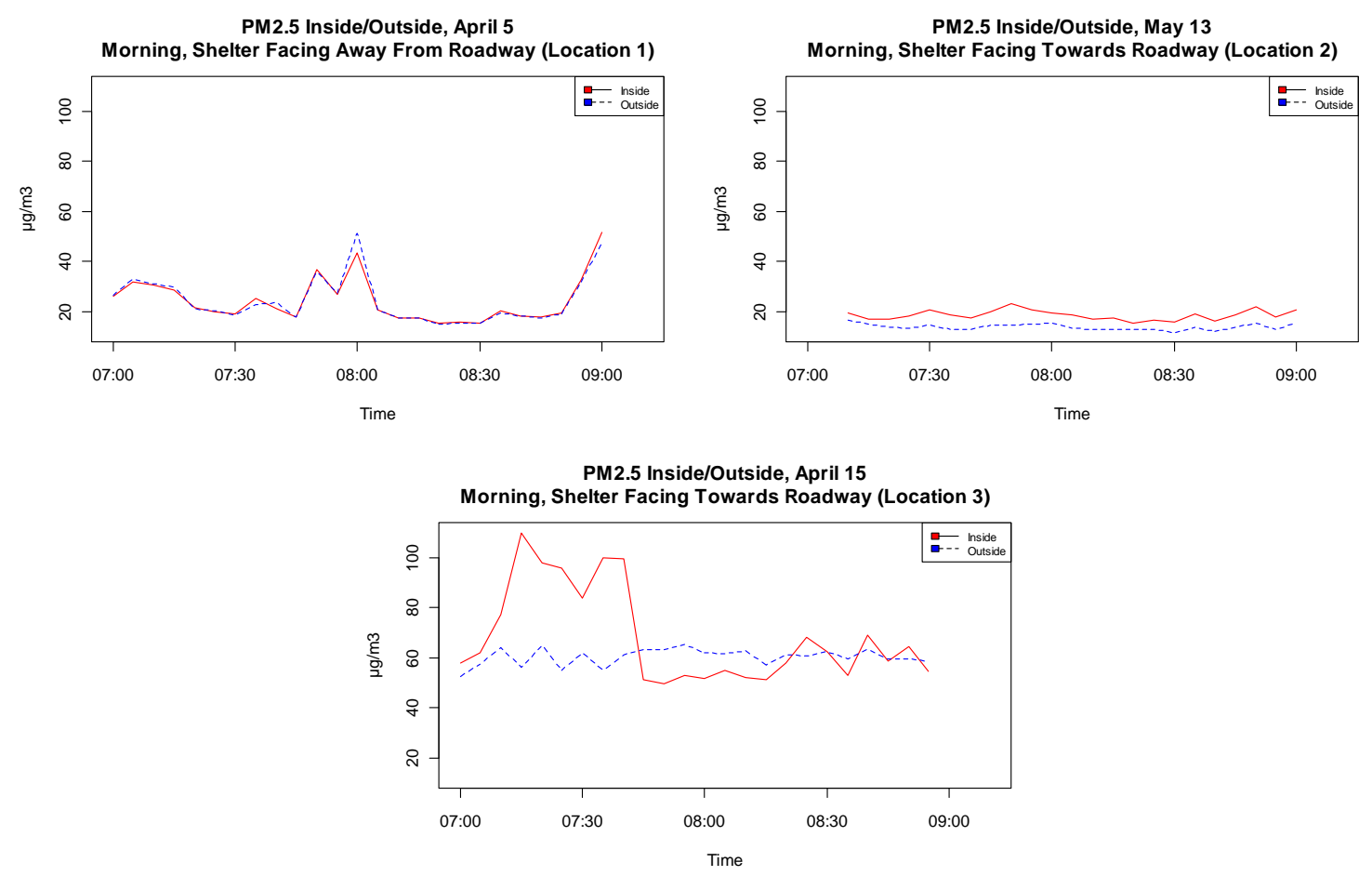

(b)

Figure 4.3.1: Morning (a) UFP and (b) $\mathrm{PM}_{2.5}$ concentrations inside and outside the bus shelter at each shelter location. 


\subsection{Time of Day}

Substantial differences between morning and evening average concentrations led to an investigation of comparative time of day concentrations. Concentration levels reflect higher morning concentrations, similar to results found in other studies (Adams, Nieuwenhuijsen, and Colvile 2001; Adams et al. 2001; Hess et al. 2010). Morning concentrations were found to be, on average, $227 \%$ higher than evening concentrations across all particulate levels and all shelter sampling locations. Such patterns are likely attributed to atmospheric conditions (temperature, relative humidity) and air circulation patterns, but may also be explained by morning and evening peak hour traffic flow. Two shelters are located on the westbound (inbound to CBD) side of Powell Boulevard, and one is located on the eastbound (outbound from CBD) side. Table 4.4.1 shows the average of morning and evening concentrations at each shelter. Concentrations are reported as the average of inside and outside shelter data.

In all instances, particulate concentration levels were greater during the morning period, often substantially so. The likeliest explanatory variable to explain such a dramatic change is atmospheric conditions; in this study, temperature and relative humidity received particular attention. Both experienced changes in magnitude between morning and evening sampling periods, indicating potential explanatory power for dramatic changes in particulate concentration levels. This idea is expanded further in Chapter 5. 
Table 4.4.1: Comparative Average Time of Day Concentrations

\begin{tabular}{|c|c|c|c|c|c|c|c|c|c|c|}
\hline \multirow{3}{*}{$\begin{array}{l}\text { Date } \\
\text { UFP }^{*} \\
(\mathrm{pt} / \mathrm{cc})\end{array}$} & \multirow{2}{*}{\multicolumn{2}{|c|}{$\begin{array}{c}\begin{array}{c}\text { Location } 1 \\
\text { (westbound) }\end{array} \\
\text { April } 29 \\
\end{array}$}} & \multicolumn{4}{|c|}{$\begin{array}{c}\text { Location } 2 \\
\text { (westbound) }\end{array}$} & \multicolumn{4}{|c|}{$\begin{array}{c}\text { Location } 3 \\
\text { (eastbound) }\end{array}$} \\
\hline & & & \multicolumn{2}{|c|}{ April 8} & \multicolumn{2}{|c|}{ May 13} & \multicolumn{2}{|c|}{ March 22} & \multicolumn{2}{|c|}{ April 15} \\
\hline & $\begin{array}{l}33,848 \\
19,092\end{array}$ & 1.77 & $\begin{array}{l}53,573 \\
11,402\end{array}$ & 4.7 & $\begin{array}{l}34,850 \\
11,725\end{array}$ & 2.97 & $\begin{array}{l}51,016 \\
29,961\end{array}$ & 1.71 & $\begin{array}{l}47,123 \\
46,292\end{array}$ & 1.02 \\
\hline $\begin{array}{l}\mathrm{PM}_{1.0}{ }^{*} \\
(\mu \mathrm{g} / \mathrm{m} 3)\end{array}$ & $\begin{array}{l}17.11 \\
10.20\end{array}$ & 1.68 & $\begin{array}{l}59.67 \\
8.06\end{array}$ & 7.4 & $\begin{array}{l}15.62 \\
14.06\end{array}$ & 1.11 & $\begin{array}{l}22.23 \\
10.38\end{array}$ & 2.14 & $\begin{array}{l}63.41 \\
9.32\end{array}$ & 6.8 \\
\hline $\begin{array}{l}\mathrm{PM}_{2.5}{ }^{*} \\
(\mu \mathrm{g} / \mathrm{m} 3)\end{array}$ & $\begin{array}{l}17.32 \\
10.31\end{array}$ & 1.68 & $\begin{array}{l}60.14 \\
8.20\end{array}$ & 7.33 & $\begin{array}{l}15.99 \\
14.27\end{array}$ & 1.12 & $\begin{array}{l}22.89 \\
10.77\end{array}$ & 2.13 & $\begin{array}{l}64.58 \\
9.48\end{array}$ & 6.81 \\
\hline $\begin{array}{l}\mathrm{PM}_{10}{ }^{*} \\
(\mu \mathrm{g} / \mathrm{m} 3)\end{array}$ & $\begin{array}{l}18.80 \\
11.82\end{array}$ & 1.59 & $\begin{array}{l}64.16 \\
10.29\end{array}$ & 5.94 & $\begin{array}{l}19.43 \\
17.89\end{array}$ & 1.09 & $\begin{array}{l}25.48 \\
14.40\end{array}$ & 1.77 & $\begin{array}{l}69.31 \\
10.25\end{array}$ & 6.76 \\
\hline
\end{tabular}

*italic type indicates average morning concentrations, regular type indicates average evening concentrations

*bold type indicates morning vs. evening ratio

\begin{tabular}{|c|c|c|c|c|c|c|c|c|c|c|}
\hline $\begin{array}{l}\operatorname{Traffic}^{\dagger} \\
(\mathrm{veh} / \mathrm{hr})\end{array}$ & $\begin{array}{l}1,054 \\
1,537\end{array}$ & $\begin{array}{l}7 \% \\
10 \%\end{array}$ & $\begin{array}{l}1,452 \\
1,104\end{array}$ & $\begin{array}{l}11 \% \\
12 \%\end{array}$ & $\begin{array}{l}1,054 \\
1,619\end{array}$ & $\begin{array}{l}14 \% \\
10 \%\end{array}$ & $\begin{array}{l}673 \\
1,650\end{array}$ & $\begin{array}{l}2 \% \\
3 \%\end{array}$ & $\begin{array}{l}1,385 \\
1,069\end{array}$ & $\begin{array}{l}6 \% \\
5 \%\end{array}$ \\
\hline $\begin{array}{c}\text { Temperature }{ }^{\dagger} \\
\left({ }^{\circ} \mathrm{C}\right)\end{array}$ & $\begin{array}{l}42 \\
55\end{array}$ & 0.76 & $\begin{array}{l}33 \\
60\end{array}$ & 0.55 & $\begin{array}{l}48 \\
71\end{array}$ & 0.68 & $\begin{array}{l}40 \\
52\end{array}$ & 0.77 & $\begin{array}{l}44 \\
49\end{array}$ & 0.90 \\
\hline $\begin{array}{c}\text { Relative } \\
\text { Humidity }^{\dagger} \\
(\%)\end{array}$ & $\begin{array}{l}86 \\
54\end{array}$ & 1.59 & $\begin{array}{l}90 \\
27\end{array}$ & 3.33 & $\begin{array}{l}75 \\
32\end{array}$ & 2.34 & $\begin{array}{l}85 \\
55\end{array}$ & 1.55 & $\begin{array}{l}94 \\
94\end{array}$ & 1.00 \\
\hline
\end{tabular}

${ }^{\dagger}$ italic type indicates average morning values, regular type indicates average evening values

† bold type indicates percent trucks (vehicles) or morning vs. evening ratio (temperature and relative humidity)

NOTE: April 5 (Location 1) omitted due to lack of evening data. See Table 3.4.1. 


\subsection{Wind Speed and Direction}

The effects of wind characteristics on particulate concentrations are investigated with a caveat pertaining to the ability of a single anemometer to accurately represent the complicated environment surrounding each bus shelter. Without comprehensive measurements at each particulate monitor (i.e. an anemometer directly adjacent to each sampling device), the results from one anemometer must be presented as a unique caseby-case depiction of wind-particulate relationships at a specific placement.

Initially, wind characteristics were investigated using a series of visual plots discussed below. Following exploratory analysis, wind data were separated into two categories: wind speed and wind direction. Wind direction data are inherently difficult to organize for analysis because they are recorded as a degree (i.e. $0-360^{\circ}$ ). Additionally, raw data were collected in five-second intervals, but analysis was conducted using oneminute intervals. Aggregating degrees is cumbersome and, if done improperly, can lead to errors in the analysis output.

An innovative method was devised to aggregate directional data from five seconds (in degrees) to one minute (in percentage), essentially capturing the percentage of one minute that the wind was blowing in a certain direction. Data were grouped into the ordinal directions shown in Table 4.5.1. Over a one-minute interval, the number of occurrences of each direction were summed, and then divided by the total sum of occurrences for that interval. The result is a set of variables describing, for instance, how long the wind blew northward during the minute-long interval in question.

Comparing ordinal directions between shelters is unintuitive given that wind blowing north at Location 1 is blowing towards the shelter while wind blowing north at 
Location 3 is blowing away from the shelter. As a means of normalizing wind direction, four new variables were created to address nomenclature discrepancies. The four variables capture: wind blowing towards the shelter, wind blowing away from the shelter, wind blowing in the direction of the flow of traffic closest to the shelter, and wind blowing against the flow of traffic closest to the shelter. These variables are summarized in Table 4.5.1. Further discussion and use of these variables is discussed in Chapter 5.

Table 4.5.1: Wind Direction Categories

\begin{tabular}{|c|c|c|c|c|c|c|c|c|}
\hline Direction & $\mathrm{N}$ & NE & $\mathrm{E}$ & SE & S & SW & W & NW \\
\hline $\begin{array}{l}\text { Corresponding } \\
\text { Degrees }\end{array}$ & $\begin{array}{c}337.5^{\circ}- \\
22.5^{\circ}\end{array}$ & $\begin{array}{l}22.5^{\circ}- \\
67.5^{\circ}\end{array}$ & $\begin{array}{l}67.5^{\circ}- \\
112.5^{\circ}\end{array}$ & $\begin{array}{l}112.5^{\circ}- \\
157.5^{\circ}\end{array}$ & $\begin{array}{l}157.5^{\circ}- \\
202.5^{\circ}\end{array}$ & $\begin{array}{l}202.5^{\circ}- \\
247.5^{\circ}\end{array}$ & $\begin{array}{l}247.5^{\circ}- \\
292.5^{\circ}\end{array}$ & $\begin{array}{l}292.5^{\circ}- \\
337.5^{\circ}\end{array}$ \\
\hline Location $1 \& 2$ & \multicolumn{2}{|c|}{$\begin{array}{c}\text { Towards } \\
\text { Shelter }\end{array}$} & Against & \multicolumn{3}{|c|}{ Away from Shelter } & With & $\begin{array}{l}\text { Towards } \\
\text { Shelter }\end{array}$ \\
\hline Location 3 & \multicolumn{2}{|c|}{$\begin{array}{l}\text { Away from } \\
\text { Shelter }\end{array}$} & With & \multicolumn{3}{|c|}{ Towards Shelter } & Against & $\begin{array}{c}\text { Away } \\
\text { from } \\
\text { Shelter }\end{array}$ \\
\hline
\end{tabular}

Figure 4.5.1 shows sample plots of observed concentrations of UFP and $\mathrm{PM}_{2.5}$ varying by wind speed and direction at each shelter location using polar plots for three dates: April 29, May 13, and March 22 for Locations 1, 2, and 3, respectively. Interactions between all particulates and wind speed and direction measurements are shown in Appendix D. In these plots, the angular coordinate is the wind direction and the radial coordinate is the wind speed. Wind speeds are denoted by concentric circles incremented to units of $0.5 \mathrm{~m} / \mathrm{s}$. At each of the coordinates in the two-dimensional plane, the third dimension is plotted based on a color-scale gradient. Higher concentrations are shown as red hues on the scale gradient and indicate concentration levels most affected by wind direction. Each vertical pair of plots represent inside (top) and outside (bottom). 
For instance, the UFP concentrations at Location 1 are highest when the wind is from the east. Shelter orientation relative to cardinal directions is given in the figure descriptions. The plots in Figure 4.5.1, as well as those in Appendix C, were created using the OpenAir package in the statistical software program R (Carslaw and Ropkins 2011).

The figure indicates UFP concentrations are at their highest when winds are from the east (Figure 4.5.1a, shelter facing north) and from the southwest (Figure 4.5.1c, shelter facing north). $\mathrm{PM}_{2.5}$ concentrations are highest when winds are from the north, though Figure 4.5.1c shows $\mathrm{PM}_{2.5}$ concentrations both inside and outside the shelter unaffected by any one wind direction.

Wind direction affects particulate concentrations differently in each shelter location and for each shelter orientation. Figure 4.5.1c best illustrates discrepancies in particulate behavior: UFP concentrations inside and outside the shelter are equally affected by wind direction, as evidenced by the highest concentrations, which are always affected by westerly winds, increasing with intensity. At the same time, $\mathrm{PM}_{2.5}$ concentrations appear to be unaffected by wind direction outside the shelter, indicated by uniform hues in all directions, while concentrations inside the shelter are minimally affected by easterly wind directions at very low wind speeds, evidenced by slightly higher hues.

Increasing wind speed generally results in lower concentrations, although this is not always the case. UFP concentrations inside the shelter in Figure 4.5.1c increase with wind speed, indicating potential entrapment of particles within the shelter. $\mathrm{PM}_{2.5}$ concentrations inside the shelter at the same location are unaffected by wind speed, in contrast with concentrations outside the shelter which exhibit expected behavior. 
UFP Inside/Outside Shelter Facing Away From Roadway (Morning)

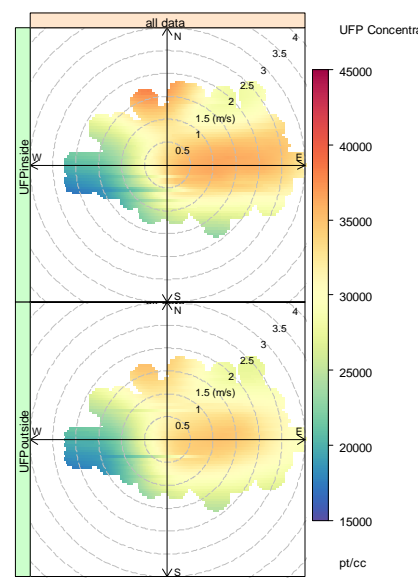

$\mathrm{PM}_{2.5}$ Inside/Outside Shelter Facing Away From Roadway (Morning)

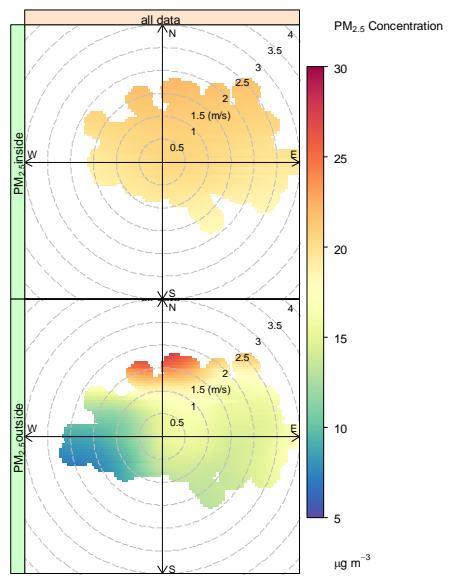

(a) Location 1, shelter facing north

UFP Inside/Outside Shelter Facing Towards Roadway (Evening)

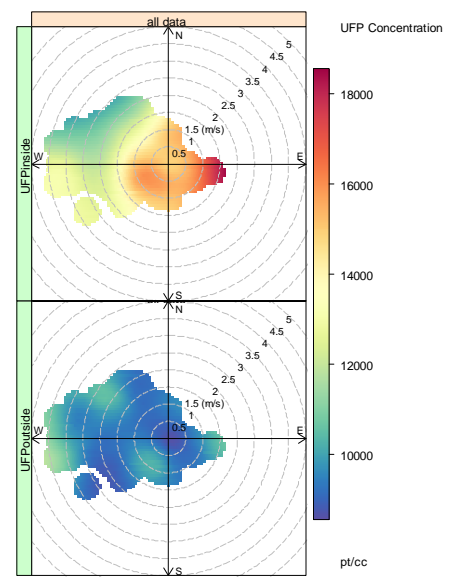

$\mathrm{PM}_{2.5}$ Inside/Outside Shelter Towards From Roadway (Evening)

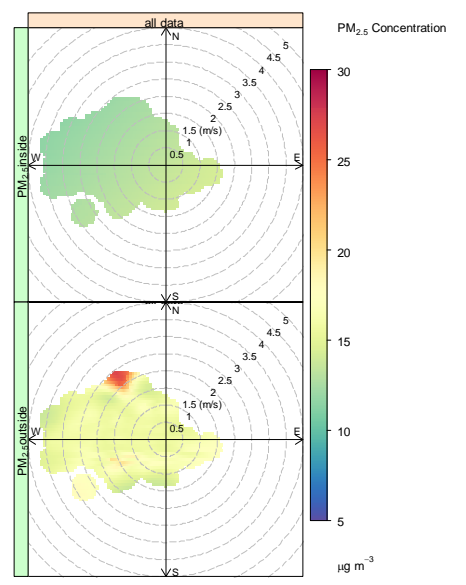

(b) Location 2, shelter facing south
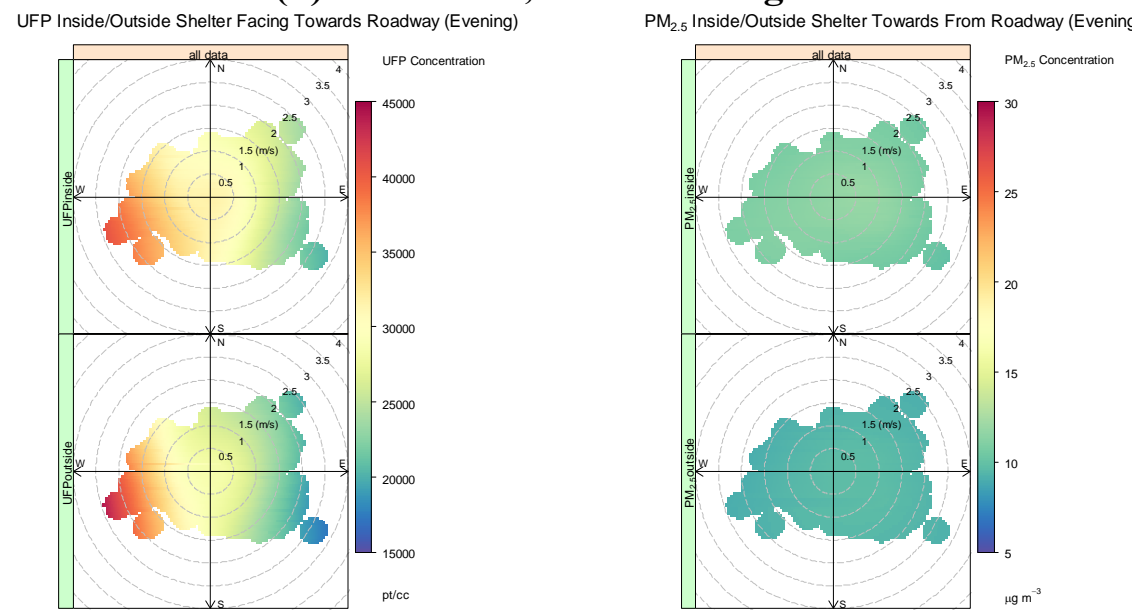

(c) Location 3, shelter facing north

Figure 4.5.1: Bivariate polar plots illustrating wind speed and direction effects on UFP and $P M_{2.5}$ concentrations at each location. 


\subsection{Vehicle Flow}

Vehicle flow data were recorded during each sampling period. The RTMS unit was calibrated to record vehicle counts every five seconds for the direction of travel closest to the bus stop shelter. As discussed in Section 3.3, the scope of the RTMS unit was limited. At Locations 1 and 2, three lanes in the westbound direction, including one left turn lane, were monitored. At Location 3, three lanes in the eastbound direction were monitored.

The bulk of analysis concerning vehicle flow is conducted in Chapter 5. However, time series plots provide intuitive information about correlations between vehicle flow and particulate concentrations. Descriptive time series plots of vehicle data overlaid with particulate concentrations is available in Appendix E.

Plots of interest are highlighted in this section. Figure 4.6.1 shows a sample of vehicle flow and either morning UFP concentrations (Figure 4.6.1a) or evening $\mathrm{PM}_{2.5}$ concentrations (Figure 4.6.1b) inside and outside bus shelter locations. Particulate concentrations are averaged to 5-minute intervals. Vehicle counts are shown in 5-minute aggregated intervals. In several cases, upward or downward traffic trends were observed, notably during the morning sampling period at Location 3 (Figure 4.6.1), in which traffic flow gradually rises from 7:00 am - 8:00 am before leveling off.

The morning sampling period at Location 2 exhibits a downward trend in vehicle flow until 8:00 am followed by a gradual rise that continues until the end of the sampling period at 9:00 am. Such a traffic flow pattern is unexpected; Location 2 is positioned on the inbound traffic side of the road and traffic volumes are expected to be at their highest in the morning rush hour between 7:00 am - 9:00 am. 
Vehicles - UFP, April 5

Morning, Shelter Facing Away From Roadway (Location 1)

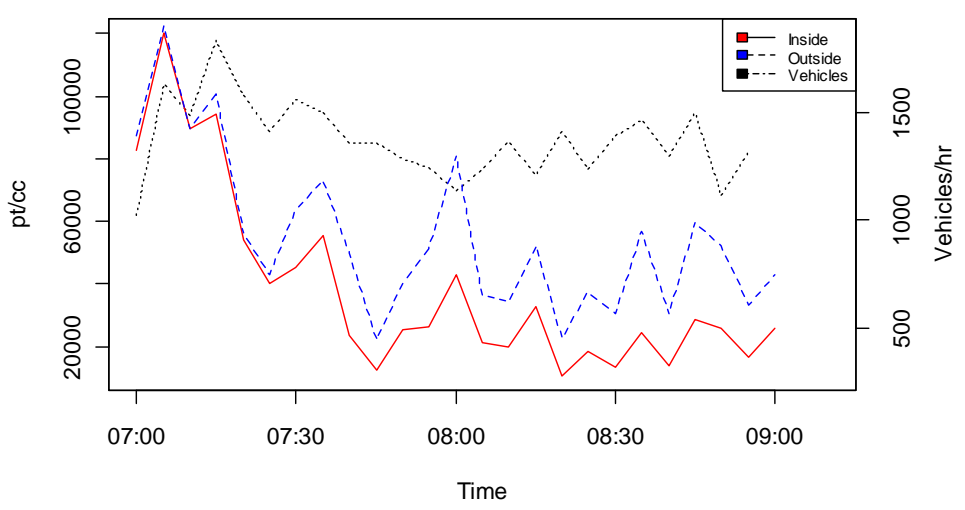

Vehicles - UFP, May 13

Morning, Shelter Facing Towards Roadway (Location 2)

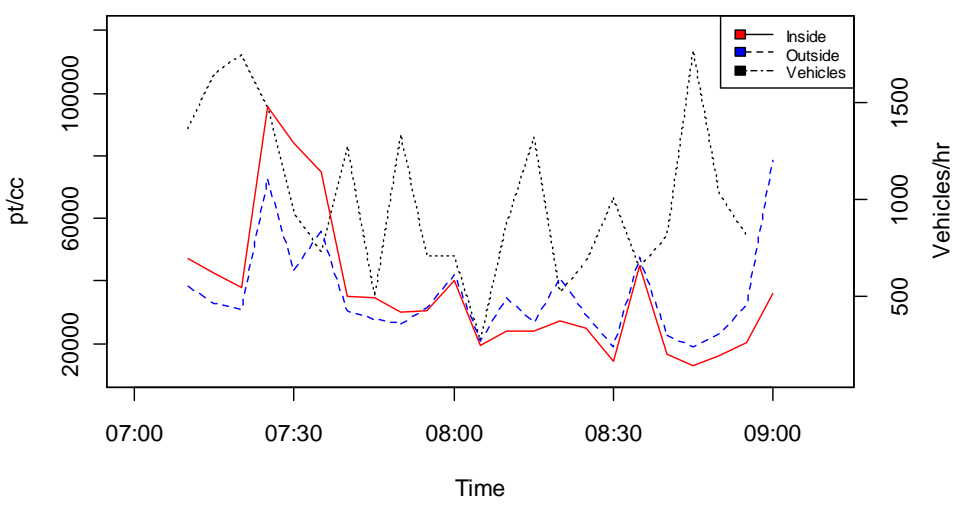

Vehicles - UFP, April 15

Morning, Shelter Facing Towards Roadway (Location 3)

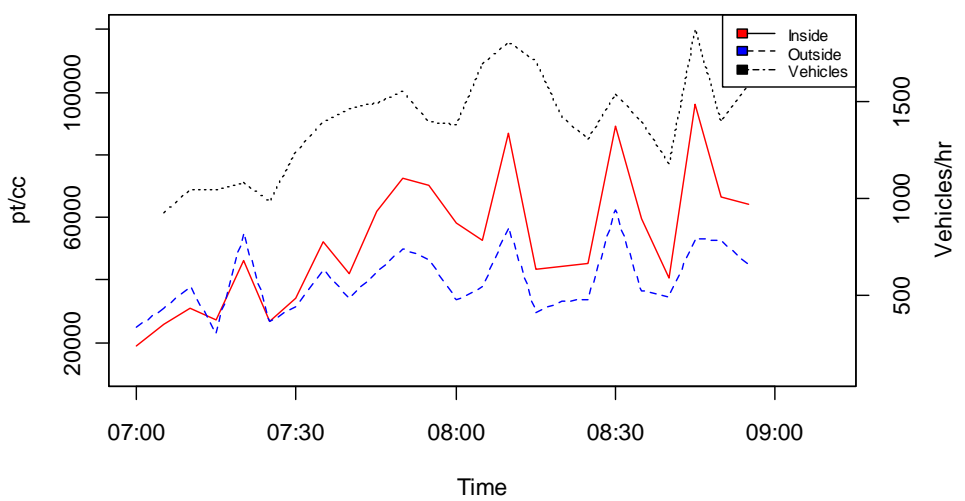

(a) 
Vehicles - PM2.5, April 5

Morning, Shelter Facing Away From Roadway (Location 1)
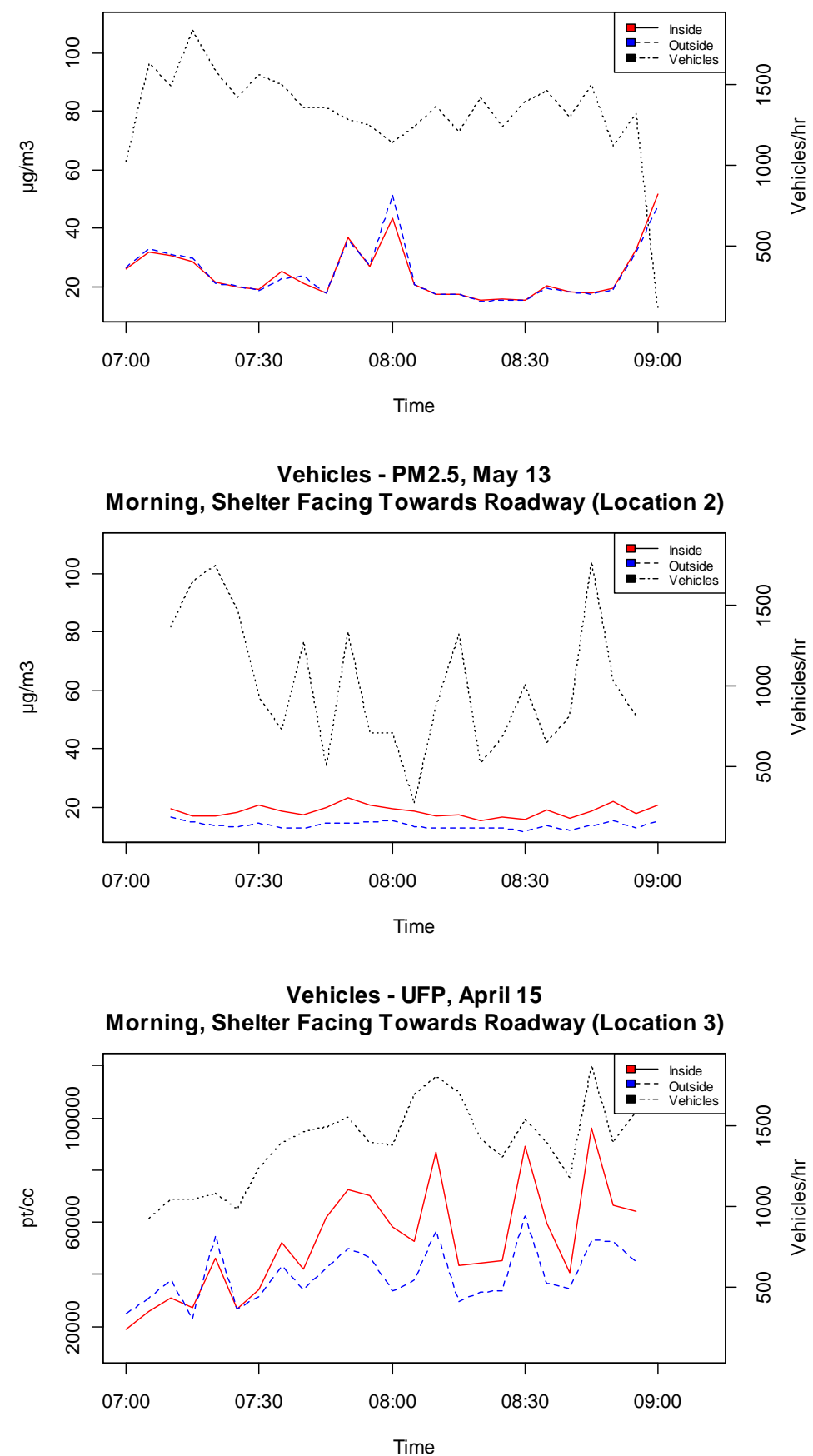

(b)

Figure 4.6.1: Morning UFP (a) and evening $\mathrm{PM}_{2.5}$ (b) concentrations at each bus shelter location overlaid with hourly vehicle flow. 


\section{ANALYSIS}

All analysis was conducted using the statistical software program $\mathrm{R}$. $\mathrm{R}$ is a language and environment for statistical computing and graphics, providing a wide variety of statistical and graphical techniques.

\subsection{Log Transformation}

Initially, the dependent data were checked for normality and found to be universally skewed to the right. To decrease the skew, dependent data were logtransformed prior to being placed in the model. An example of the effects of log transformation on normality is shown in Figure 5.1.1 and Figure 5.1.2. UFP density distribution plots are shown first for non-transformed data to illustrate the skew. Particle concentrations are primarily distributed in the $0-50,000 \mathrm{pt} / \mathrm{cc}$ range with outliers up to approximately $250,000 \mathrm{pt} / \mathrm{cc}$. In addition, quantile-quantile (QQ) plots are shown in which data are plotted against a line drawn between their first and third quartiles. Deviation from the line indicates non-normality. The effect of the log transformation is data that are more appropriate for regression analysis, seen in both the density distribution and QQ plots. 

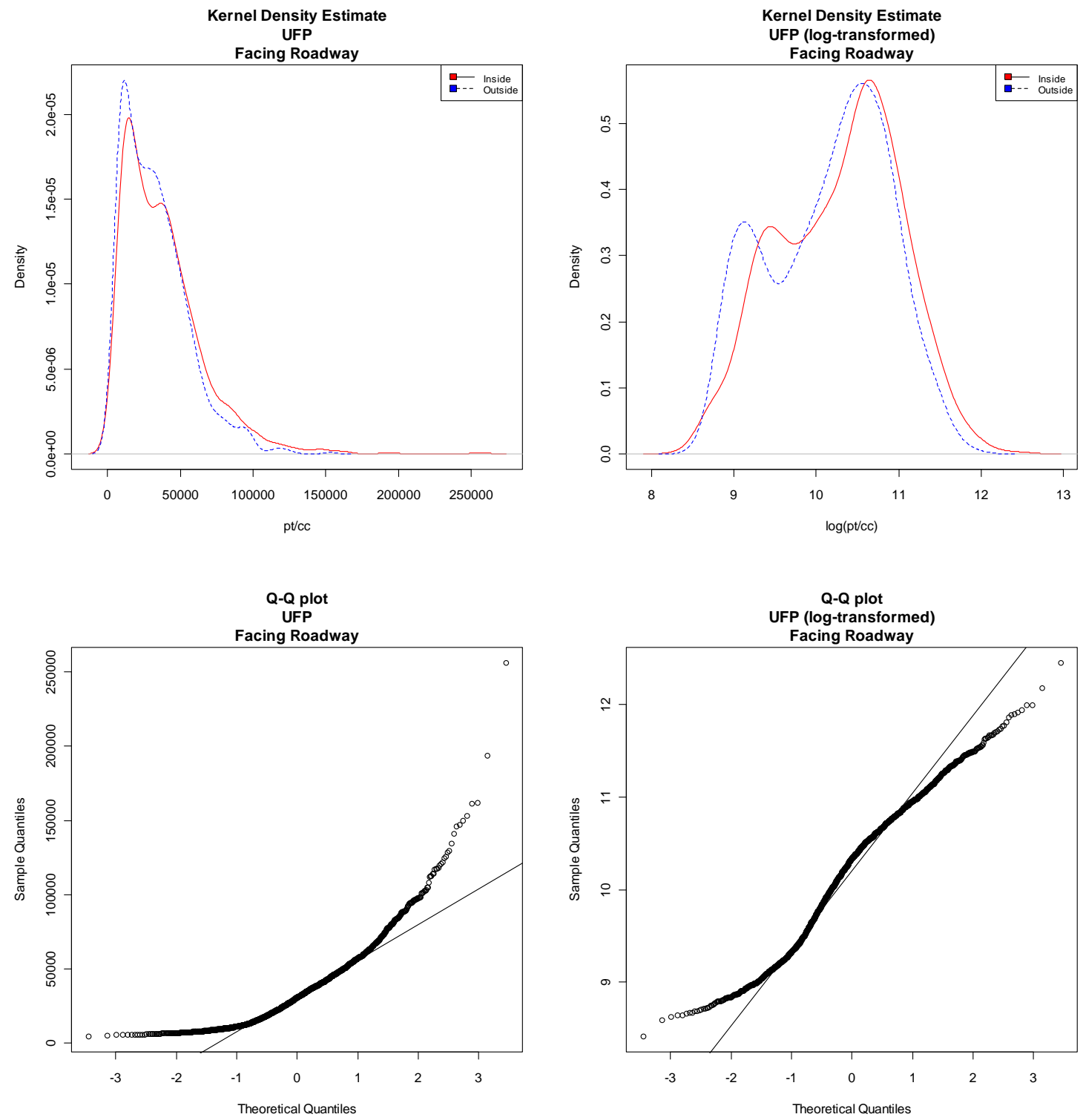

Figure 5.1.1: Sample comparisons of UFP distributions, shelter facing roadway. 

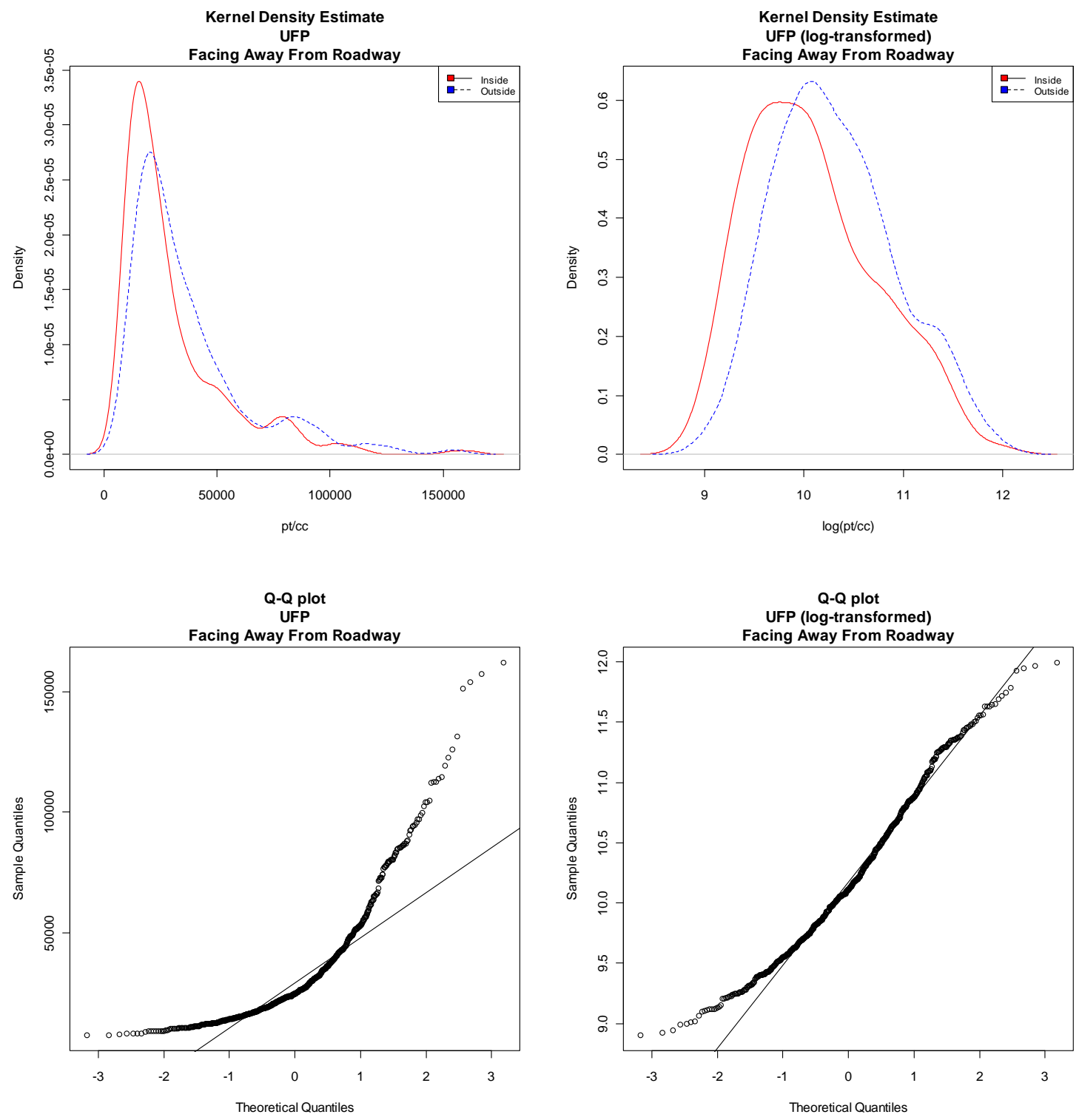

Figure 5.1.2: Sample comparisons of UFP distributions, shelter facing away from roadway. 


\subsection{Correlation}

To investigate initial relationships between each particulate size and independent variables, Pearson correlations were calculated for each associated pair (i.e. UFP and vehicles, $\mathrm{PM}_{10}$ and temperature, etc.). This process was conducted for log-transformed dependent variables, as well. Complete correlation results are presented in Appendix A.

For non-log transformed data, correlation results were generally inconsistent between particulates and independent variables. For instance, UFP in Table 0.1 exhibit noteworthy negative correlation (-0.35) with vehicle flow inside the shelter at Location 1 , but fail to do so at any other location. Correlations were most consistently observed between particulates of all sizes and temperature (generally negative) or humidity (generally positive).

In addition to testing correlations with independent variables, particulates were also tested against each other, revealing extremely high positive correlations between $\mathrm{PM}_{1.0}, \mathrm{PM}_{2.5}$, and $\mathrm{PM}_{10}(\sim 0.95)$. Correlations between UFP and larger particulate sizes were inconsistent, ranging from $0.25-0.75$, and one instance of negative correlation outside the shelter at Location 2.

To investigate the relationship with independent variables further, a Pearson test for association $(\alpha=0.05)$ was performed between vehicle, weather, and particulate variables. Vehicle flow was subdivided into vehicles (all vehicles) and heavy vehicles (vehicles with length $>6 \mathrm{~m}$ ). Reasoning that high correlations between $\mathrm{PM}_{1.0}, \mathrm{PM}_{2.5}$, and $\mathrm{PM}_{10}$ made correlation tests for each redundant, only $\mathrm{PM}_{2.5}$ correlations were performed for this analysis. Results are presented in Table 5.2.1. 
Table 5.2.1: Association Correlation Test (UFP and PM $\left.\mathbf{P M}_{2.5}\right)$

\begin{tabular}{|c|c|c|c|c|c|c|c|c|c|}
\hline & \multicolumn{4}{|c|}{ Inside } & \multicolumn{4}{|c|}{ Outside } \\
\hline & & \multicolumn{2}{|c|}{ UFP } & \multicolumn{2}{|c|}{$\mathrm{PM}_{2.5}$} & \multicolumn{2}{|c|}{ UFP } & \multicolumn{2}{|c|}{$\mathrm{PM}_{2.5}$} \\
\hline & & $r$ & $p$ & $r$ & $p$ & $r$ & $p$ & $r$ & $p$ \\
\hline & & \multicolumn{8}{|c|}{ Location 1 (Shelter Facing Away from Roadway) } \\
\hline \multirow{3}{*}{\multicolumn{2}{|c|}{$\begin{array}{l}\text { Vehicles } \\
\text { Heavy Veh } \\
\text { Wind Speed }\end{array}$}} & -0.04 & 0.464 & -0.13 & 0.040 & -0.03 & 0.591 & -0.03 & 0.591 \\
\hline & & -0.15 & 0.008 & -0.15 & 0.022 & -0.14 & 0.018 & -0.06 & 0.310 \\
\hline & & -0.04 & 0.660 & -0.08 & 0.549 & -0.04 & 0.708 & 0.01 & 0.949 \\
\hline \multirow{4}{*}{ 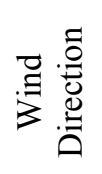 } & TS & -0.07 & 0.457 & 0.07 & 0.609 & -0.04 & 0.653 & -0.05 & 0.614 \\
\hline & AS & -0.04 & 0.682 & 0.00 & 0.991 & -0.01 & 0.895 & 0.21 & 0.041 \\
\hline & WT & 0.19 & 0.055 & -0.03 & 0.844 & 0.15 & 0.123 & 0.09 & 0.406 \\
\hline & $\mathrm{AT}$ & -0.15 & 0.130 & 0.00 & 0.988 & -0.14 & 0.165 & -0.27 & 0.007 \\
\hline \multirow{2}{*}{\multicolumn{2}{|c|}{$\begin{array}{l}\text { Temperature } \\
\text { Rel. Humidity }\end{array}$}} & -0.43 & 0.000 & -0.69 & 0.000 & -0.46 & 0.000 & -0.41 & 0.000 \\
\hline & & 0.43 & 0.000 & 0.69 & 0.000 & 0.47 & 0.000 & 0.43 & 0.000 \\
\hline & & \multicolumn{8}{|c|}{ Location 2 (Shelter Facing Towards Roadway) } \\
\hline \multirow{3}{*}{\multicolumn{2}{|c|}{$\begin{array}{l}\text { Vehicles } \\
\text { Heavy Veh } \\
\text { Wind Speed }\end{array}$}} & 0.03 & 0.476 & 0.13 & 0.006 & 0.03 & 0.478 & 0.27 & 0.000 \\
\hline & & 0.00 & 0.928 & 0.06 & & 0.03 & 0.461 & & 0.688 \\
\hline & & -0.29 & 0.000 & -0.42 & 0.000 & -0.32 & 0.000 & 0.02 & 0.787 \\
\hline \multirow{4}{*}{$\vec{\Xi} \cdot \stackrel{0}{0}$} & TS & 0.10 & 0.133 & 0.33 & 0.000 & 0.23 & 0.000 & 0.08 & 0.375 \\
\hline & AS & -0.07 & 0.301 & -0.16 & 0.012 & -0.10 & 0.112 & -0.03 & 0.782 \\
\hline & WT & 0.08 & 0.219 & 0.29 & 0.000 & 0.18 & 0.006 & 0.23 & 0.013 \\
\hline & $\mathrm{AT}$ & -0.05 & 0.412 & -0.26 & 0.000 & -0.18 & 0.007 & -0.03 & 0.736 \\
\hline \multirow{2}{*}{\multicolumn{2}{|c|}{$\begin{array}{l}\text { Temperature } \\
\text { Rel. Humidity }\end{array}$}} & -0.61 & 0.000 & -0.84 & 0.000 & -0.80 & 0.000 & 0.23 & 0.000 \\
\hline & & 0.64 & 0.000 & 0.82 & 0.000 & 0.79 & 0.000 & 0.31 & 0.000 \\
\hline & & \multicolumn{8}{|c|}{ Location 3 (Shelter Facing Towards Roadway) } \\
\hline \multirow{3}{*}{\multicolumn{2}{|c|}{$\begin{array}{l}\text { Vehicles } \\
\text { Heavy Veh } \\
\text { Wind Speed }\end{array}$}} & -0.09 & 0.064 & 0.04 & 0.460 & -0.16 & 0.001 & 0.07 & 0.148 \\
\hline & & 0.01 & 0.827 & 0.13 & 0.005 & -0.03 & 0.493 & 0.17 & 0.000 \\
\hline & & -0.11 & 0.252 & -0.03 & 0.730 & -0.05 & 0.601 & -0.02 & 0.813 \\
\hline \multirow{4}{*}{ 롤. } & TS & 0.04 & 0.722 & 0.09 & 0.353 & -0.02 & 0.863 & -0.03 & 0.741 \\
\hline & AS & -0.07 & 0.511 & -0.03 & 0.771 & -0.11 & 0.270 & -0.02 & 0.819 \\
\hline & WT & 0.05 & 0.636 & -0.12 & 0.238 & 0.07 & 0.488 & -0.14 & 0.157 \\
\hline & $\mathrm{AT}$ & -0.01 & 0.931 & 0.06 & 0.518 & -0.05 & 0.635 & 0.16 & 0.108 \\
\hline \multirow{2}{*}{\multicolumn{2}{|c|}{$\begin{array}{l}\text { Temperature } \\
\text { Rel. Humidity }\end{array}$}} & -0.24 & 0.000 & -0.42 & 0.000 & -0.37 & 0.000 & -0.49 & 0.000 \\
\hline & & 0.38 & 0.000 & 0.40 & 0.000 & 0.24 & 0.000 & 0.47 & 0.000 \\
\hline
\end{tabular}

$r=$ Pearson correlation coefficient, $p=$ observed significance level

bold $r$-values indicate significance at $\mathrm{p}=0.05$ level

"TS" = Towards Shelter, "AS" = Away from Shelter, "WT" = With Traffic, "AT" =

Against Traffic

Significant correlations were consistently observed between temperature and relative humidity for both UFP and $\mathrm{PM}_{2.5}$. In most instances, temperature is negatively correlated, though it is positively correlated with $\mathrm{PM}_{2.5}$ outside the shelter at Location 2. Several unexpected results are highlighted, indicating correlations with signs opposite of the expected. Positive correlations with temperature are an unexpected result given the 
trends observed in Section 4.4. Relative humidity was consistently observed to have a significant positive correlation with both particulate sizes.

Table 5.2.2: Association Correlation Test $\left(\log U F P\right.$ and $\left.\log P M_{2.5}\right)$

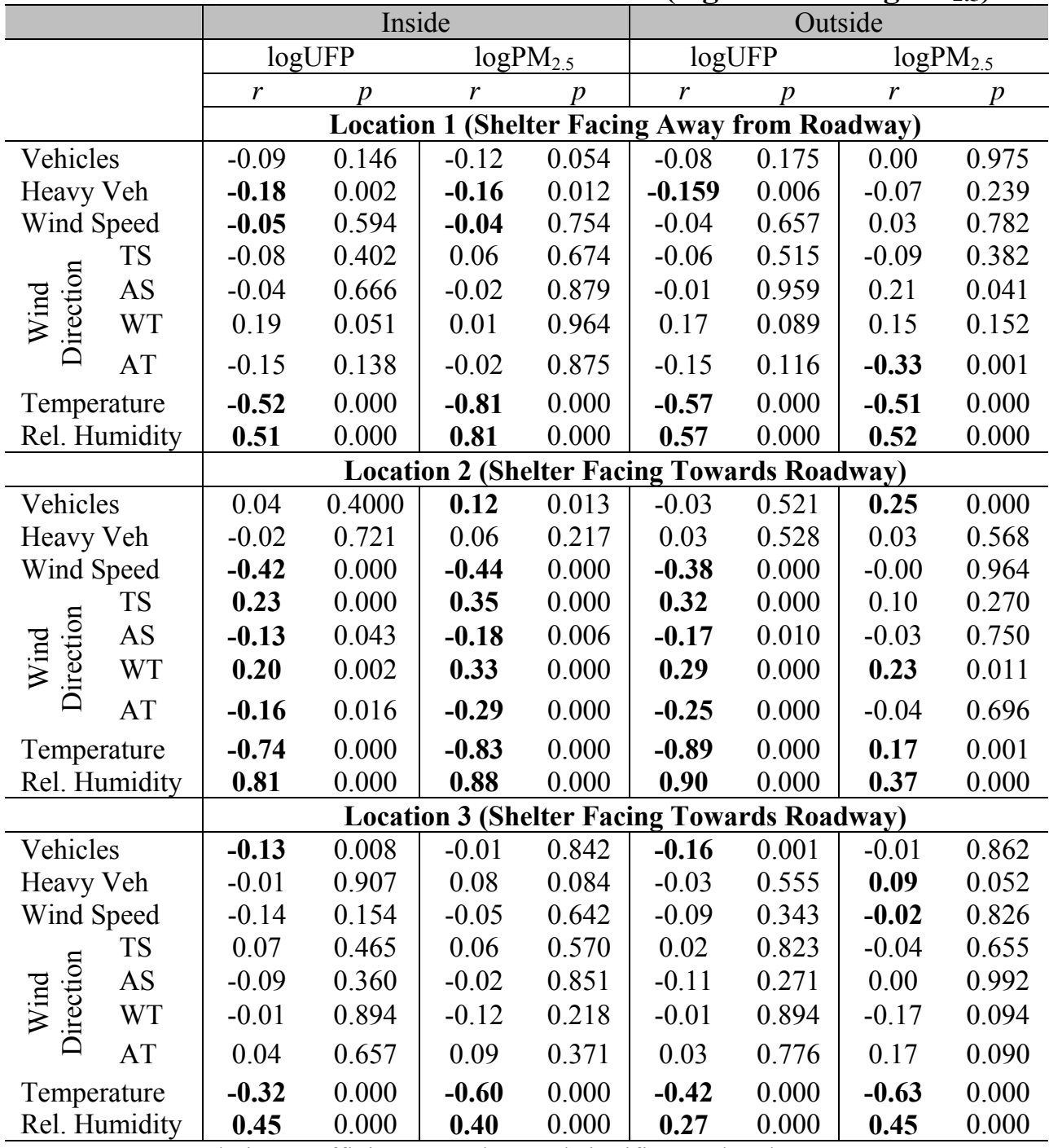

$r=$ Pearson correlation coefficient, $p=$ observed significance level

bold $r$-values indicate significance at $\mathrm{p}=0.05$ level

"TS" = Towards Shelter, "AS" = Away from Shelter, "WT" = With Traffic, "AT" = Against Traffic

Wind speed significantly affected particulates only at Location 2. As expected, correlations are negative, indicating a dispersion effect. 
Vehicle and heavy vehicle flow was inconsistently observed to significantly correlate with particulate levels. Literature suggests a positive correlation, though correlations were primarily negative in these data. Location 1 exhibited the most significant vehicle correlations, perhaps due to its close proximity to the roadway relative to the other shelters $(\sim 0.5 \mathrm{~m})$.

The inconsistencies in these results indicate the complexity of the environment surrounding the bus stop shelters, and the effect such complexity has on particulate concentrations.

\subsection{Linear Regression}

Correlations alone are not enough to explain the relationship between multiple variables and particulate concentrations. A series of linear regression models were estimated to further explain the correlations found in Section 5.2. The reader is directed to Table 4.1.1 for variable definitions in the models and for explanation of dummy variable values.

Given high correlations between $\mathrm{PM}_{1.0}, \mathrm{PM}_{2.5}$, and $\mathrm{PM}_{10}$, only $\mathrm{PM}_{2.5}$ is included in the regression analysis, along with UFP. This paper uses log-transformed particulate data for all regression analysis. Select log-transformed regression models are included in Appendix B, though non-log-transformed models are also included in Appendix B for reference. For the remainder of this section, however, all references to Appendix B will imply reference to the log-transformed data.

Initially, three location-specific linear regression models were estimated, each representing a different category of variables: location, traffic, and weather. Categorized 
models are shown in Appendix B. From these categorized models, general conclusions were drawn about the influence of each category on particulate concentrations. Following this, all variables were combined into a comprehensive model. In an iterative process, non-significant variables were removed from the model and the model was re-run until all included variables were statistically significant at $\alpha=0.05$.

Before the models were estimated, the expected signs of the coefficients were noted, in order to better judge the regression results. The expected signs are shown in Table 5.3.1. These signs were chosen based on findings in the literature as well as findings from the correlation tables in Section 5.2.

Table 5.3.1: Expected Coefficient Signs for Regression Analysis

\begin{tabular}{|c|c|c|c|c|c|c|c|}
\hline $\begin{array}{c}\text { Independent } \\
\text { Variable }\end{array}$ & $\begin{array}{c}\text { Location } \\
1\end{array}$ & $\begin{array}{c}\text { Location } \\
3\end{array}$ & $\begin{array}{c}\text { Vehicles/Heavy } \\
\text { Vehicles }\end{array}$ & $\begin{array}{c}\text { Wind } \\
\text { Speed }\end{array}$ & $\begin{array}{c}\text { Wind } \\
\text { Direction }\end{array}$ & Temp & $\begin{array}{c}\text { Rel. } \\
\text { Humidity }\end{array}$ \\
\cline { 2 - 8 } & Loc1 & Loc3 & V/HV & WS & WD & T & RH \\
\hline $\begin{array}{c}\text { Expected } \\
\text { Coefficient } \\
\text { Sign }\end{array}$ & $(-)$ & $(-)$ & $(+)$ & $(-)$ & $(-)$ & $(-)$ & $(+)$ \\
\hline
\end{tabular}

Location 1 and Location 3 are singled out for their unique built environment attributes: Location 1 is the only location with a shelter facing away from the roadway, and Location 3 is the only location on the far-side of an intersection. The reasoning behind this decision is discussed on the next page.

The regression model is structured in the theoretical form shown in Equation 5.1, where $\hat{y}$ is the dependent variable, $\widehat{\beta_{0}}$ is the intercept, $\widehat{\beta}_{l}$ is the ith coefficient, and $X_{i}$ is the given value of the $i$ th variable. The ^ symbol denotes sample data, as opposed to population data. 


$$
\hat{y}=\widehat{\beta_{0}}+\widehat{\beta}_{l} X_{i} \quad \text { for } i=1 \ldots n
$$

With the expected signs as stated, the theoretical linear regression equation can then be proposed, shown in Equation 5.2:

$$
\begin{gathered}
\hat{y}=\widehat{\beta_{0}}-\widehat{\beta_{1}} \operatorname{Loc} 1-\widehat{\beta_{2}} L o c 3+\widehat{\beta_{3}} V+\widehat{\beta_{4}} H V-\widehat{\beta_{5}} W S-\widehat{\beta_{6}} W D-\widehat{\beta_{7}} T \\
+\widehat{\beta_{8}} R H
\end{gathered}
$$

The primary variables of interest in each model are the location-specific variables, capturing the unique qualities of Location 1 and Location 3. As dummy variables, the regression is comparing whether concentration levels are greater or lesser at each location than the other locations. For example, the Loc1 variable compares particulate concentrations at Location 1 against Locations 2 and 3. Ideally, the regression would compare an orientation-specific variable, but shortcomings in the number of shelters sampled limit the ability of the model to compare orientation without inadvertently capturing other location factors inherent to Location 1, which is the only shelter facing away from the roadway.

The regression tables in this section, as well as those in Appendix B, show the estimated coefficients of each variable, the sum of the squared standard error, as well as the t-statistic and the associated statistical significance. Statistical significance is indicated by the number of stars, with corresponding $\mathrm{p}$-values given at the bottom of the table (significance accepted at $\alpha=0.05$ ). 
The two remaining sections in Chapter 5 present results from the categorical and comprehensive models, respectively. All categorical models are presented in Appendix B. Select comprehensive models are presented in this chapter.

\subsubsection{Categorical Models}

Each of the three categories in the categorized linear regression model reveals the expected level of influence on particulate concentrations. The adjusted $\mathrm{R}^{2}$ in Table 0.1, for instance, shows that the "location" model explains $21 \%$ of UFP concentration variability inside the shelter. The "traffic" model only explains 5\%. The "weather" model is the most descriptive, explaining over half of UFP concentration variability. This pattern is repeated for the other categorized regression models, with the "traffic" model consistently explaining less than $5 \%$ of particulate variability.

Low adjusted $\mathrm{R}^{2}$ values for the traffic models were unexpected, given the amount of literature linking emissions with roadway particulate concentration levels. Two possible explanations may account for the low adjusted $\mathrm{R}^{2}$. First, as mentioned in Section 3.3, the RTMS vehicle monitoring unit was only able to capture approximately half of the roadway environment. Capturing the entire roadway would give more explanatory power to the traffic models. Second, controlling the multitude of other variables, especially weather, may severely reduce the resolution of traffic-specific influences. Emissions from vehicles may be attributed in these models to wind, for instance, because the wind transfers the emissions from the roadway to the shelter. 
The "weather" category explains as much as $78 \%$ of particulate variability for UFP concentrations (Table 0.2 ) and as much as $73 \%$ of particulate variability for $\mathrm{PM}_{2.5}$ concentrations (Table 0.3).

The categorical models in this section do not account for time lags for variables. In the following section, time lags were investigated and shown to affect significance of the vehicle variables. A time-lagged vehicle category in this section, then, would be expected to explain a larger percentage of particulate variation.

\subsubsection{Comprehensive Models}

The comprehensive regression models estimated in this study are more descriptive and better represent the entire environment surrounding the shelters by estimating all variable coefficients simultaneously. As such, they are the focus for the remainder of this section.

Comprehensive models were estimated in three parts. First, all variables were combined and those that were non-significant (at $\alpha=0.05$ ) were removed sequentially. These results are displayed in Table 5.3.2 through Table 5.3.5. Second, select variables were lagged up to three minutes (in units of one minute) and checked for significance. Lagged variables included vehicle flow, wind speed, and wind direction. Third, interactions between groups of variables were investigated. The Loc1 and Loc3 variables were tested for interaction with wind-related variables to compare wind effects for a shelter facing away from the roadway versus towards the roadway. Vehicle flow was tested for interaction with both wind speed and wind direction to compare particulate levels when wind blows towards the shelter in the presence of a vehicle. Significant 
interactions were added to the models and the results are displayed in Table 5.3.6 through Table 5.3.9.

The exponential coefficient -0.67 for $\mathrm{PM}_{2.5}$ inside the shelter (Table 5.3.4) is the ratio of the expected geometric mean for the shelter facing away from the roadway over the expected geometric mean for the shelter facing towards the roadway, holding constant all other variables. The ratio can be expressed as $\exp ($ orientation $)=-\exp (0.67)=$ -1.95 . Thus, $\mathrm{PM}_{2.5}$ levels are expected to decrease an average of $95 \%$ when inside the shelter at Location 1, holding constant all other variables. Such a substantial decrease is a surprising result given the results presented in Section 4.2 and Section 4.3, in which observed $\mathrm{PM}_{2.5}$ concentration decreases were not as pronounced as the model predicts.

Weather was a consistently significant descriptor in the models. Temperature and/or relative humidity were significant in every model. In several instances during processing, temperature and relative humidity were both significant, but the sign of one was the opposite of expected. This was not consistent with the expectations outlined in Table 5.3.1. For example, temperature and relative humidity both had negative coefficients in the model for UFP inside the shelter, indicative of high correlation and near multicolinearity. To correct the issue, one of the two variables was removed whichever had the least effect on the overall model.

Relative to Location 2 (the reference point), UFP levels inside the shelter are expected to decrease an average of $6 \%$ per degree Celsius increase in temperature, holding constant all other variables. That is, the ratio of the expected change in the geometric mean is $\exp ($ temperature $)=-\exp (0.03)=-1.03 . \mathrm{PM}_{2.5}$ levels inside the 
shelter are expected to decrease a relative average of $6 \%$ per degree Celsius increase in temperature as well, holding constant all other variables.

Wind speed and direction were intermittently significant. Wind speed was only significant in the model for UFP inside the shelter. The sign is consistent with expectations, and UFP levels are expected to decrease an average of $23 \%$ with an incremental increase in wind speed (measured in $\mathrm{m} / \mathrm{s}$ ), holding constant all other variables. $\mathrm{PM}_{2.5}$ levels outside the shelter are expected to decrease an average of $21 \%$ when wind blows against the direction of traffic for one minute.

Table 5.3.2: Comprehensive Linear Regression Model (logUFP Inside)

\begin{tabular}{|c|c|c|c|c|}
\hline logUFP (inside) & \multicolumn{4}{|c|}{ Comprehensive } \\
\hline Variable & Beta & SSE & $\mathbf{t}$ & Sig. ${ }^{\dagger}$ \\
\hline Intercept & 11.89 & 0.07 & 162.4 & $* * *$ \\
\hline \multicolumn{5}{|l|}{ Weather } \\
\hline Wind Speed & -0.21 & 0.06 & -3.4 & $* * *$ \\
\hline Temperature & -0.03 & 0.00 & -23.1 & $* * *$ \\
\hline Adjusted $\mathrm{R}^{2}$ & \multicolumn{4}{|c|}{0.59} \\
\hline
\end{tabular}

Table 5.3.3: Comprehensive Linear Regression Model (logUFP Outside)

\begin{tabular}{|c|c|c|c|c|}
\hline \multirow{2}{*}{$\begin{array}{l}\text { logUFP (outside) } \\
\text { Variable }\end{array}$} & \multicolumn{4}{|c|}{ Comprehensive } \\
\hline & Beta & SSE & $\mathbf{t}$ & Sig. ${ }^{\dagger}$ \\
\hline Intercept & 12.57 & 0.07 & 179.8 & $* * *$ \\
\hline \multicolumn{5}{|l|}{ Location } \\
\hline Location 1 & -0.07 & 0.03 & -2.1 & $*$ \\
\hline Location 3 & 0.21 & 0.03 & 7.0 & $* * *$ \\
\hline \multicolumn{5}{|l|}{ Weather } \\
\hline Temperature & -0.05 & 0.00 & -40.1 & $* * *$ \\
\hline Adjusted $\mathrm{R}^{2}$ & \multicolumn{4}{|c|}{0.62} \\
\hline
\end{tabular}


Table 5.3.4: Comprehensive Linear Regression Model $\left(\log P M_{2.5}\right.$ Inside)

\begin{tabular}{|c|c|c|c|c|}
\hline $\log \mathrm{M}_{2.5}$ (inside) & \multicolumn{4}{|c|}{ Comprehensive } \\
\hline Variable & Beta & SSE & $\mathbf{t}$ & Sig. $^{\dagger}$ \\
\hline Intercept & 3.69 & 0.24 & 15.3 & $* * *$ \\
\hline \multicolumn{5}{|l|}{ Location } \\
\hline Location 1 & -0.67 & 0.04 & -16.0 & $* * *$ \\
\hline Location 3 & -0.43 & 0.04 & -10.2 & $* * *$ \\
\hline \multicolumn{5}{|l|}{ Weather } \\
\hline Temperature & -0.03 & 0.00 & -9.1 & $* * *$ \\
\hline Relative Humidity & 0.01 & 0.00 & 8.9 & $* * *$ \\
\hline Adjusted $\mathrm{R}^{2}$ & \multicolumn{4}{|c|}{0.53} \\
\hline
\end{tabular}

Table 5.3.5: Comprehensive Linear Regression Model $\left(\log P M_{2.5}\right.$ Outside)

\begin{tabular}{|c|c|c|c|c|}
\hline $\log M_{2.5}$ (inside) & \multicolumn{4}{|c|}{ Comprehensive } \\
\hline Variable & Beta & SSE & $\mathbf{t}$ & Sig. ${ }^{\dagger}$ \\
\hline Intercept & 3.46 & 0.08 & 42.3 & $* * *$ \\
\hline \multicolumn{5}{|l|}{ Location } \\
\hline Location 1 & 0.95 & 0.07 & 13.2 & $* * *$ \\
\hline \multicolumn{5}{|l|}{ Weather } \\
\hline $\begin{array}{l}\text { Wind Direction } \\
\text { Against Traffic }\end{array}$ & -0.19 & 0.08 & -2.4 & * \\
\hline Relative Humidity & -0.02 & 0.00 & -13.0 & $* * *$ \\
\hline Adjusted $\mathrm{R}^{2}$ & \multicolumn{4}{|c|}{0.36} \\
\hline
\end{tabular}

Additionally, vehicle and heavy vehicle variables were lagged, in one-minute intervals, to investigate the possible influence of time-lagged vehicle presence on particulate concentrations. Lagged heavy vehicle variables were not significant in any model. Lagged vehicle variables, however, were consistently significant. Lagged significance explains the time it takes vehicle-based pollution to reach the shelter from the roadway.

Interactions between wind characteristics and the location dummy variables yielded significance in Table 5.3.6, the UFP concentrations inside the shelter. UFP 
concentrations are expected to be lower when wind speed at Location 1 increases, and higher when wind blows in the direction of traffic at Location 1. Finally, interactions between lagged vehicles, wind speed, and lagged wind direction were estimated to lower UFP concentrations outside the shelter.

The models in Table 5.3.6 through Table 5.3.9 are presented as the "final" linear regression models.

Table 5.3.6: Final logUFP Linear Regression Model, Inside Shelter

\begin{tabular}{|c|c|c|c|c|}
\hline $\operatorname{logUFP}$ (inside) & \multicolumn{4}{|c|}{ Comprehensive } \\
\hline Variable & Beta & SSE & $\mathbf{t}$ & Sig. ${ }^{\dagger}$ \\
\hline Intercept & 11.65 & 0.11 & 103.0 & $* * *$ \\
\hline \multicolumn{5}{|l|}{ Weather } \\
\hline Wind Speed & -0.17 & 0.06 & -2.6 & $* * *$ \\
\hline Temperature & -0.03 & 0.00 & -24.3 & $* * *$ \\
\hline \multicolumn{5}{|l|}{ Lag Variables } \\
\hline Vehicles Lag 2 & 0.00012 & 0.00004 & 3.1 & $* * *$ \\
\hline Vehicles Lag 3 & 0.00013 & 0.00004 & 3.3 & $* * *$ \\
\hline \multicolumn{5}{|l|}{ Interaction } \\
\hline Location 1 : Wind Speed & -0.27 & 0.11 & -2.5 & $* * *$ \\
\hline $\begin{array}{l}\text { Location } 1: \text { Wind } \\
\text { Direction, With Traffic }\end{array}$ & 0.81 & 0.20 & 4.1 & $* * *$ \\
\hline Adjusted $\mathrm{R}^{2}$ & \multicolumn{4}{|c|}{0.66} \\
\hline
\end{tabular}


Table 5.3.7: Final logUFP Linear Regression Model, Outside Shelter

\begin{tabular}{|c|c|c|c|c|}
\hline logUFP (outside) & \multicolumn{4}{|c|}{ Comprehensive } \\
\hline Variable & Beta & SSE & $\mathbf{t}$ & Sig. ${ }^{\dagger}$ \\
\hline Intercept & 12.28 & 0.09 & 140.0 & $* * *$ \\
\hline \multicolumn{5}{|l|}{ Location } \\
\hline Location 3 & 0.16 & 0.04 & 4.2 & $* * *$ \\
\hline \multicolumn{5}{|l|}{ Weather } \\
\hline Temperature & -0.05 & 0.00 & -40.7 & $* * *$ \\
\hline \multicolumn{5}{|l|}{ Lag Variables } \\
\hline Vehicles Lag 2 & 0.000065 & 0.00003 & 2.0 & $*$ \\
\hline Vehicles Lag 3 & 0.000072 & 0.00003 & 2.3 & $*$ \\
\hline \multicolumn{5}{|l|}{ Interaction } \\
\hline $\begin{array}{l}\text { Vehicles Lag 3: } \\
\text { Wind Speed } \\
\text { Dummy : Wind } \\
\text { Direction, With } \\
\text { Traffic, Dummy, } \\
\text { Lag 3 }\end{array}$ & -0.00013 & 0.00006 & -2.1 & $*$ \\
\hline Adjusted $\mathrm{R}^{2}$ & \multicolumn{4}{|c|}{0.82} \\
\hline
\end{tabular}

Table 5.3.8: Final $\log P M_{2.5}$ Linear Regression Model, Inside Shelter

\begin{tabular}{|c|c|c|c|c|}
\hline $\operatorname{logPM}_{2.5}$ (inside) & \multicolumn{4}{|c|}{ Comprehensive } \\
\hline Variable & Beta & SSE & $\mathbf{t}$ & Sig. ${ }^{\dagger}$ \\
\hline Intercept & 3.35 & 0.24 & 14.1 & $* * *$ \\
\hline \multicolumn{5}{|l|}{ Location } \\
\hline Location 1 & -0.74 & 0.04 & -17.3 & $* * *$ \\
\hline Location 3 & -0.40 & 0.04 & -9.8 & $* * *$ \\
\hline \multicolumn{5}{|l|}{ Weather } \\
\hline Temperature & -0.03 & 0.00 & -10.6 & $* * *$ \\
\hline Rel. Humidity & 0.01 & 0.00 & 9.2 & $* * *$ \\
\hline \multicolumn{5}{|l|}{ Lag Variables } \\
\hline Vehicles Lag 1 & 0.0001 & 0.00003 & 3.7 & $* * *$ \\
\hline Vehicles Lag 2 & 0.0002 & 0.00003 & 7.7 & $* * *$ \\
\hline Vehicles Lag 3 & 0.0001 & 0.00003 & 3.2 & $* *$ \\
\hline Adjusted $\mathrm{R}^{2}$ & \multicolumn{4}{|c|}{0.57} \\
\hline
\end{tabular}




Table 5.3.9: Final $\log \mathbf{P M}_{2.5}$ Linear Regression Model, Outside Shelter
\begin{tabular}{|l|c|c|c|c}
\hline logPM $_{2.5}$ (outside) & \multicolumn{5}{|c}{ Comprehensive } \\
\hline Variable & Beta & SSE & t & Sig. ${ }^{\dagger}$ \\
\hline Intercept & 1.69 & 0.16 & 10.7 & $* * *$ \\
\hline Location & -1.05 & 0.10 & -10.3 & $* * *$ \\
\hline Location 3 & \multicolumn{7}{|l}{} \\
\hline Weather
\end{tabular}

\begin{tabular}{|c|c|c|c|c|}
\hline Rel. Humidity & 0.03 & 0.004 & 5.8 & $* * *$ \\
\hline \multicolumn{5}{|l|}{ Lag Variables } \\
\hline Vehicles Lag 2 & 0.000056 & 0.00002 & 3.1 & $* *$ \\
\hline Vehicles Lag 3 & 0.000052 & 0.00002 & 2.9 & $* *$ \\
\hline Wind Speed Lag 2 & 0.074 & 0.030 & 2.5 & $*$ \\
\hline $\begin{array}{l}\text { Wind Direction, } \\
\text { With Traffic Lag } 1\end{array}$ & 1.853 & 0.654 & 2.8 & $* *$ \\
\hline \multicolumn{5}{|l|}{ Interaction } \\
\hline $\begin{array}{l}\text { Location } 3 \text { : Wind } \\
\text { Direction, With } \\
\text { Traffic Lag } 1\end{array}$ & -1.904 & 0.659 & -2.9 & $* *$ \\
\hline Adjusted $\mathrm{R}^{2}$ & \multicolumn{4}{|c|}{0.81} \\
\hline
\end{tabular}

The classical assumptions of linear regression state that the error terms of successive periods must be uncorrelated. Time series models are prone to serial correlation because the error term from one time period depends in some systematic way on the value of the error term in other time periods. As a preliminary method to investigate serial correlation, residuals for each model were plotted in Figure 5.3.1. Serial correlation is evident in the $\mathrm{PM}_{2.5}$ Inside plot, particularly for April 5 (morning) and May 13 (morning), in which residuals follow a trend. Similar autocorrelation effects are evident in the other residual plots, as well.

Final models were tested for autocorrelation using the Durbin-Watson test (Table 5.3.10). All four models exhibit positive autocorrelation, indicating correlation between successive error terms. 

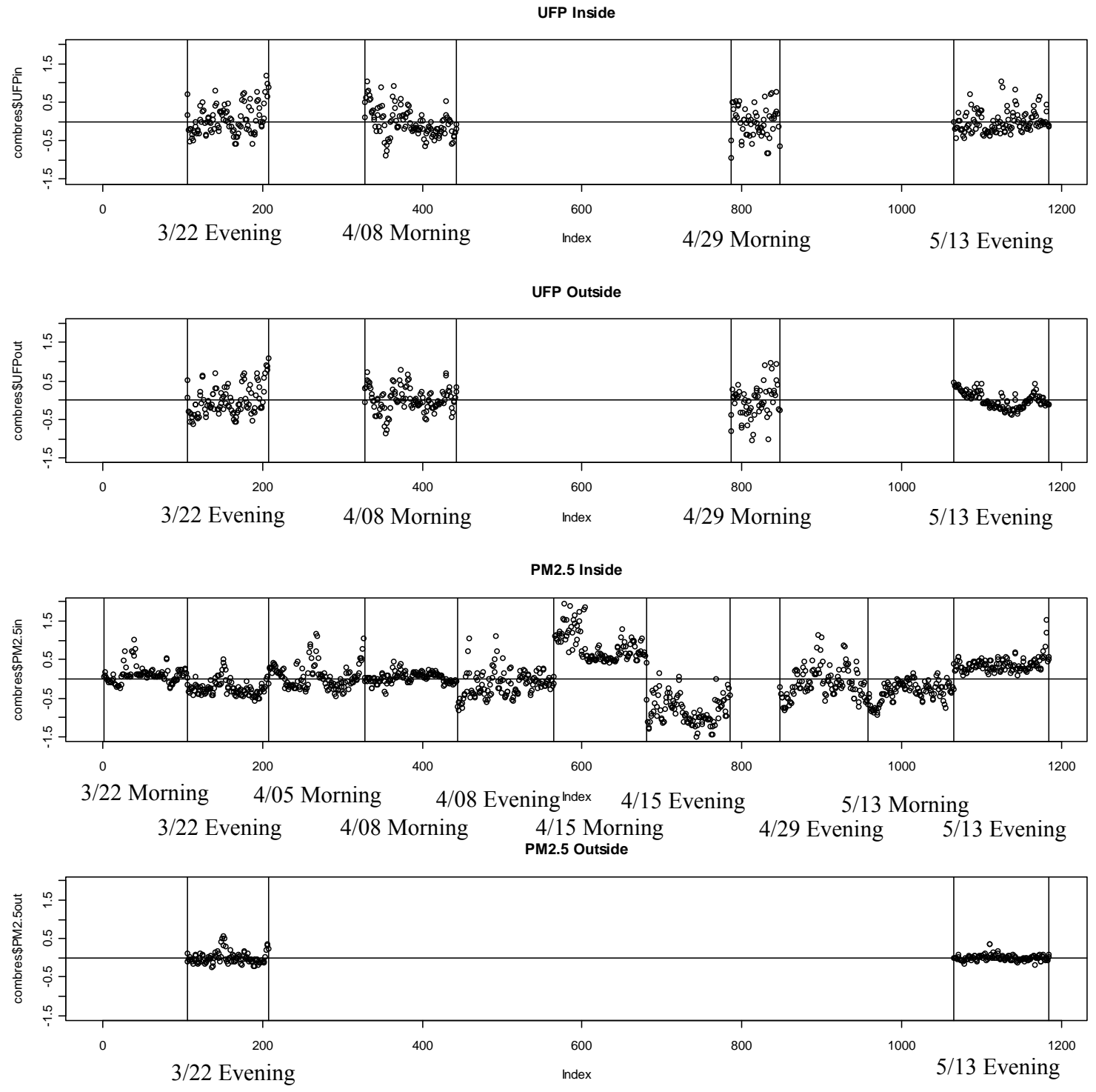

Figure 5.3.1: Model residuals for each particualte size.

Table 5.3.10: Durbin-Watson Test Results

\begin{tabular}{|c|c|c|}
\hline Particulate & DW Test Statistic & Autocorrelated? \\
\hline UFP Inside Shelter & 0.6279 & Yes \\
\hline UFP Outside Shelter & 0.5555 & Yes \\
\hline $\mathrm{PM}_{2.5}$ Inside Shelter & 0.1731 & Yes \\
\hline $\mathrm{PM}_{2.5}$ Outside Shelter & 0.6691 & Yes \\
\hline
\end{tabular}


To correct for some degree of positive serial correlation, autoregressive error terms were estimated using the AR(1) autorregresive model of degree one. The results are displayed in Table 5.3.11 through Table 5.3.14.

The addition of the autoregressive term alters significance of variables in all models. Notably, lagged vehicle variables become universally insignificant at $\alpha=0.05$. The location dummy variables generally remains significant.

In some instances, the sign of the coefficient changes. In the $\mathrm{PM}_{2.5}$ Outside model (Table 5.3.14), the humidity variable becomes negative and no longer agrees with expectations.

Durbin-Watson tests were run on the autoregressive models and improvement in autocorrelation was made in every case (Table 5.3.15). The autoregressive results demonstrate the need for further time series analysis and a better understanding of the lagging effects on particulate concentrations.

Table 5.3.11: Final UFP Model + Autoregresive Term, Inside Shelter

\begin{tabular}{|c|c|c|c|}
\hline \multicolumn{4}{|l|}{ logUFP Inside } \\
\hline Variable & Parameter & SE & $\mathbf{p}$ \\
\hline $\operatorname{ar}(1)$ & 0.74 & 0.03 & 0.000 \\
\hline Intercept & 11.74 & 0.18 & 0.000 \\
\hline \multicolumn{4}{|l|}{ Weather } \\
\hline Temp & -0.03 & 0.00 & 0.000 \\
\hline Wind Speed & -0.06 & 0.05 & 0.063 \\
\hline \multicolumn{4}{|l|}{ Lag Variables } \\
\hline Vehicles Lag 2 & 0.00006 & 0.00005 & 0.072 \\
\hline Vehicles Lag 3 & 0.00006 & 0.00005 & 0.064 \\
\hline \multicolumn{4}{|l|}{ Interaction } \\
\hline $\begin{array}{l}\text { Location 1: Wind } \\
\text { Speed }\end{array}$ & -0.15 & 0.11 & 0.043 \\
\hline $\begin{array}{l}\text { Location } 1: \text { Wind } \\
\text { Direction, With } \\
\text { Traffic }\end{array}$ & 0.40 & 0.13 & 0.000 \\
\hline
\end{tabular}


Table 5.3.12: Final UFP Model + Autoregresive Term, Outside Shelter

\begin{tabular}{l|c|c|c}
\hline logUFP Outside & \multicolumn{1}{c}{ SE } & p \\
\hline Variable & Parameter & 0.02 & 0.000 \\
\hline ar(1) & 0.76 & 0.16 & 0.000 \\
\hline Intercept & 12.52 & & \\
\hline Location & & & 0.000 \\
\hline \multicolumn{1}{c}{ Location 3 } & 0.26 & 0.00 & 0.000 \\
\hline Weather & -0.05 & & \\
\hline \multicolumn{1}{c}{ Temp } & & & 0.00003 \\
\hline Lag Variables & 0.00003 & 0.00003 & 0.077 \\
\hline Vehicles Lag 2 & 0.00003 & & \\
Vehicles Lag 3 &
\end{tabular}

Table 5.3.13: Final $\mathbf{P M}_{2.5}$ Model + Autoregresive Term, Inside Shelter

\begin{tabular}{|c|c|c|c|}
\hline \multicolumn{4}{|l|}{$\log \mathrm{PM}_{2.5}$ Inside } \\
\hline Variable & Parameter & SE & $\mathbf{p}$ \\
\hline $\operatorname{ar}(1)$ & 0.94 & 0.01 & 0.000 \\
\hline Intercept & 2.17 & 0.79 & 0.002 \\
\hline \multicolumn{4}{|l|}{ Location } \\
\hline Location 1 & -0.36 & 0.12 & 0.001 \\
\hline Location 3 & -0.25 & 0.15 & 0.022 \\
\hline \multicolumn{4}{|l|}{ Weather } \\
\hline Temp & -0.01 & 0.01 & 0.050 \\
\hline Rel. Humidity & 0.02 & 0.00 & 0.000 \\
\hline \multicolumn{4}{|l|}{ Lag Variables } \\
\hline Vehicles Lag 1 & 0.000006 & 0.00002 & 0.199 \\
\hline Vehicles Lag 2 & 0.000013 & 0.00003 & 0.159 \\
\hline Vehicles Lag 3 & 0.000011 & 0.00003 & 0.170 \\
\hline
\end{tabular}


Table 5.3.14: Final $\mathbf{P M}_{2.5}$ Model + Autoregresive Term, Outside Shelter

\begin{tabular}{|c|c|c|c|}
\hline \multicolumn{4}{|l|}{$\log \mathrm{PM}_{2.5}$ Outside } \\
\hline Variable & Parameter & SE & $\mathbf{p}$ \\
\hline $\operatorname{ar}(1)$ & 0.83 & 0.03 & 0.000 \\
\hline Intercept & 2.67 & 0.13 & 0.000 \\
\hline \multicolumn{4}{|l|}{ Location } \\
\hline Location 3 & -0.38 & 0.08 & 0.000 \\
\hline \multicolumn{4}{|l|}{ Weather } \\
\hline Rel. Humidity & -0.003 & 0.00 & 0.020 \\
\hline \multicolumn{4}{|l|}{ Lag Variables } \\
\hline Vehicles Lag 2 & 0.00003 & 0.00008 & 0.185 \\
\hline Vehicles Lag 3 & 0.00003 & 0.00009 & 0.193 \\
\hline \multicolumn{4}{|l|}{ Lag Variables } \\
\hline Wind Speed Lag 2 & 0.07 & 0.04 & 0.011 \\
\hline $\begin{array}{l}\text { Wind Direction, } \\
\text { With Traffic Lag } 1\end{array}$ & -0.06 & 0.11 & 0.150 \\
\hline \multicolumn{4}{|l|}{ Interaction } \\
\hline $\begin{array}{l}\text { Location } 3 \text { : Wind } \\
\text { Direction, With } \\
\text { Traffic Lag } 1\end{array}$ & -0.04 & 0.12 & 0.192 \\
\hline
\end{tabular}

Table 5.3.15: Durbin-Watson Test Results for Autoregressive Term

\begin{tabular}{|c|c|}
\hline Particulate & DW Test Statistic \\
\hline UFP Inside Shelter & 1.40 \\
\hline UFP Outside Shelter & 1.51 \\
\hline $\mathrm{PM}_{2.5}$ Inside Shelter & 1.56 \\
\hline $\mathrm{PM}_{2.5}$ Outside Shelter & 1.61 \\
\hline
\end{tabular}




\section{DISCUSSION}

Previous studies have reinforced the influence of location, vehicle, and environmental variables categorized in this study, at least to a degree. This study, however, is among the first to investigate the role shelter orientation plays in particulate concentration levels.

While results were not consistent, data collected rejected each of the three null hypotheses proposed in Section 3.1. Average particulate concentration levels were generally found to be significantly different inside and outside a shelter facing away from the roadway. These findings complement those of Hess et al. (2010), who found levels to be different for a shelter facing towards the roadway.

Additionally, average particulate concentration levels were generally found to be significantly greater inside the bus shelter when the shelter faces towards the roadway, and significantly greater outside the bus shelter when the shelter faces away from the roadway.

Given the volatile nature of a near-road micro-environment and the limited ability of instruments used in this study to capture all aspects of the environment, it would be unreasonable to expect results to consistently uphold (or dispel) hypotheses. With enough data, however, confident conclusions can be made pertaining to the orientation of the shelter. It is not unreasonable to state that orienting a shelter away from the roadway has the potential to aid in shielding bus patrons from particulate matter compared to a shelter facing towards the roadway.

Shelter orientation is an issue due to the shape of the shelter, which encloses a volume of air subject to different interactions with air pollution than the open roadway 
environment. When the shelter faces the roadway, this enclosed volume of air may be described as a "trap" for particulates, suspending particulate matter in an enclosed area where dispersion does not immediately take place.

Allowing for increased airflow through a shelter that faces the roadway could increase circulation and speed dispersal of particulates. Shelter designs exist such that the side panels are made of a porous wire mesh rather than Plexiglas windows. A shelter oriented towards the roadway, and outfitted with porous side walls, would allow increased airflow and could potential eliminate the "trap" effect.

Particulates from the roadway are not immediately introduced into a shelter facing away from the roadway, allowing time for dispersion. This effect is shown in Figure 4.3.1 as spikes in concentration are typically less inside the shelter at Location 1, indicating a "buffer" or "dilution" effect. Such buffer effects are particularly important at shelters very close to the roadway (less than five feet), as is the case at Location 1. Shelters situated within close proximity to the roadway would be exposed to the highest particulate concentrations that have not yet dispersed over greater distances.

Understanding and controlling for the built environment is essential to accurately interpreting the results of this study. Care was taken to select shelters with similar surroundings, but inevitably some variation will require compensation. The built environment is not substantially different at Location 3, with two exceptions. First, the cross street, $39^{\text {th }}$ Avenue, is markedly busier than the cross streets at Locations 1 and 2. Monitoring cross street vehicle volumes could add descriptive power to this analysis.

Second, a gas station is present across the street, 25 meters from the shelter. Unfortunately, only one far-side shelter was examined in this study; more far-side 
shelters will need to be investigated before definitive conclusions can be made about the influence of shelter location relative to the intersection on particulate concentration levels.

Conclusions regarding placement of shelters either near-side or far-side relative to an intersection are difficult to make from the inconsistent regression model results. Depending on the particulate size, the Loc3 variable (which controls in part for intersection placement) can be either positive or negative, and can vary by an order of magnitude.

Regular vehicle flow and heavy vehicle flow was inconsistently observed to significantly correlate with particulate levels. Literature suggests a positive correlation, though correlations were primarily negative in these data. Location 1 exhibited the most significant correlations, perhaps due to its close proximity to the roadway $(\sim 0.5 \mathrm{~m})$.

Categorized regression models demonstrated the inability of the vehicle data to explain particulate concentrations. The vehicle-specific models explained no more than $5 \%$ of the particulate variation. Compared to the location- and weather-specific models, this is a negligible amount of explanatory power. Vehicle flow in the comprehensive models was found to be significant when lagged up to three minutes, indicating particulate matter concentrations are affected long after a vehicle has left the area.

Vehicle significance was expected based on a review of literature, though this study is considerably less comprehensive than past studies in terms of documenting vehicle presence. The RTMS unit used to measure vehicle activity was not capable of monitoring the entire roadway, instead only monitoring the direction of travel closest to the shelter. In effect, this study monitored just half of the roadway environment. 
A limited investigation of vehicle classification effects on particulates was conducted by isolating heavy vehicle flow as a variable. No significance was found for such vehicles, though this could be attributable to a lack of observed instances more than an accurate representation of heavy vehicle influences. Previous literature has shown a definite influence of large, diesel-powered vehicles on particulate concentrations, especially UFP.

Further investigation will need to consider a more detailed vehicle classification variable, which may help to explain spikes in concentration such as the $\mathrm{PM}_{2.5}$ spikes at Location 3 (e.g. Figure 0.2).

Evening particle concentrations are significantly lower on average than morning concentrations. This study has shown temperature and relative humidity to be a primary cause of diurnal variation, though consideration can be made for vehicular influences based solely on substantial evidence of such from the literature. Consideration must be made for shelter location on the inbound (westbound) or outbound (eastbound) roadside; that is, whether a roadway next to the shelter will see larger morning or evening traffic volumes. Shelters sited along the inbound roadway lanes (Locations 1 and 2) may experience lower particulate levels in the evening due to lower vehicle volumes.

Examining wind speed and direction was difficult given limited data from just one anemometer and inherently cumbersome directional data. Categorized regression models revealed wind speed and direction to significantly affect average particulate concentrations in conjunction with temperature and relative humidity. When combined with the other variables in the comprehensive models, wind speed and direction seldom significantly affected particulate concentrations. 
Shelters on the study corridor are situated with their primary axes oriented eastwest, parallel to the east-west roadway. Prevailing winds in Portland are typically from the east out of the Columbia Gorge during the fall and winter months (from about October to March), and from the west off of the ocean during the spring and summer months (April to September). The discrepancy in prevailing winds at the shelter and prevailing winds for the city as a whole demonstrate sensitivity of wind measurements at microsites. Future studies would do well to setup multiple anemometers close to the shelter. Comparing wind measurements at each of these anemometer locations would help to reinforce findings (assuming agreement in wind speed and measurements at each anemometer) and strengthen conclusions made.

Studying shelters both parallel and perpendicular to the prevailing wind, such that the wind blows into the shelter opening or its sides, may reveal different interactions between particulate concentrations and wind speed or wind direction. No shelters parallel to the prevailing south-southwest winds were available on the study corridor.

\subsection{Limitations}

The primary limitation of this study stems from the lack of sample sites. Only one shelter facing away from the roadway was studied, eventually limiting the ability of the regression models to discern shelter orientation effects from other environmental effects unique to Location 1. Ultimately, it became necessary to repurpose the orientation variable in the model to account for all environmental characteristics of Location 1. This new variable, Loc1, gives some information about the effects of orientation, but any 
orientation-specific conclusions must be made with the caveat of uncontrolled external influences.

A similar limitation exists for the analysis of near-side/far-side effects; Location 3 is the only far-side shelter, again limiting the ability of the model to discern shelter placement effects relative to an intersection.

Both the orientation and the near-side/far-side limitations may be overcome with the addition of more shelters to the model, helping to diversity built environment characteristics for shelter orientations and placements.

Consideration must be made for the autocorrelation effects evident in all four models. The existence of serial correlation in the error term violates one of the classical assumptions of linear regression. Consequently, the model is no longer the theoretically minimum variance estimator and the sum of squared errors are biased, making hypothesis testing less reliable. Autocorrelation does not necessarily invalidate results, but it must be accounted for in future models.

Another limitation of this study involves accuracy of wind measurements and the ability of these measurements to represent the entirety of the environment surrounding the bus shelter. The anemometer, while consistently placed in the same location at each shelter, was ultimately determined to be a weak indicator of wind speed and direction at all points in proximity to the study location. In a complicated near-road environment, wind is affected by myriad factors ranging from tail winds of tractor-trailers to turbulence created by trees and signposts. Thus, the measurements presented can only be said to accurately represent wind's influence on particulate levels at that exact location. Though this may initially appear to severely limit the usefulness of the wind data, it is important 
to note that the anemometer was placed adjacent to the particulate monitors outside the shelter and as such the data constitute a fair representation of particulate dependence on wind speed and direction for passengers waiting outside bus stop shelters.

The sidewalls of the shelter may play a role in shielding efficiency of a shelter that faces away from the roadway. Along the study corridor, available shelter types limited complete comparisons between shelters towards and away from the roadway.. The shelter facing away from the roadway in this study had shorter walls ( $\sim 2$ feet long) than the shelters facing the roadway ( $\sim 4$ feet long). It is possible that the volume of air contained in the shelter, which is less than a shelter with longer walls, could affect particulate concentration levels. This would need to be investigated in a future study because no shelters with longer sidewalls facing away from the roadway exist along the studied corridor.

This study focuses on a few aspects of particulate concentrations in a complicated environment that includes wind variation, changing traffic patterns, and routine presence of large diesel vehicles (such as buses). Although orientation, wind speed and direction, and vehicle flow appear to have an impact on exposure levels, future studies will need to consider other variables to effectively control for as many factors as possible when determining the significance of varying particulate levels. Many unexplored factors could affect particulate concentration levels, including routine presence of diesel buses, smokers near the shelter, and coordinated signals along a corridor. Air quality data will need to be synchronized with these missing factors to most accurately determine relationships between particulate levels, traffic volume and vehicle type, and the surrounding built environment. 


\section{CONCLUSION}

Particulate matter, as a common air pollutant recognized by NAAQS, is a key contributor to urban air quality concerns. Understanding roadside particulate exposure requires detailed measurements in complicated microenvironments. This study uses a comparative approach to determine particulate matter concentrations inside and outside bus shelters along a busy urban corridor, with particular attention paid to the orientation of the bus stop shelter. To the best of the author's knowledge this is the first study that analyzes the impact of shelter orientation on transit users' exposure at bus stops.

Bus stop orientation is shown to play a statistically significant role in particulate matter levels and, consequently, exposure. In addition, a number of other variables demonstrate an influence on particulate matter, most notably time of day. Analysis of these variables helps to create a more robust understanding of a microenvironment's effects on particulate concentrations.

Currently, guidelines for the location and design of bus stops do not take into account air quality or exposure considerations. The results of this research suggest that it is possible to reduce exposure by changing the orientation of the bus shelter. Additional research is needed to expand the number of case studies and better understand the impact of traffic levels, location, and weather as well as to warrant a stronger recommendation in bus shelter location and design guidelines. 


\section{REFERENCES}

Adams, H. S., M. J. Nieuwenhuijsen, and R. N. Colvile. 2001. "Determinants of Fine Particle (PM2. 5) Personal Exposure Levels in Transport Microenvironments, London, UK.” Atmospheric Environment 35 (27): 4557-4566.

Adams, H. S., M. J. Nieuwenhuijsen, R. N. Colvile, M. A. S. McMullen, and P. Khandelwal. 2001. "Fine Particle (PM2.5) Personal Exposure Levels in Transport Microenvironments, London, UK.” The Science of The Total Environment 279 (13) (November 12): 29-44. doi:10.1016/S0048-9697(01)00723-9.

Ballester, F., S. Medina, E. Boldo, P. Goodman, M. Neuberger, C. Iniguez, N. Kunzli, and on behalf of the Apheis network. 2008. "Reducing Ambient Levels of Fine Particulates Could Substantially Improve Health: a Mortality Impact Assessment for 26 European Cities." Journal of Epidemiology \& Community Health 62 (2) (February): 98-105. doi:10.1136/jech.2007.059857.

Bedada, G. B, J. Heinrich, T. Glötschi, S. H Downs, B. Forsberg, D. Jarvis, C. Luczynska, et al. 2007. "Urban Background Particulate Matter and Allergic Sensitization in Adults of ECRHS II." International Journal of Hygiene and Environmental Health 210 (6): 691-700.

Briggs, D. J, K. de Hoogh, C. Morris, and J. Gulliver. 2008. "Effects of Travel Mode on Exposures to Particulate Air Pollution.” Environment International 34 (1): 12-22.

Carslaw, D.C., and K Ropkins. 2011. "Open-source Tools for Analysing Air Pollution Data.” Environmental Research Group, King's College London (April 21). 
Chan, L. Y., W. L. Lau, S. C. Lee, and C. Y. Chan. 2002. "Commuter Exposure to Particulate Matter in Public Transportation Modes in Hong Kong." Atmospheric Environment 36 (21): 3363-3373.

Chuang, K. J, C. C Chan, N. T Chen, T. C Su, and L. Y Lin. 2005. "Effects of Particle Size Fractions on Reducing Heart Rate Variability in Cardiac and Hypertensive Patients." Environmental Health Perspectives 113 (12): 1693.

Chuang, K. J, C. C Chan, T. C Su, C. T Lee, and C. S Tang. 2007. "The Effect of Urban Air Pollution on Inflammation, Oxidative Stress, Coagulation, and Autonomic Dysfunction in Young Adults." American Journal of Respiratory and Critical Care Medicine 176 (4): 370.

EPA. 1990. "National Ambient Air Quality Standards (NAAQS)." http://www.epa.gov/air/criteria.html.

__ 2007. "Heavy-Duty Highway Compression-Ignition Engines And Urban Buses -

- Exhaust Emission Standards.” Heavy-Duty Highway Compression-Ignition Engines And Urban Buses -- Exhaust Emission Standards. http://www.epa.gov/otaq/standards/heavy-duty/hdci-exhaust.htm.

Fitzpatrick, K., K. Hall, D. Perkinson, and L. Nowlin. 1996. TCRP Report 19: Guidelines for the Location and Design of Bus Stops. TRB, National Research Council, Washington, DC.

Gulliver, J., and D. J. Briggs. 2004. "Personal Exposure to Particulate Air Pollution in Transport Microenvironments." Atmospheric Environment 38 (1): 1-8. 
Hess, D. B, P. D Ray, A. E Stinson, and J. Y Park. 2010. "Determinants of Exposure to Fine Particulate Matter (PM2. 5) For Waiting Passengers at Bus Stops." Atmospheric Environment.

Hill, L. B, N. J Zimmerman, J. Gooch, and C. A.T Force. 2005. A Multi-city Investigation of the Effectiveness of Retrofit Emissions Controls in Reducing Exposures to Particulate Matter in School Buses. Clean Air Task Force.

Hitchins, J., L. Morawska, R. Wolff, and D. Gilbert. 2000. "Concentrations of Submicrometre Particles from Vehicle Emissions Near a Major Road." Atmospheric Environment 34 (1) (January): 51-59. doi:10.1016/S13522310(99)00304-0.

Holmén, B. A, and A. Ayala. 2002. "Ultrafine PM Emissions from Natural Gas, Oxidation-catalyst Diesel, and Particle-trap Diesel Heavy-duty Transit Buses." Environ. Sci. Technol 36 (23): 5041-5050.

Jackson, E. D, and B. A Holmén. 2009. "Modal Analysis of Vehicle Operation and Particulate Emissions from Connecticut Transit Buses.” Transportation Research Record: Journal of the Transportation Research Board 2123 (-1): 76-87.

Kaur, S. 2006. "Exposure Assessment of Urban Street Users to Particulate Matter and Carbon Monoxide". Ph.D. Thesis, Imperial College London, University of London.

Kaur, S., M. J. Nieuwenhuijsen, and R. N. Colvile. 2005. "Pedestrian Exposure to Air Pollution Along a Major Road in Central London, UK." Atmospheric Environment 39 (38): 7307-7320. 
_ 2007. "Fine Particulate Matter and Carbon Monoxide Exposure Concentrations in Urban Street Transport Microenvironments." Atmospheric Environment 41 (23): 4781-4810.

Kendrick, Christine, Adam Moore, Ashley Haire, Alexander Bigazzi, Miguel Figliozzi, Christopher Monsere, and Linda George. 2011. "Impact of Bicycle Lane Characteristics on Exposure of Bicyclists to Traffic-Related Particulate Matter." Transportation Research Record: Journal of the Transportation Research Board 2247 (-1) (December 1): 24-32. doi:10.3141/2247-04.

Kittelson, D. B. 1998. "Engines and Nanoparticles:: a Review." Journal of Aerosol Science 29 (5-6): 575-588.

Law, P., and B. D Taylor. 2001. "Shelter from the Storm: Optimizing Distribution of Bus Stop Shelters in Los Angeles." Transportation Research Record: Journal of the Transportation Research Board 1753 (-1): 79-85.

Levy, J. I, T. Dumyahn, and J. D Spengler. 2002. "Particulate Matter and Polycyclic Aromatic Hydrocarbon Concentrations in Indoor and Outdoor Microenvironments in Boston, Massachusetts." Journal of Exposure Analysis and Environmental Epidemiology 12 (2): 104-114.

Lung, S.C., H.Y. Kao, and C.W. Peng. 2005. “Pedestrians' Exposure Concentrations of PM2.5, Ultrafine Particles and Particulate Polycyclic Aromatic Hydrocarbons in Taiwan at Intersections with Different Surroundings." Unpublished Manuscript.

Michaels, R. A, and M. T Kleinman. 2000. "Incidence and Apparent Health Significance of Brief Airborne Particle Excursions." Aerosol Science and Technology 32 (2): 93-105. 
Møller, P., J. K Folkmann, L. Forchhammer, E. V Bräuner, P. H Danielsen, L. Risom, and S. Loft. 2008. "Air Pollution, Oxidative Damage to DNA, and Carcinogenesis." Cancer Letters 266 (1): 84-97.

Morawska, L., N. D Bofinger, L. Kocis, and A. Nwankwoala. 1998. "Submicrometer and Supermicrometer Particles from Diesel Vehicle Emissions.” Environ. Sci. Technol 32 (14): 2033-2042.

Morawska, L., M. R. Moore, and Z. D. Ristovski. 2004. "Health Impacts of Ultrafine Particles: Desktop Literature Review and Analysis." Report to the Australian Department of the Environment and Heritage.

Pinto, Angelo C, Lilian L. N Guarieiro, Michelle J. C Rezende, Núbia M Ribeiro, Ednildo A Torres, Wilson A Lopes, Pedro A. de P Pereira, and Jailson B. de Andrade. 2005. "Biodiesel: An Overview." Journal of the Brazilian Chemical Society $16 \quad$ (6B) (November): 1313-1330. doi:10.1590/S010350532005000800003.

Pisarski, Alan. 2006. Commuting in America. Transportation Research Board.

Pope III, C. A, R. T Burnett, G. D Thurston, M. J Thun, E. E Calle, D. Krewski, and J. J Godleski. 2004. "Cardiovascular Mortality and Long-term Exposure to Particulate Air Pollution." Circulation 109 (1): 71-77.

Project for Public Spaces, Inc. 1997. The Role of Transit in Creating Livable Metropolitan Communities. TCRP Report 19. Washington, D.C.: TRB, National Research Council. 
Ristovski, Z. D., L. Morawska, N. D. Bofinger, and J. Hitchins. 1998. "Submicrometer and Supermicrometer Particles from Spark Ignition Vehicles." Environ Sci Technol 32: 3845-3852.

Samet, J. M, F. Dominici, F. C Curriero, I. Coursac, and S. L Zeger. 2000. "Fine Particulate Air Pollution and Mortality in 20 US Cities, 1987-1994." New England Journal of Medicine 343 (24): 1742.

Schimek, Paul. 2001. "Reducing Emissions from Transit Buses." Regional Science and Urban Economics 31 (4) (July): 433-451. doi:10.1016/S0166-0462(00)00083-1.

U.S. Architectural and Transportation Barriers Compliance Board. 2002. "Americans with Disabilities Act (ADA) Accessibility Guidelines for Buildings and Facilities." Washington, DC.

Vallero, D. A. 2008. Fundamentals of Air Pollution. Academic press.

Vardoulakis, S., B. E.A Fisher, K. Pericleous, and N. Gonzalez-Flesca. 2003. "Modelling Air Quality in Street Canyons: a Review.” Atmospheric Environment 37 (2): 155182.

Vinzents, P. S, P. Møller, M. Sørensen, L. E Knudsen, O. Hertel, F. P Jensen, B. Schibye, and S. Loft. 2005. "Personal Exposure to Ultrafine Particles and Oxidative DNA Damage.” Environmental Health Perspectives 113 (11): 1485.

Wang, L., R. Jayaratne, D. Heuff, and L. Morawska. 2010. "Development of a Composite Line Source Emission Model for Traffic Interrupted Microenvironments and Its Application in Particle Number Emissions at a Bus Station." Atmospheric Environment. 
Wayne, W. S, N. N Clark, R. D Nine, and D. Elefante. 2004. "A Comparison of Emissions and Fuel Economy from Hybrid-electric and Conventional-drive Transit Buses.” Energy Fuels 18 (1): 257-270.

Yin, Jianxin, and Roy M. Harrison. 2008. "Pragmatic Mass Closure Study for PM1.0, PM2.5 and PM10 at Roadside, Urban Background and Rural Sites." Atmospheric Environment 42 (5) (February): 980-988. doi:10.1016/j.atmosenv.2007.10.005.

Zhu, S., P. Demokritou, and J. Spengler. 2010. "Experimental and Numerical Investigation of Micro-environmental Conditions in Public Transportation Buses.” Building and Environment 45 (10): 2077-2088.

Zhu, Y., W. C Hinds, S. Kim, S. Shen, and C. Sioutas. 2002. "Study of Ultrafine Particles Near a Major Highway with Heavy-duty Diesel Traffic." Atmospheric Environment 36 (27): 4323-4335. 


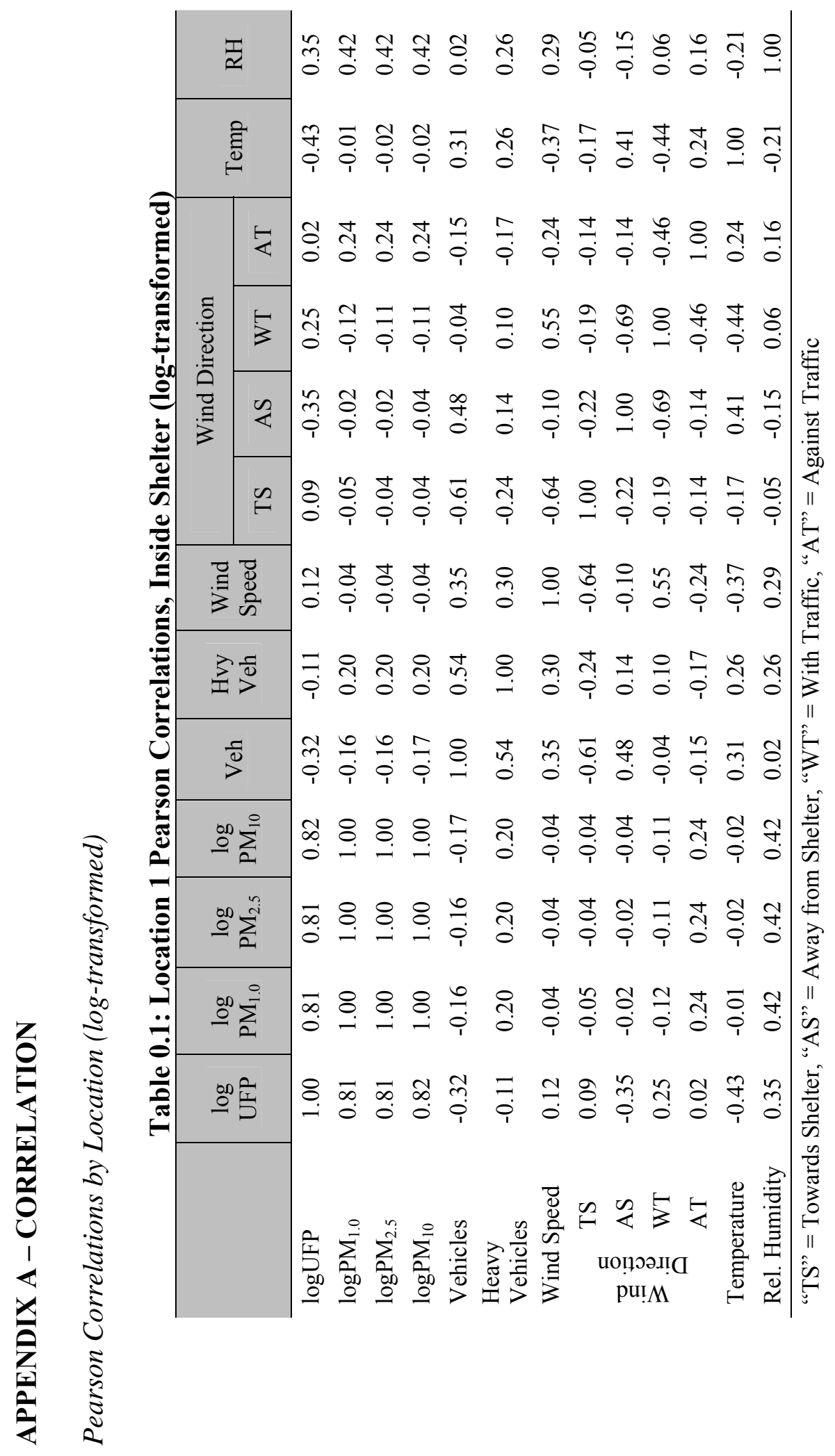




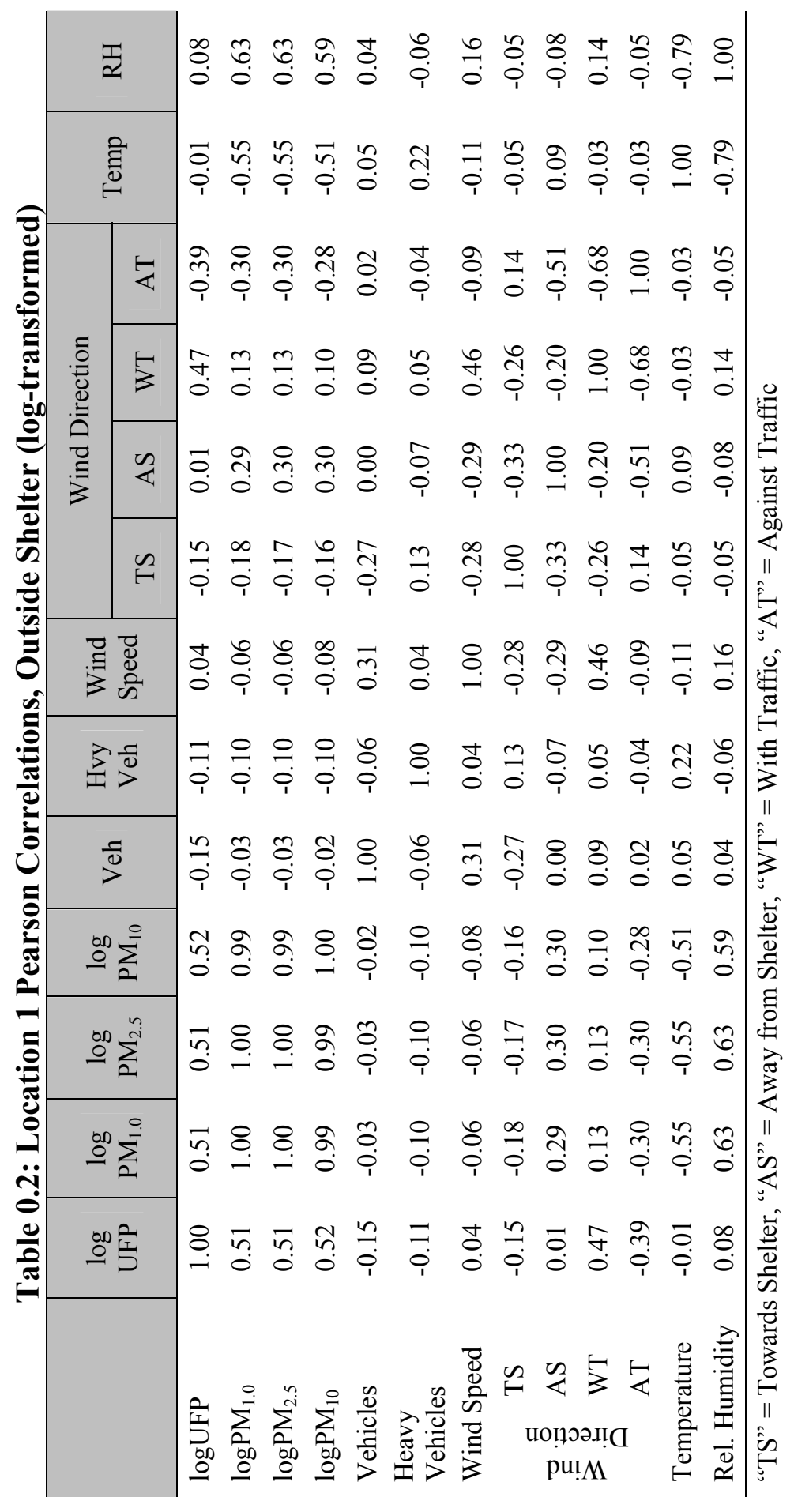




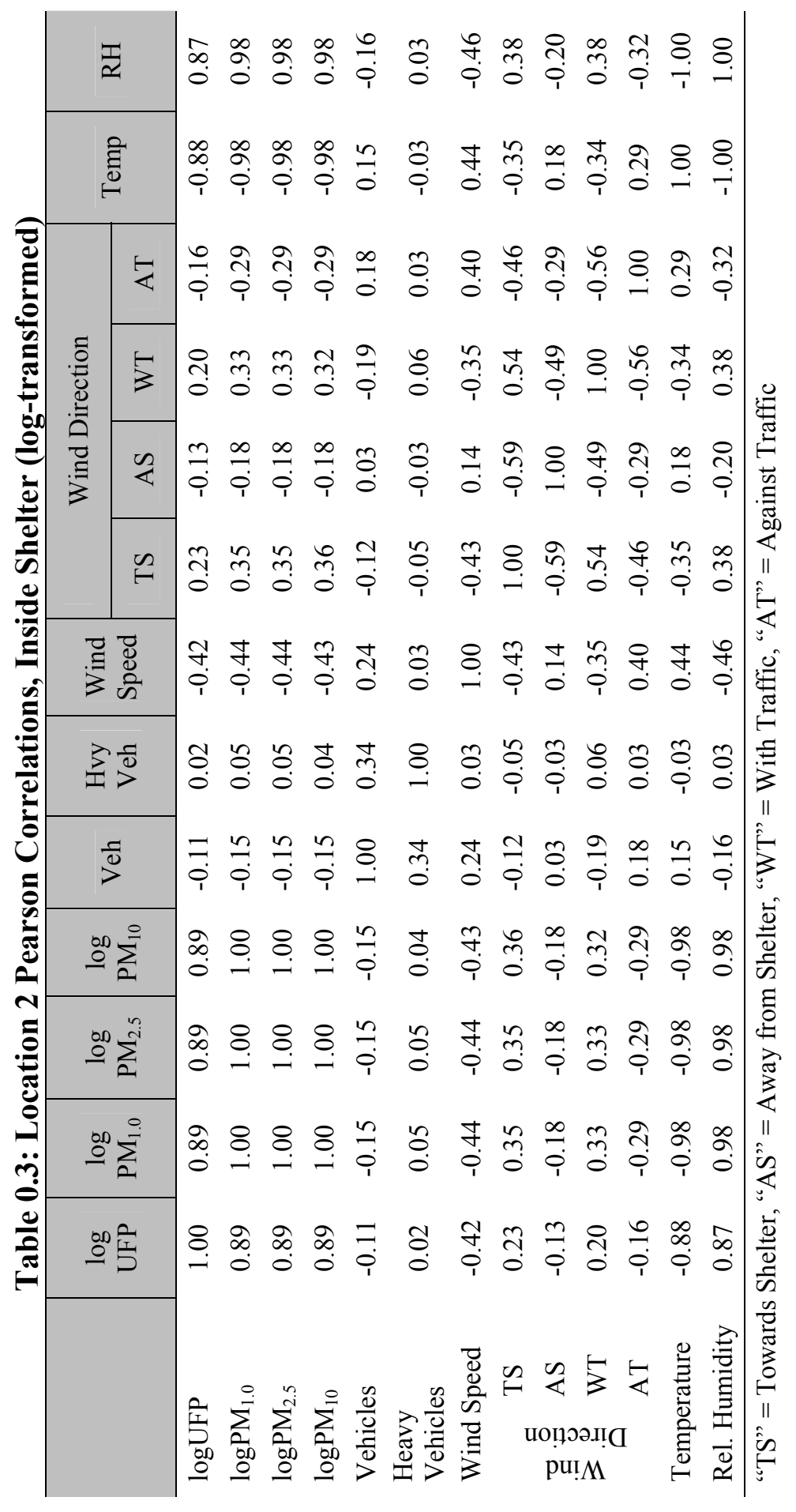




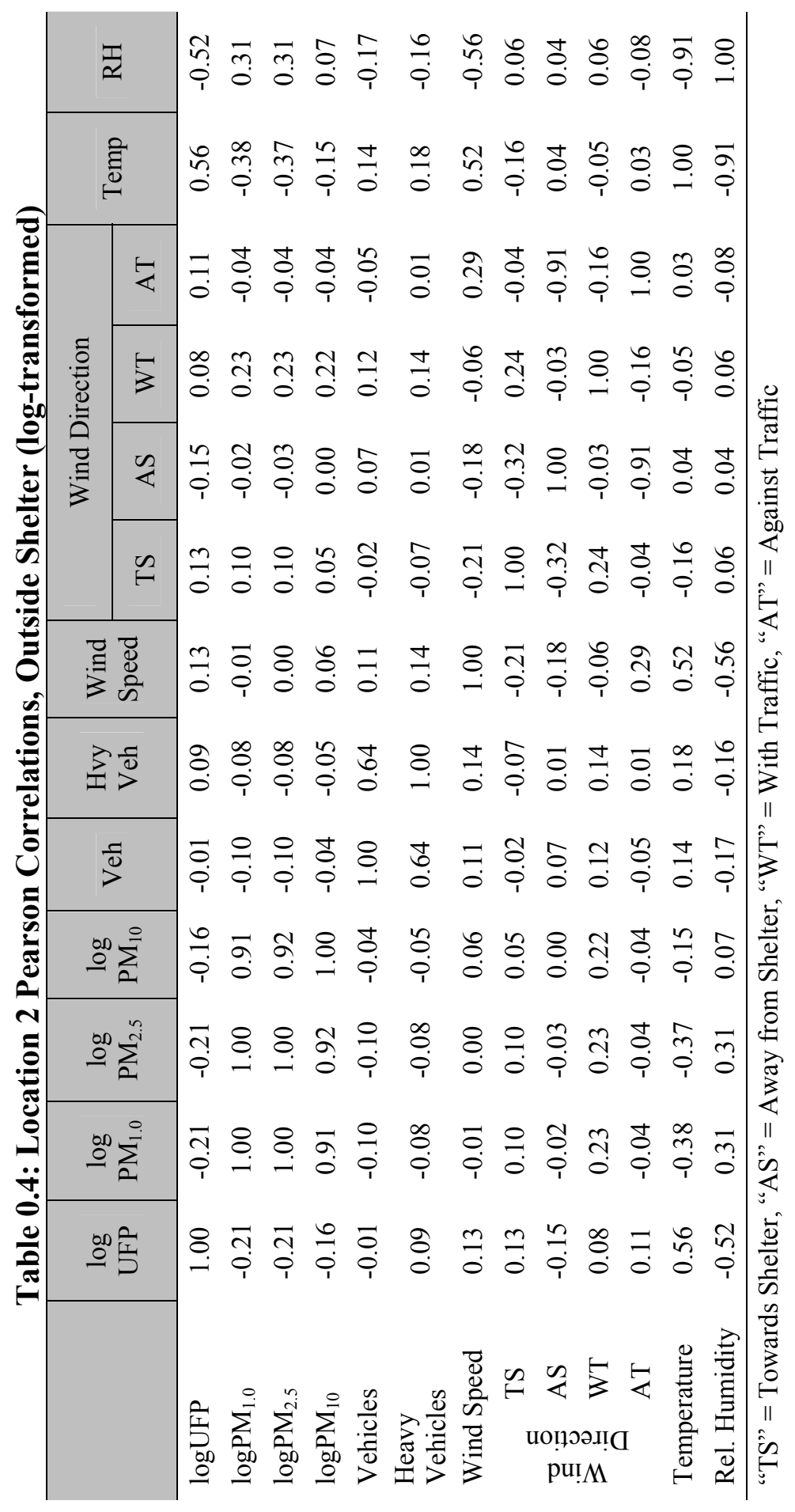




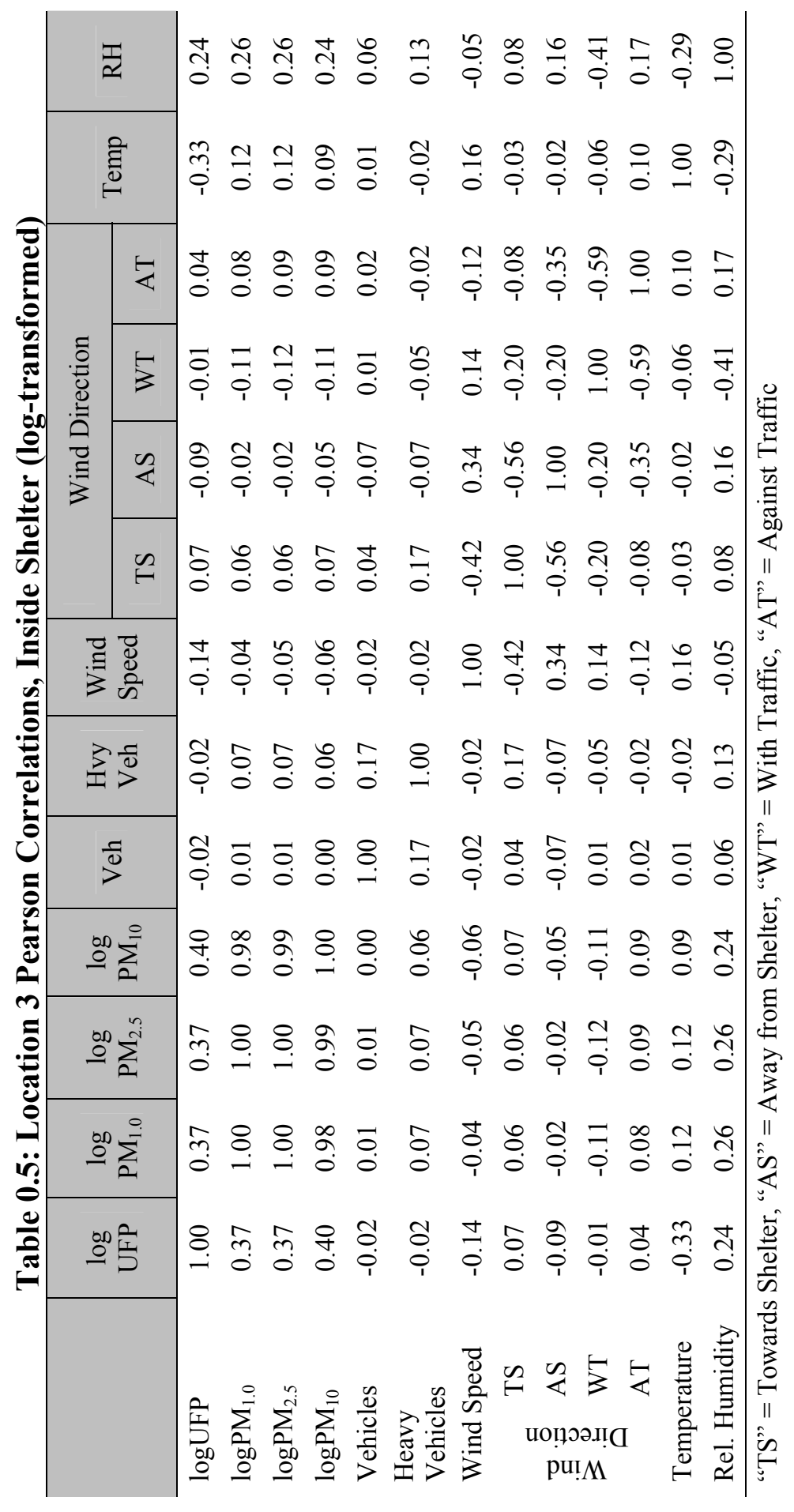




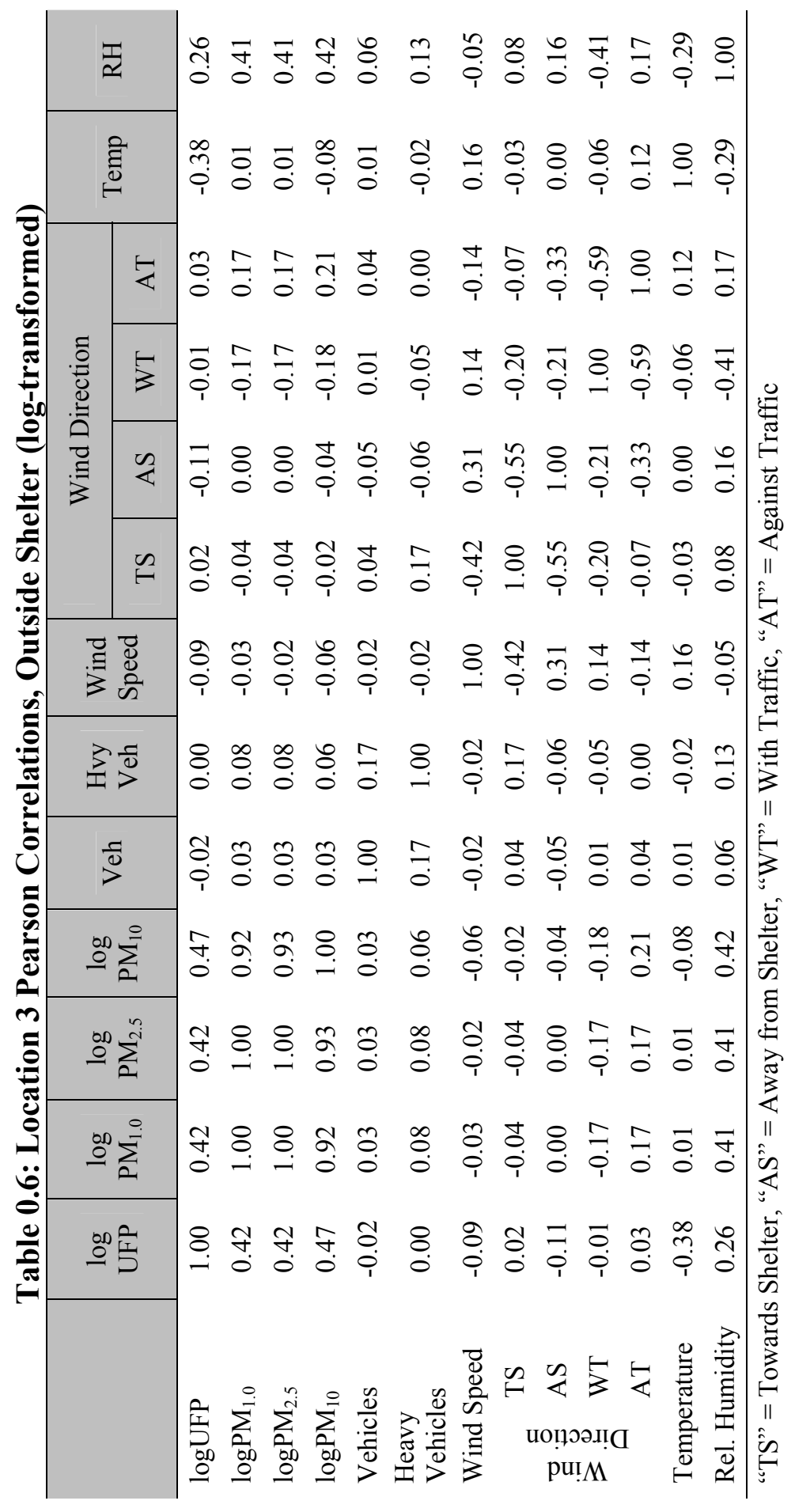




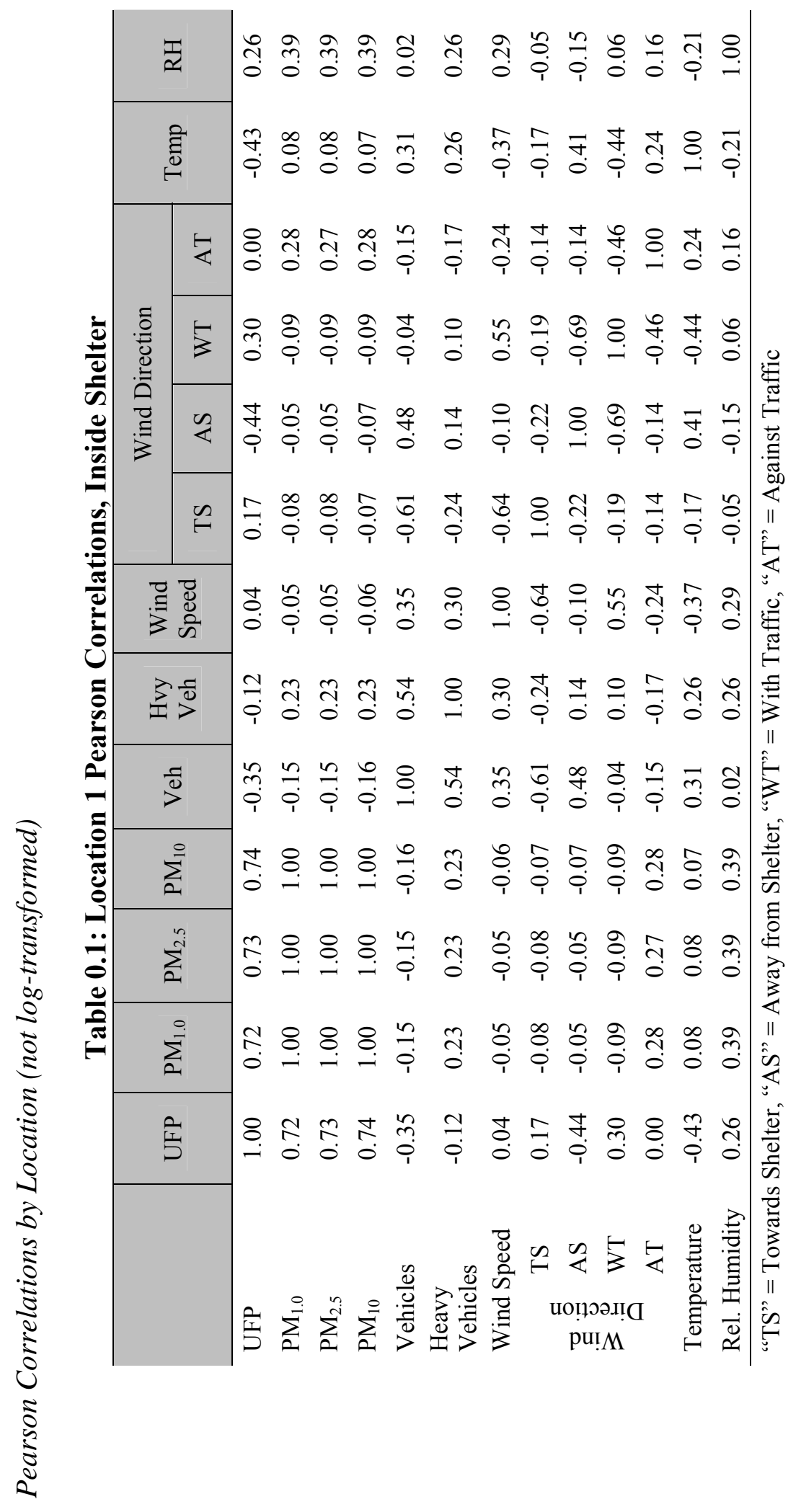




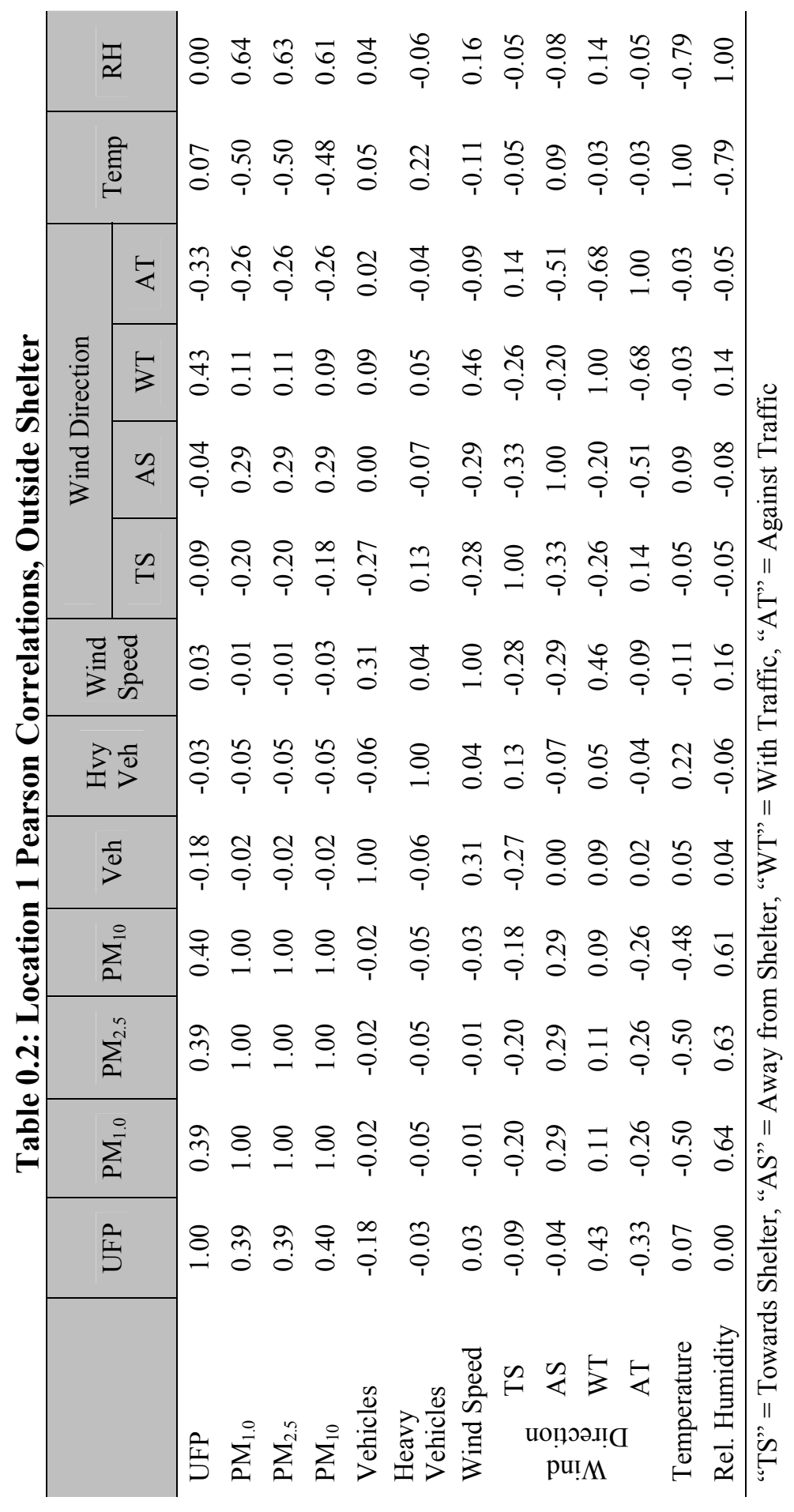




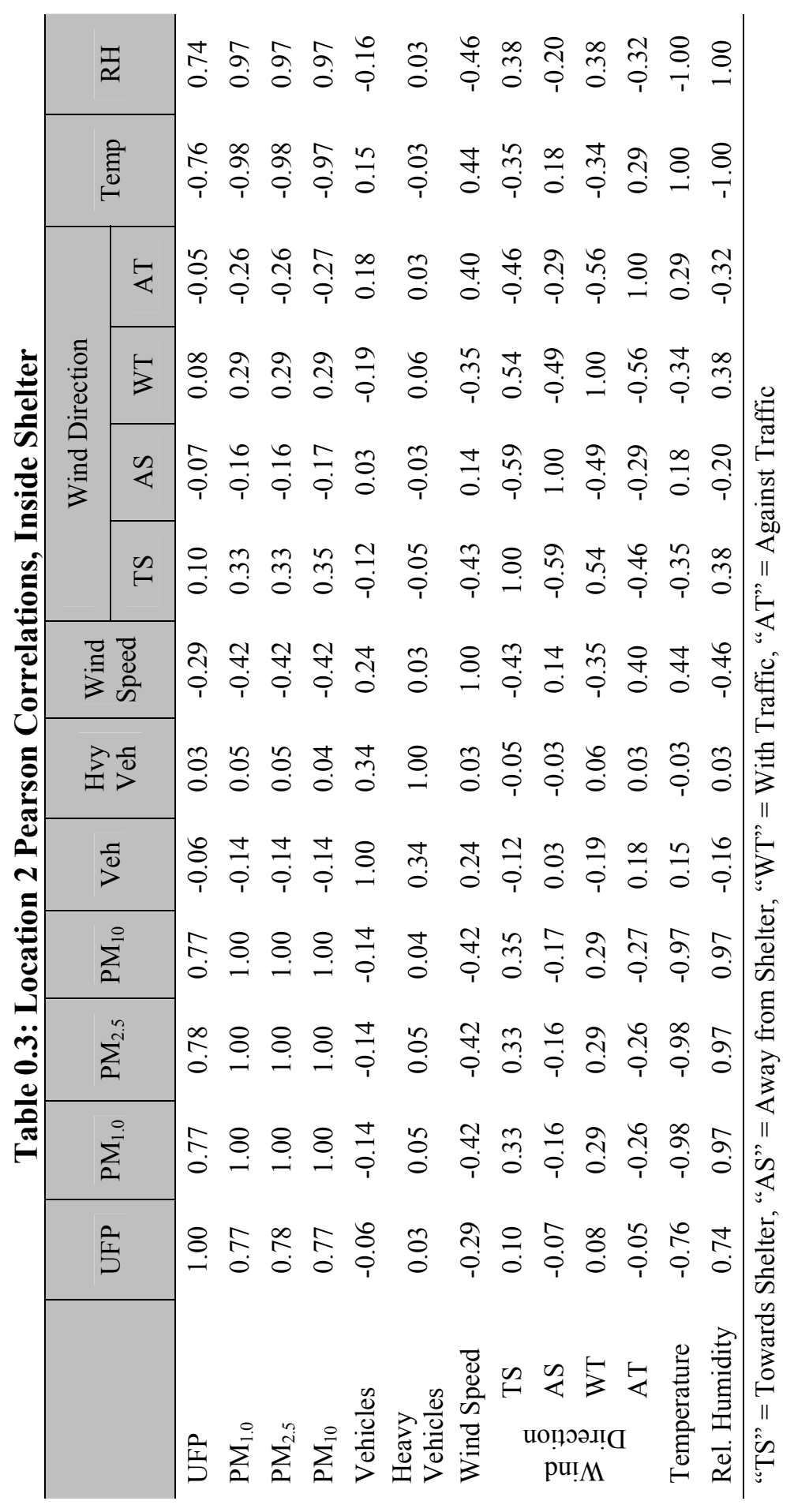




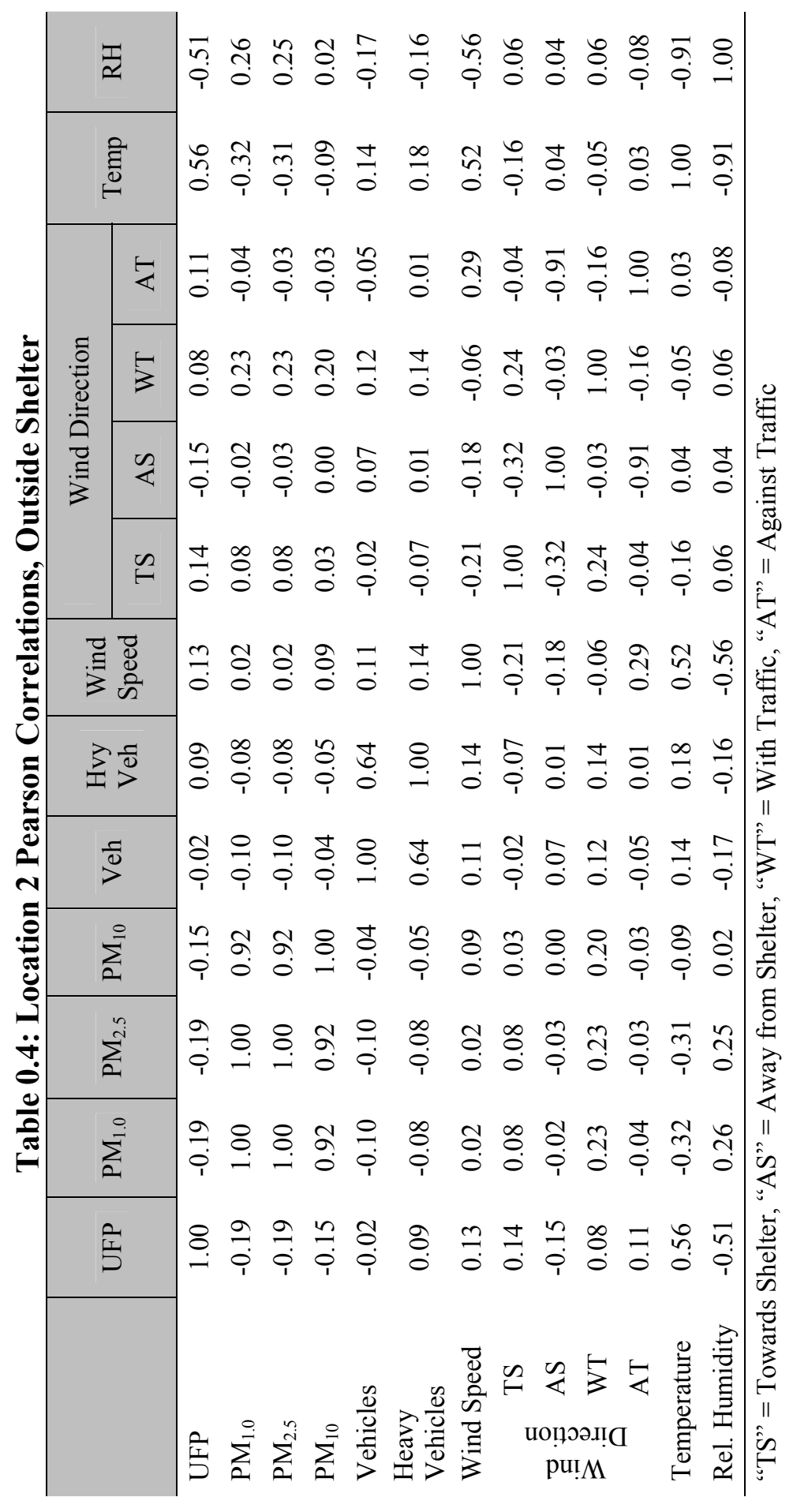




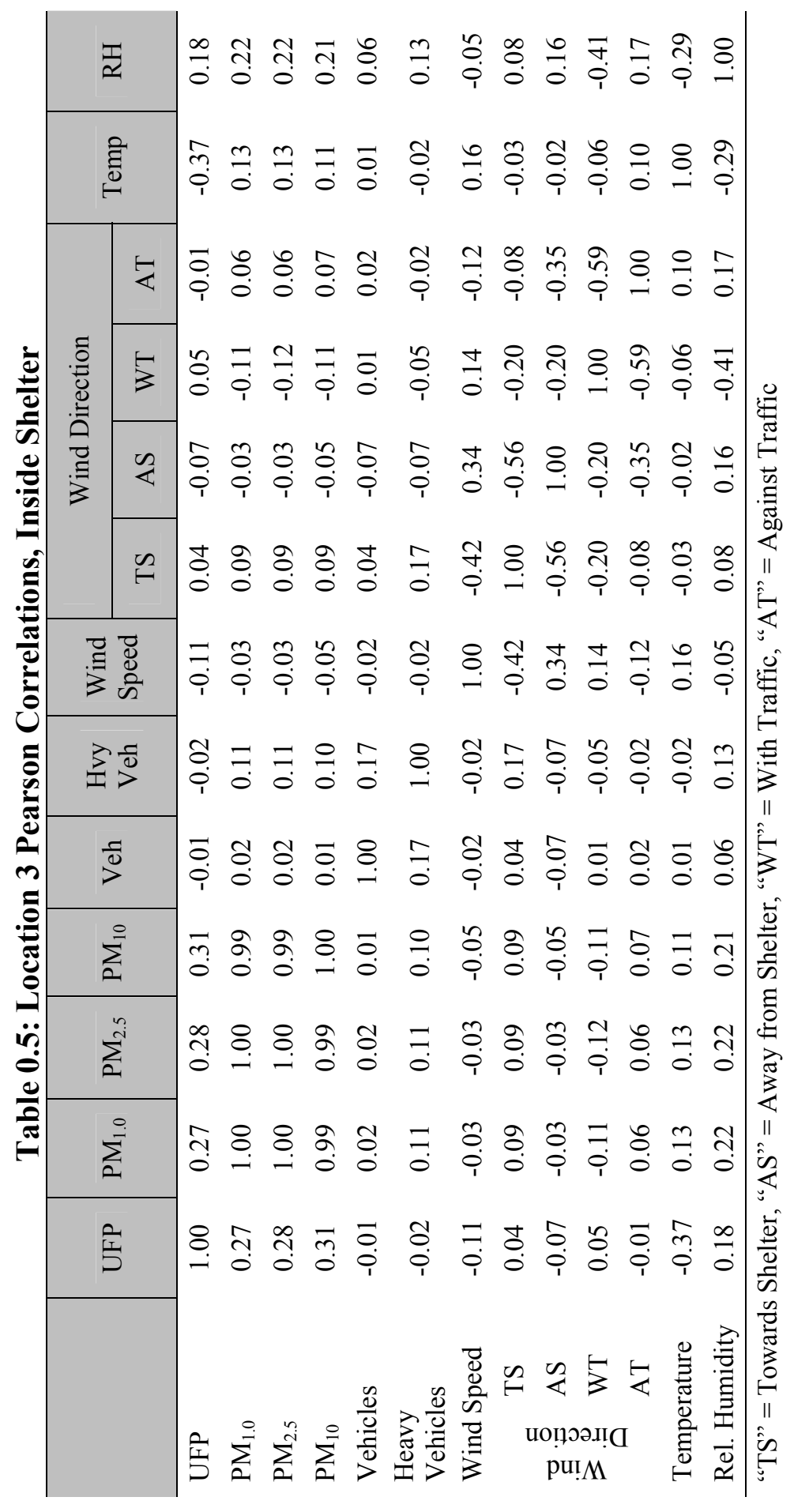




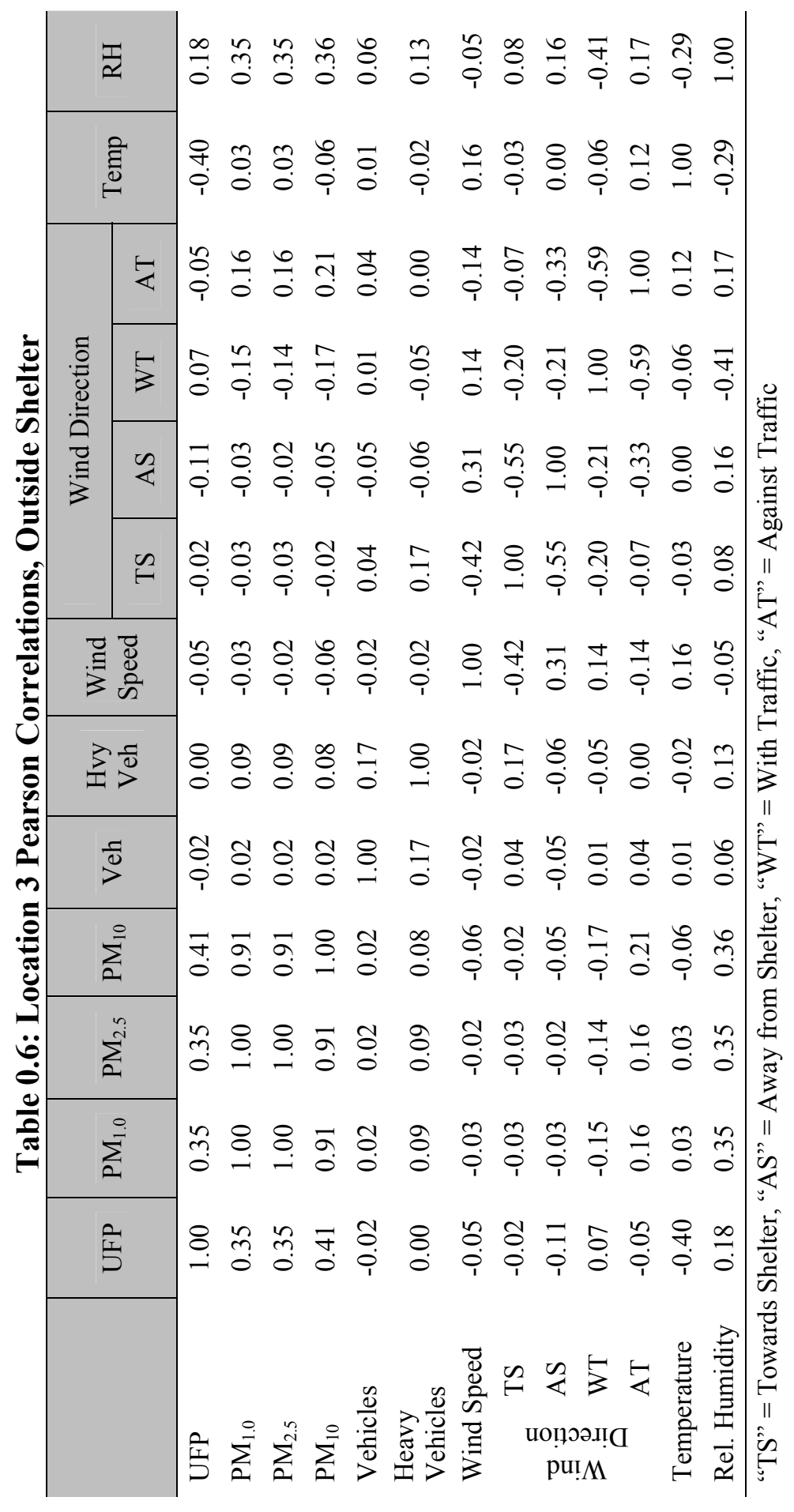




\section{APPENDIX B - Linear Regression}

\section{Categorical (log-transformed)}

Table 0.1: Categorical Linear Regression Model (logUFP Inside Shelter)

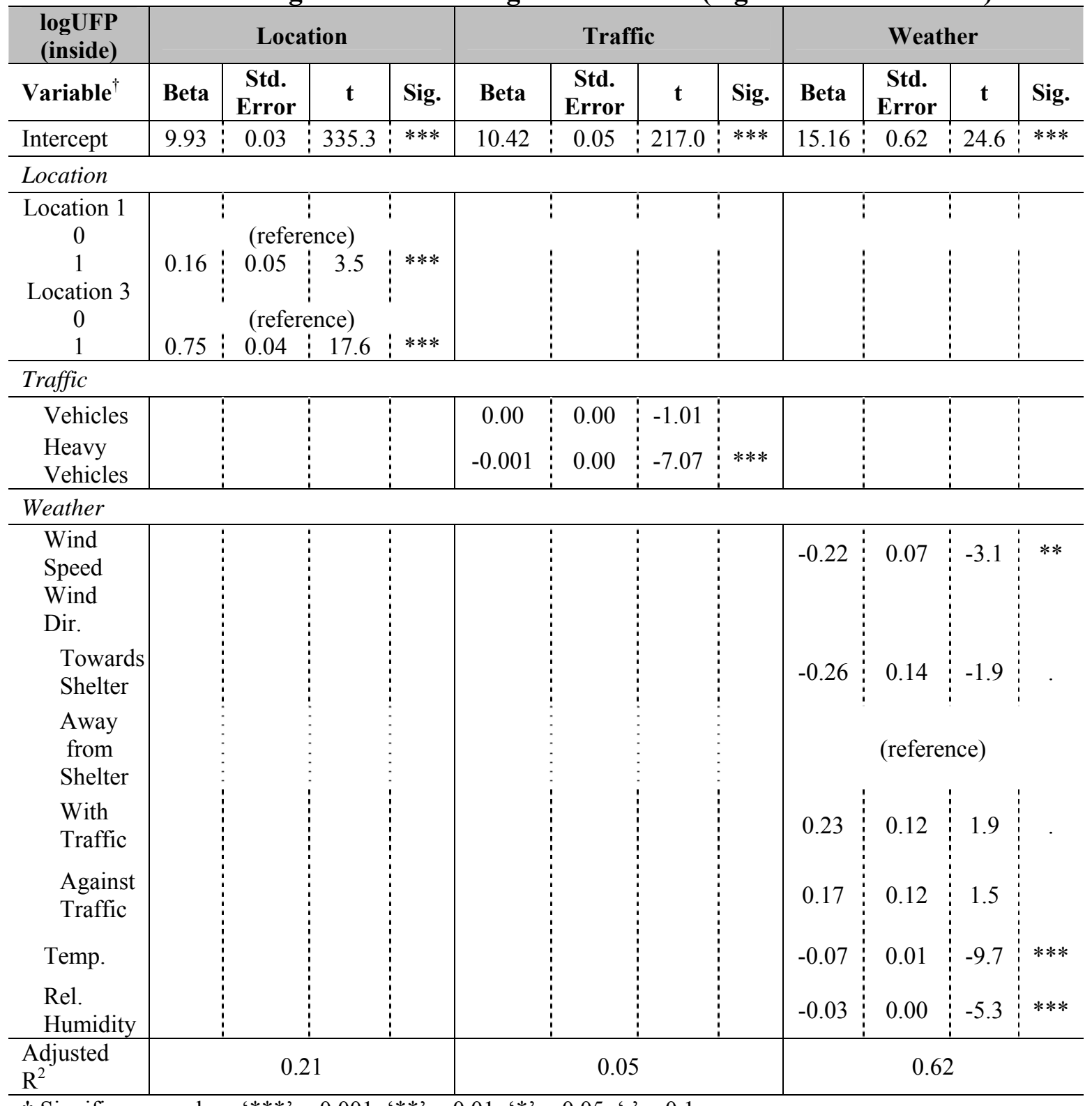

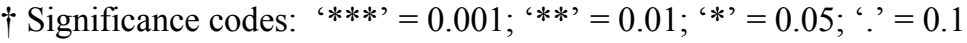


Table 0.2: Categorical Linear Regression Model (logUFP Outside Shelter)

\begin{tabular}{|c|c|c|c|c|c|c|c|c|c|c|c|c|}
\hline \multirow{2}{*}{$\begin{array}{c}\begin{array}{c}\log \text { UFP } \\
\text { (outside) }\end{array} \\
\text { Variable }^{\dagger}\end{array}$} & \multicolumn{4}{|c|}{ Location } & \multicolumn{4}{|c|}{ Traffic } & \multicolumn{4}{|c|}{ Weather } \\
\hline & Beta & $\begin{array}{l}\text { Std. } \\
\text { Error }\end{array}$ & $\mathbf{t}$ & Sig. & Beta & $\begin{array}{c}\text { Std. } \\
\text { Error }\end{array}$ & $\mathbf{t}$ & Sig. & Beta & $\begin{array}{c}\text { Std. } \\
\text { Error }\end{array}$ & t & Sig. \\
\hline Intercept & 9.88 & 0.03 & 325.9 & $* * *$ & 10.37 & 0.05 & 219.0 & $* * *$ & 15.84 & 0.58 & 27.3 & $* * *$ \\
\hline \multicolumn{13}{|l|}{ Location } \\
\hline $\begin{array}{c}\text { Location } 1 \\
0\end{array}$ & & (refer & nce) & & & & & & & & & \\
\hline $\begin{array}{c}1 \\
\text { Location } 3 \\
0\end{array}$ & 0.43 & $\begin{array}{l}0.05 \\
\text { (refere }\end{array}$ & $\begin{array}{l}9.3 \\
\text { nce) }\end{array}$ & $* * *$ & & & & & & & & \\
\hline 1 & 0.56 & 0.04 & 12.9 & $* * *$ & & & & & & & & \\
\hline \multicolumn{13}{|l|}{ Traffic } \\
\hline Vehicles & & & & & $-7 e-5$ & 0.00 & -2.1 & $*$ & & & & \\
\hline $\begin{array}{l}\text { Heavy } \\
\text { Vehicles }\end{array}$ & & & & & $-7 e-4$ & 0.00 & -4.1 & $* * *$ & & & & \\
\hline \multicolumn{13}{|l|}{ Weather } \\
\hline $\begin{array}{l}\text { Wind } \\
\text { Speed } \\
\text { Wind } \\
\text { Dir. }\end{array}$ & & & & & & & & & -0.01 & 0.07 & -0.1 & \\
\hline $\begin{array}{l}\text { Towards } \\
\text { Shelter }\end{array}$ & & & & & & & & & 0.06 & 0.13 & 0.5 & \\
\hline $\begin{array}{l}\text { Away } \\
\text { from } \\
\text { Shelter }\end{array}$ & & & & & & & & & & (refer & nce) & \\
\hline $\begin{array}{l}\text { With } \\
\text { Traffic }\end{array}$ & & & & & & & & & 0.05 & 0.11 & 0.5 & \\
\hline $\begin{array}{l}\text { Against } \\
\text { Traffic }\end{array}$ & & & & & & & & & 0.00 & 0.11 & 0.0 & \\
\hline Temp. & & & & & & & & & -0.08 & 0.01 & -12.9 & $* * *$ \\
\hline $\begin{array}{l}\text { Rel. } \\
\text { Humidity }\end{array}$ & & & & & & & & & -0.02 & 0.00 & -6.1 & $* * *$ \\
\hline $\begin{array}{l}\text { Adjusted } \\
\mathrm{R}^{2}\end{array}$ & \multicolumn{4}{|c|}{0.13} & \multicolumn{4}{|c|}{0.02} & \multicolumn{4}{|c|}{0.78} \\
\hline
\end{tabular}

$\dagger$ Significance codes: ' $* * * ’=0.001 ;{ }^{\prime * *}{ }^{*}=0.01 ;^{\prime *}{ }^{\prime}=0.05 ;{ }^{\prime} . ’=0.1$ 
Table 0.3: Categorical Linear Regression Model $\left(\operatorname{logPM} M_{2.5}\right.$ Inside Shelter)

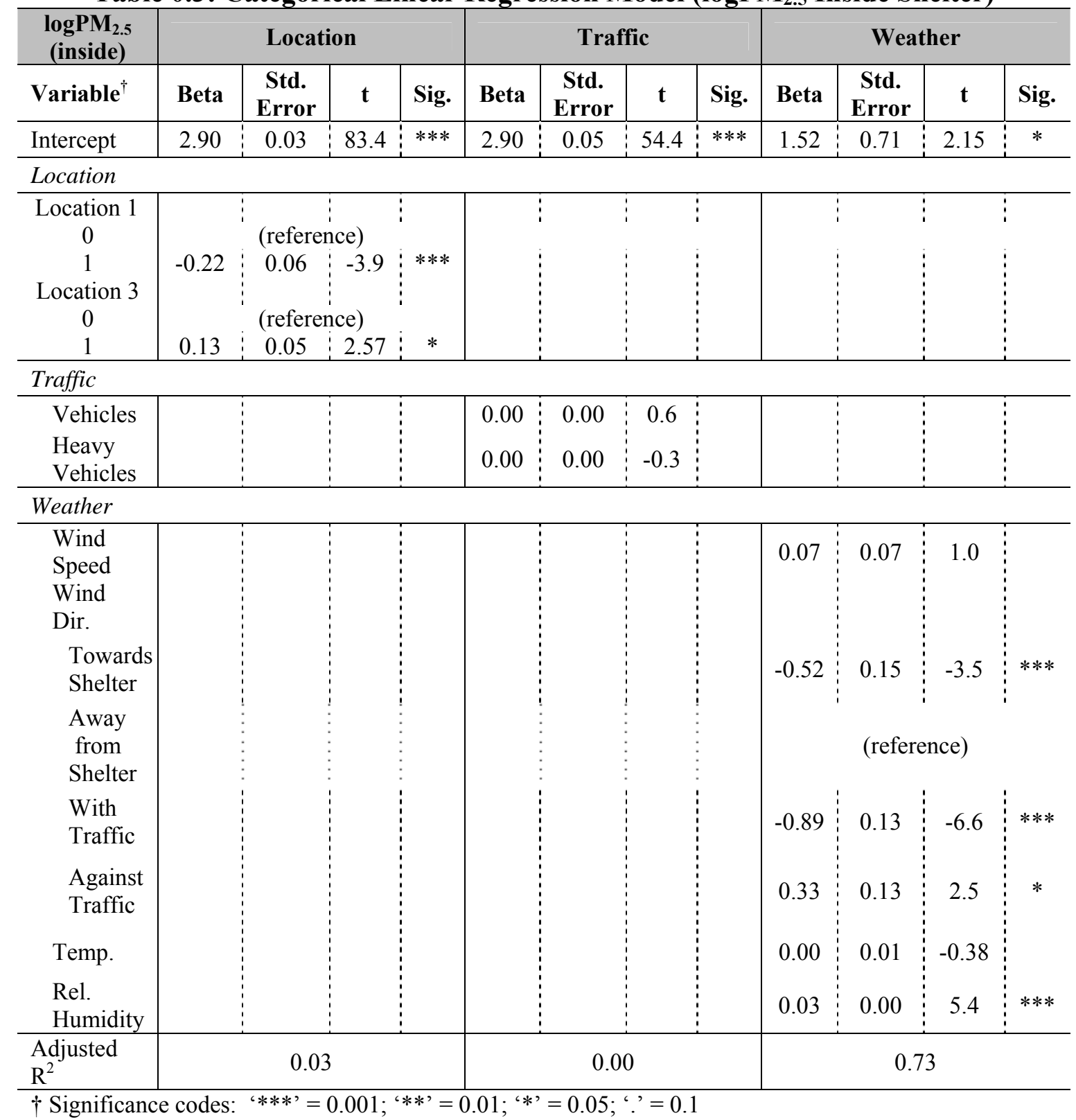


Table 0.4: Categorical Linear Regression Model $\left(\log P M_{2.5}\right.$ Outside Shelter)

\begin{tabular}{|c|c|c|c|c|c|c|c|c|c|c|c|c|}
\hline \multirow{2}{*}{$\begin{array}{r}\operatorname{logPM} M_{2.5} \\
\text { (outside) } \\
\text { Variable }^{\dagger} \\
\end{array}$} & \multicolumn{4}{|c|}{ Location } & \multicolumn{4}{|c|}{ Traffic } & \multicolumn{4}{|c|}{ Weather } \\
\hline & Beta & $\begin{array}{c}\text { Std. } \\
\text { Error }\end{array}$ & $\mathbf{t}$ & Sig. & Beta & $\begin{array}{c}\text { Std. } \\
\text { Error }\end{array}$ & $\mathbf{t}$ & Sig. & Beta & $\begin{array}{c}\text { Std. } \\
\text { Error }\end{array}$ & $\mathbf{t}$ & Sig. \\
\hline Intercept & 2.45 & 0.03 & 75.3 & $* * *$ & 2.70 & 0.05 & 59.9 & $* * *$ & -3.39 & 0.57 & -6.0 & $* * *$ \\
\hline \multicolumn{13}{|l|}{ Location } \\
\hline $\begin{array}{c}\text { Location } 1 \\
0\end{array}$ & & (refere & nce) & & & & & & & & & \\
\hline $\begin{array}{c}1 \\
\text { Location } 3 \\
0\end{array}$ & 0.29 & $\begin{array}{l}0.05 \\
\text { (refere }\end{array}$ & $\begin{array}{l}6.1 \\
\text { nce) }\end{array}$ & $* * *$ & & & & & & & & \\
\hline 1 & 0.47 & 0.04 & 10.8 & $* * *$ & & & & & & & & \\
\hline \multicolumn{13}{|l|}{ Traffic } \\
\hline Vehicles & & & & & 0.00 & 0.00 & 1.5 & & & & & \\
\hline $\begin{array}{l}\text { Heavy } \\
\text { Vehicles }\end{array}$ & & & & & $-5 e-4$ & 0.00 & -3.0 & $* *$ & & & & \\
\hline \multicolumn{13}{|l|}{ Weather } \\
\hline $\begin{array}{l}\text { Wind } \\
\text { Speed } \\
\text { Wind } \\
\text { Dir. }\end{array}$ & & & & & & & & & 0.02 & 0.05 & 0.3 & \\
\hline $\begin{array}{l}\text { Towards } \\
\text { Shelter }\end{array}$ & & & & & & & & & -0.08 & 0.14 & -0.6 & \\
\hline $\begin{array}{l}\text { Away } \\
\text { from } \\
\text { Shelter }\end{array}$ & & & & & & & & & & (refer & ace) & \\
\hline $\begin{array}{l}\text { With } \\
\text { Traffic }\end{array}$ & & & & & & & & & 0.00 & 0.10 & -0.02 & \\
\hline $\begin{array}{l}\text { Against } \\
\text { Traffic }\end{array}$ & & & & & & & & & -0.23 & 0.09 & -2.7 & $* *$ \\
\hline Temp. & & & & & & & & & 0.07 & 0.01 & 10.9 & $* * *$ \\
\hline $\begin{array}{l}\text { Rel. } \\
\text { Humidity }\end{array}$ & & & & & & & & & 0.04 & 0.00 & 10.3 & $* * *$ \\
\hline $\begin{array}{l}\text { Adjusted } \\
\mathrm{R}^{2}\end{array}$ & \multicolumn{4}{|c|}{0.09} & \multicolumn{4}{|c|}{0.01} & \multicolumn{4}{|c|}{0.45} \\
\hline
\end{tabular}


Comprehensive (log-transformed)

Table 0.1: Initial Comprehensive Linear Regression Model (logUFP Inside Shelter)

\begin{tabular}{|c|c|c|c|c|}
\hline logUFP (inside) & \multicolumn{4}{|c|}{ Comprehensive } \\
\hline Variable & Beta & SSE & $\mathbf{t}$ & Sig. ${ }^{\dagger}$ \\
\hline Intercept & 15.05 & 1.39 & 10.8 & $* * *$ \\
\hline \multicolumn{5}{|l|}{ Location } \\
\hline Location 1 (dummy) & 0.13 & 0.10 & 1.3 & \\
\hline Location 3 (dummy) & 0.03 & 0.08 & 0.4 & \\
\hline \multicolumn{5}{|l|}{ Traffic } \\
\hline Vehicles & 0.00 & 0.00 & 0.17 & \\
\hline Heavy Vehicles & 0.00 & 0.00 & -0.8 & \\
\hline \multicolumn{5}{|l|}{ Weather } \\
\hline Wind Speed & -0.18 & 0.07 & -2.4 & $*$ \\
\hline Wind Direction & & & & \\
\hline Towards Shelter & -0.31 & 0.15 & -2.0 & $*$ \\
\hline Away from Shelter & & (ref & & \\
\hline With Traffic & 0.25 & 0.14 & 1.8 & . \\
\hline Against Traffic & 0.14 & 0.12 & 1.2 & \\
\hline Temperature & -0.07 & 0.01 & -4.4 & $* * *$ \\
\hline Relative Humidity & -0.02 & 0.01 & -2.2 & $*$ \\
\hline Adjusted $\mathrm{R}^{2}$ & \multicolumn{4}{|c|}{0.66} \\
\hline
\end{tabular}


Table 0.2: Initial Comprehensive Linear Regression Model (logUFP Outside Shelter)

\begin{tabular}{|c|c|c|c|c|}
\hline \multirow{2}{*}{$\begin{array}{l}\text { logUFP (outside) } \\
\text { Variable }\end{array}$} & \multicolumn{4}{|c|}{ Comprehensive } \\
\hline & Beta & SSE & t & Sig. ${ }^{\dagger}$ \\
\hline Intercept & 12.74 & 1.29 & 9.9 & $* * *$ \\
\hline \multicolumn{5}{|l|}{ Location } \\
\hline Location 1 (dummy) & -0.11 & 0.09 & -1.2 & \\
\hline Location 3 (dummy) & 0.19 & 0.08 & 2.4 & $*$ \\
\hline \multicolumn{5}{|l|}{ Traffic } \\
\hline Vehicles & 0.00 & 0.00 & -0.2 & \\
\hline Heavy Vehicles & 0.00 & 0.00 & 0.4 & \\
\hline \multicolumn{5}{|l|}{ Weather } \\
\hline Wind Speed & 0.07 & 0.07 & 1.1 & \\
\hline Wind Direction & & & & \\
\hline Towards Shelter & -0.08 & 0.14 & -0.6 & \\
\hline Away from Shelter & & (ref & & \\
\hline With Traffic & 0.15 & 0.13 & 1.2 & \\
\hline Against Traffic & -0.02 & 0.11 & -0.1 & \\
\hline Temperature & -0.05 & 0.01 & -3.7 & $* * *$ \\
\hline Relative Humidity & 0.00 & 0.00 & -0.2 & \\
\hline Adjusted $\mathrm{R}^{2}$ & \multicolumn{4}{|c|}{0.81} \\
\hline
\end{tabular}


Table 0.3: Initial Comprehensive Linear Regression Model $\left(\log \mathrm{PM}_{2.5}\right.$ Inside Shelter) $\log \mathrm{PM}_{2.5}$ (inside)

Variable Comprehensive

Intercep Beta

\begin{tabular}{l|l|l} 
SSE & $\mathbf{t}$ & Sig.
\end{tabular}

Location

Location 1 (dummy)

Location 3 (dummy)

3.63

0.66

Traffic

Vehicles

Heavy Vehicles

Weather

Wind Speed

Wind Direction

Towards Shelter Away from Shelter

With Traffic

Against Traffic

Temperature

Relative Humidity

\begin{tabular}{l|l|l|l}
-0.75 & 0.06 & -11.8 & $* * *$ \\
-0.77 & 0.04 & -19.4 & $* * *$ \\
\hline
\end{tabular}

\begin{tabular}{l|r}
\hline Adjusted $\mathrm{R}^{2}$ & 0.95 \\
\hline
\end{tabular}

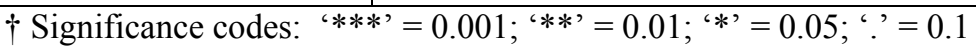


Table 0.4: Initial Comprehensive Linear Regression Model $\left(\log \mathrm{PM}_{2.5}\right.$ Outside Shelter)

\begin{tabular}{|c|c|c|c|c|}
\hline \multirow{2}{*}{$\begin{array}{l}\log P M_{2.5} \text { (inside) } \\
\text { Variable }\end{array}$} & \multicolumn{4}{|c|}{ Comprehensive } \\
\hline & Beta & SSE & $\mathbf{t}$ & Sig. $^{\dagger}$ \\
\hline Intercept & -1.13 & 2.45 & -0.5 & \\
\hline \multicolumn{5}{|l|}{ Location } \\
\hline Location 1 (dummy) & -1.52 & 0.72 & -2.1 & $*$ \\
\hline Location 3 (dummy) & -0.78 & 0.48 & -1.6 & \\
\hline \multicolumn{5}{|l|}{ Traffic } \\
\hline Vehicles & 0.00 & 0.00 & -0.1 & \\
\hline Heavy Vehicles & 0.00 & 0.00 & -0.3 & \\
\hline \multicolumn{5}{|l|}{ Weather } \\
\hline Wind Speed & 0.04 & 0.05 & 0.7 & \\
\hline Wind Direction & & & & \\
\hline Towards Shelter & -0.15 & 0.13 & -1.2 & \\
\hline Away from Shelter & & (ref & & \\
\hline With Traffic & 0.00 & 0.11 & 0.0 & \\
\hline Against Traffic & -0.16 & 0.08 & -2.0 & \\
\hline Temperature & 0.04 & 0.03 & 1.1 & \\
\hline Relative Humidity & 0.04 & 0.01 & 4.5 & $* * *$ \\
\hline Adjusted $\mathrm{R}^{2}$ & \multicolumn{4}{|c|}{0.53} \\
\hline
\end{tabular}


Categorical (not log-transformed)

Table 0.1: Categorical Linear Regression Model (UFP Inside Shelter)

\begin{tabular}{|c|c|c|c|c|c|c|c|c|c|c|c|c|}
\hline \multirow{2}{*}{$\begin{array}{c}\begin{array}{c}\text { UFP } \\
\text { (inside) }\end{array} \\
\text { Variable }^{\dagger}\end{array}$} & \multicolumn{4}{|c|}{ Location } & \multicolumn{4}{|c|}{ Traffic } & \multicolumn{4}{|c|}{ Weather } \\
\hline & Beta & $\begin{array}{c}\text { Std. } \\
\text { Error }\end{array}$ & $\mathbf{t}$ & Sig. & Beta & $\begin{array}{c}\text { Std. } \\
\text { Error }\end{array}$ & $\mathbf{t}$ & Sig. & Beta & $\begin{array}{c}\text { Std. } \\
\text { Error }\end{array}$ & $\mathbf{t}$ & Sig. \\
\hline Intercept & 27549 & 1163 & 23.7 & $* * *$ & 41599 & 1814 & 22.9 & $* * *$ & 221977 & 25224 & 8.8 & $* * *$ \\
\hline \multicolumn{13}{|l|}{ Location } \\
\hline $\begin{array}{c}\text { Location } 1 \\
0\end{array}$ & & (referer & (ce) & & & & & & & & & \\
\hline $\begin{array}{c}1 \\
\text { Location } 3 \\
0 \\
1\end{array}$ & 2677 & $\begin{array}{l}1799 \\
\text { (referer } \\
1679\end{array}$ & 1.49 & & & & & & & & & \\
\hline \multicolumn{13}{|l|}{ Traffic } \\
\hline Vehicles & & & & & -1.48 & 1.28 & -1.2 & & & & & \\
\hline $\begin{array}{l}\text { Heavy } \\
\text { Vehicles }\end{array}$ & & & & & -34.2 & 6.55 & -5.2 & $* * *$ & & & & \\
\hline \multicolumn{13}{|l|}{ Weather } \\
\hline $\begin{array}{l}\text { Wind } \\
\text { Speed } \\
\text { Wind } \\
\text { Dir. }\end{array}$ & & & & & & & & & -3323 & 2876 & -1.2 & \\
\hline $\begin{array}{l}\text { Towards } \\
\text { Shelter }\end{array}$ & & & & & & & & & -21309 & 5732 & -3.7 & $* * *$ \\
\hline $\begin{array}{l}\text { Away } \\
\text { from } \\
\text { Shelter }\end{array}$ & & & & & & & & & & (referer & & \\
\hline $\begin{array}{l}\text { With } \\
\text { Traffic }\end{array}$ & & & & & & & & & 3222 & 4873 & 0.7 & \\
\hline $\begin{array}{l}\text { Against } \\
\text { Traffic }\end{array}$ & & & & & & & & & 5986 & 4704 & 1.3 & \\
\hline Temp. & & & & & & & & & -2490 & 281 & -8.9 & $* * *$ \\
\hline $\begin{array}{l}\text { Rel. } \\
\text { Humidity }\end{array}$ & & & & & & & & & -948 & 172 & -535 & $* * *$ \\
\hline $\begin{array}{l}\text { Adjusted } \\
\mathrm{R}^{2}\end{array}$ & \multicolumn{4}{|c|}{0.13} & \multicolumn{4}{|c|}{0.03} & \multicolumn{4}{|c|}{0.46} \\
\hline
\end{tabular}


Table 0.2: Categorical Linear Regression Model (UFP Outside Shelter)

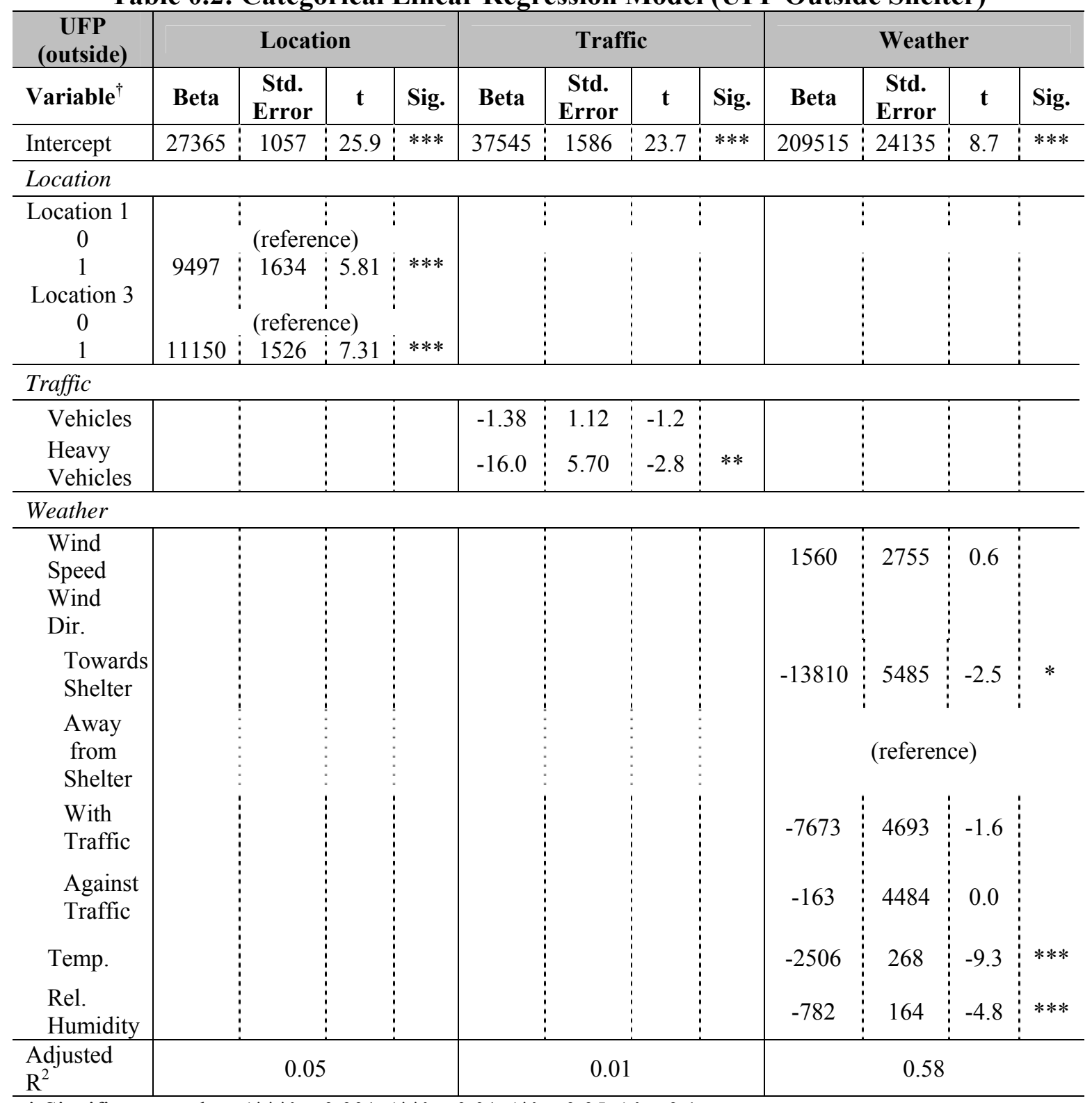

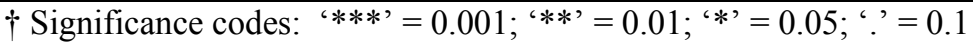


Table 0.3: Categorical Linear Regression Model (PM $\mathbf{P M}_{2.5}$ Inside Shelter)

\begin{tabular}{|c|c|c|c|c|c|c|c|c|c|c|c|c|}
\hline \multirow{2}{*}{$\begin{array}{r}\begin{array}{r}\mathbf{P M}_{2.5} \\
\text { (inside) }\end{array} \\
\text { Variable }^{\dagger}\end{array}$} & \multicolumn{4}{|c|}{ Location } & \multicolumn{4}{|c|}{ Traffic } & \multicolumn{4}{|c|}{ Weather } \\
\hline & Beta & $\begin{array}{c}\text { Std. } \\
\text { Error }\end{array}$ & $\mathbf{t}$ & Sig. & Beta & $\begin{array}{c}\text { Std. } \\
\text { Error }\end{array}$ & $\mathbf{t}$ & Sig. & Beta & $\begin{array}{c}\text { Std. } \\
\text { Error }\end{array}$ & $\mathbf{t}$ & Sig. \\
\hline Intercept & 24.89 & 1.03 & 24.2 & $* * *$ & 23.73 & 1.59 & 14.9 & $* * *$ & 53.40 & 21.65 & 2.5 & $*$ \\
\hline \multicolumn{13}{|l|}{ Location } \\
\hline $\begin{array}{c}\text { Location } 1 \\
0\end{array}$ & & (refere & (ce) & & & & & & & & & \\
\hline $\begin{array}{c}1 \\
\text { Location } 3 \\
0\end{array}$ & -7.76 & $\begin{array}{l}1.66 \\
\text { (refere }\end{array}$ & $\begin{array}{l}-4.7 \\
\text { ce) }\end{array}$ & & & & & & & & & \\
\hline 1 & 4.65 & 1.48 & 3.13 & $* *$ & & & & & & & & \\
\hline \multicolumn{13}{|l|}{ Traffic } \\
\hline Vehicles & & & & & 0.00 & 0.00 & 0.8 & & & & & \\
\hline $\begin{array}{l}\text { Heavy } \\
\text { Vehicles }\end{array}$ & & & & & 0.00 & 0.01 & 0.0 & & & & & \\
\hline \multicolumn{13}{|l|}{ Weather } \\
\hline $\begin{array}{l}\text { Wind } \\
\text { Speed } \\
\text { Wind } \\
\text { Dir. }\end{array}$ & & & & & & & & & 2.82 & 2.28 & 1.23 & \\
\hline $\begin{array}{l}\text { Towards } \\
\text { Shelter }\end{array}$ & & & & & & & & & -16.54 & 4.59 & -3.6 & $* * *$ \\
\hline $\begin{array}{l}\text { Away } \\
\text { from } \\
\text { Shelter }\end{array}$ & & & & & & & & & & (referer & & \\
\hline $\begin{array}{l}\text { With } \\
\text { Traffic }\end{array}$ & & & & & & & & & -29.79 & 4.09 & -7.3 & $* * *$ \\
\hline $\begin{array}{l}\text { Against } \\
\text { Traffic }\end{array}$ & & & & & & & & & 10.00 & 3.98 & 2.5 & $*$ \\
\hline Temp. & & & & & & & & & -0.87 & 0.24 & -3.7 & $* * *$ \\
\hline $\begin{array}{l}\text { Rel. } \\
\text { Humidity }\end{array}$ & & & & & & & & & 0.30 & 0.15 & 2.0 & $*$ \\
\hline $\begin{array}{l}\text { Adjusted } \\
\mathrm{R}^{2}\end{array}$ & \multicolumn{4}{|c|}{0.04} & \multicolumn{4}{|c|}{0.00} & \multicolumn{4}{|c|}{0.72} \\
\hline
\end{tabular}


Table 0.4: Categorical Linear Regression Model (PM $\mathbf{P M}_{2.5}$ Outside Shelter)

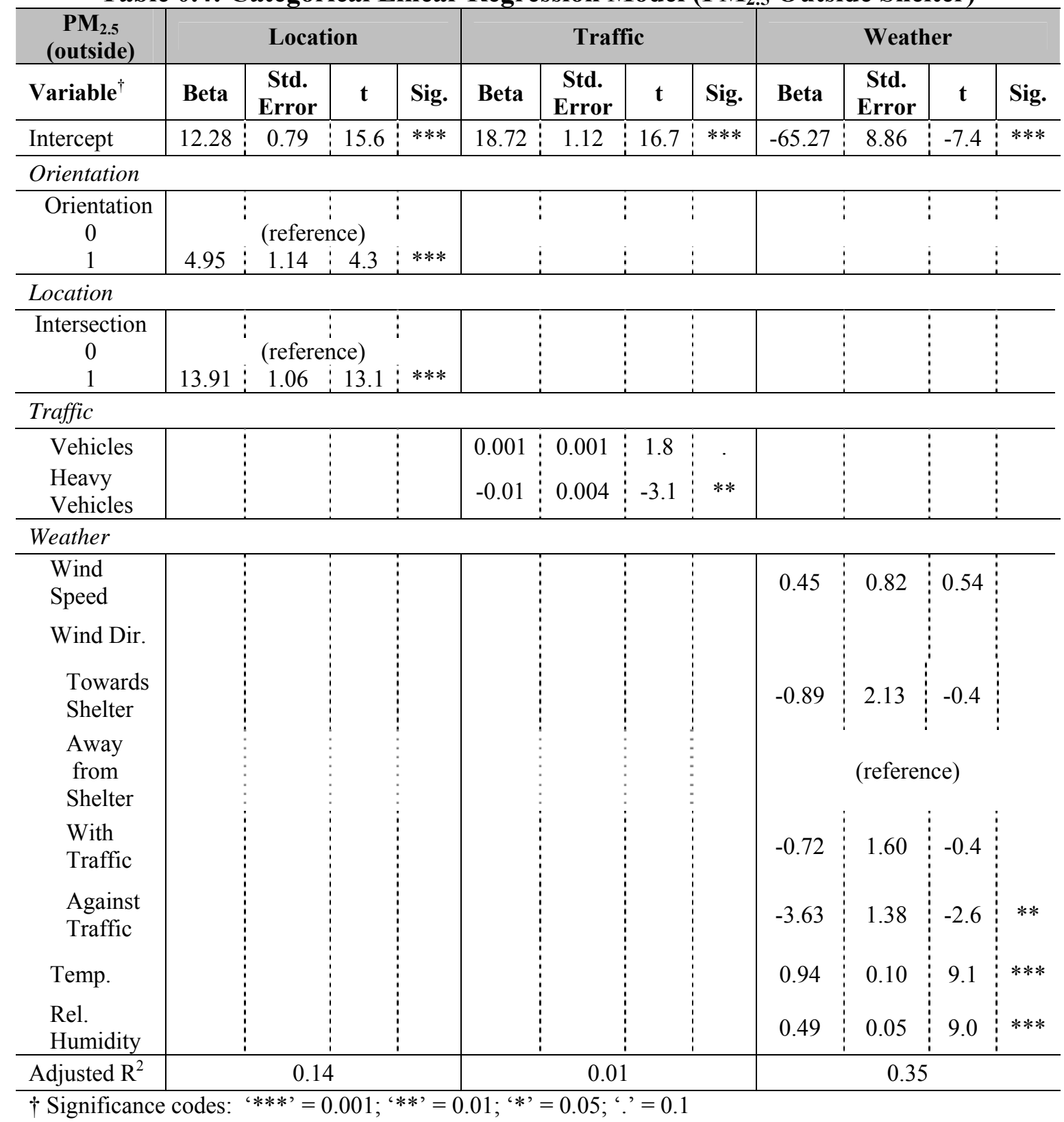




\section{Comprehensive (not log-transformed)}

Table 0.1: Comprehensive Linear Regression Model (UFP Inside)

\begin{tabular}{|c|c|c|c|c|}
\hline UFP (inside) & \multicolumn{4}{|c|}{ Comprehensive } \\
\hline Variable & Beta & SSE & $\mathbf{t}$ & Sig. $^{\dagger}$ \\
\hline Intercept & 363500 & 57920 & 6.3 & $* * *$ \\
\hline \multicolumn{5}{|l|}{ Location } \\
\hline Location 1 (dummy) & 11080 & 4223 & 2.6 & $* *$ \\
\hline Location 3 (dummy) & -10002 & 3517 & -2.9 & $* *$ \\
\hline \multicolumn{5}{|l|}{ Traffic } \\
\hline Vehicles & 0.19 & 1.25 & 0.2 & \\
\hline Heavy Vehicles & -1.78 & 6.45 & -0.3 & \\
\hline \multicolumn{5}{|l|}{ Weather } \\
\hline Wind Speed & -3349 & 3020 & -1.1 & \\
\hline Wind Dir. & & & & \\
\hline Towards Shelter & -14410 & 6374 & -2.3 & $*$ \\
\hline Away from Shelter & & (refe & & \\
\hline With Traffic & 6713 & 5629 & 1.2 & \\
\hline Against Traffic & 4541 & 4823 & 0.9 & \\
\hline Temperature & -4012 & 623 & -6.4 & $* * *$ \\
\hline Relative Humidity & -1957 & 408 & -4.8 & $* * *$ \\
\hline Adjusted $\mathrm{R}^{2}$ & \multicolumn{4}{|c|}{0.50} \\
\hline
\end{tabular}

Table 0.2: Comprehensive Linear Regression Model (UFP Outside)

\begin{tabular}{|c|c|c|c|c|}
\hline \multirow{2}{*}{$\begin{array}{l}\text { UFP (inside) } \\
\text { Variable }\end{array}$} & \multicolumn{4}{|c|}{ Comprehensive } \\
\hline & Beta & SSE & $\mathbf{t}$ & Sig. ${ }^{\dagger}$ \\
\hline Intercept & 198500 & 54630 & 3.6 & $* * *$ \\
\hline \multicolumn{5}{|l|}{ Location } \\
\hline Location 1 (dummy) & -4632 & 3980 & -1.2 & \\
\hline Location 3 (dummy) & -5753 & 3319 & 1.7 & . \\
\hline \multicolumn{5}{|l|}{ Traffic } \\
\hline Vehicles & -0.12 & 1.18 & -0.10 & \\
\hline Heavy Vehicles & 4.58 & 6.10 & 0.75 & \\
\hline \multicolumn{5}{|l|}{ Weather } \\
\hline $\begin{array}{l}\text { Wind Speed } \\
\text { Wind Dir. }\end{array}$ & 2473 & 2847 & 0.7 & \\
\hline Towards Shelter & -8777 & 6004 & -1.5 & \\
\hline Away from Shelter & & $($ refer & & \\
\hline With Traffic & 2182 & 5344 & 0.4 & \\
\hline Against Traffic & -1448 & 4525 & -0.3 & \\
\hline Temperature & -2381 & 588 & -4.1 & $* * *$ \\
\hline Relative Humidity & -701 & 385 & -1.8 & . \\
\hline Adjusted $\mathrm{R}^{2}$ & \multicolumn{4}{|c|}{0.63} \\
\hline
\end{tabular}


Table 0.3: Comprehensive Linear Regression Model (PM $\mathbf{P}_{2.5}$ Inside)

\begin{tabular}{|c|c|c|c|c|}
\hline $\mathbf{P M}_{2.5}$ (inside) & \multicolumn{4}{|c|}{ Comprehensive } \\
\hline Variable & Beta & SSE & $\mathbf{t}$ & Sig. ${ }^{\dagger}$ \\
\hline Intercept & 132.9 & 17.95 & 7.4 & $* * *$ \\
\hline \multicolumn{5}{|l|}{ Location } \\
\hline Location 1 (dummy) & -23.5 & 1.70 & -13.8 & $* * *$ \\
\hline Location 3 (dummy) & -25.4 & 1.07 & -23.8 & $* * *$ \\
\hline \multicolumn{5}{|l|}{ Traffic } \\
\hline Vehicles & -0.0001 & 0.0004 & -0.3 & \\
\hline Heavy Vehicles & 0.003 & 0.002 & 1.8 & . \\
\hline \multicolumn{5}{|l|}{ Weather } \\
\hline Wind Speed & -0.011 & 0.96 & 0.0 & \\
\hline Wind Dir. & & & & \\
\hline Towards Shelter & 1.66 & 2.04 & 0.8 & \\
\hline Away from Shelter & & (refe & & \\
\hline With Traffic & -5.93 & 2.00 & -3.0 & $* *$ \\
\hline Against Traffic & 0.17 & 1.63 & 0.1 & \\
\hline Temperature & -1.59 & 0.19 & -8.5 & $* * *$ \\
\hline Relative Humidity & -0.20 & 0.12 & -1.6 & \\
\hline Adjusted $\mathrm{R}^{2}$ & \multicolumn{4}{|c|}{0.96} \\
\hline
\end{tabular}

Table 0.4: Comprehensive Linear Regression Model ( $\mathrm{PM}_{2.5}$ Outside)

\begin{tabular}{|c|c|c|c|c|}
\hline \multirow{2}{*}{\begin{tabular}{|l|}
$\mathrm{PM}_{2.5}$ (inside) \\
Variable
\end{tabular}} & \multicolumn{4}{|c|}{ Comprehensive } \\
\hline & Beta & SSE & $\mathbf{t}$ & Sig. ${ }^{\dagger}$ \\
\hline Intercept & -15.57 & 36.83 & -0.4 & \\
\hline \multicolumn{5}{|l|}{ Location } \\
\hline Location 1 (dummy) & -23.14 & 10.82 & -2.1 & $*$ \\
\hline Location 3 (dummy) & -12.96 & 7.19 & -1.8 & . \\
\hline \multicolumn{5}{|l|}{ Traffic } \\
\hline Vehicles & 0.00 & 0.00 & -0.2 & \\
\hline Heavy Vehicles & 0.00 & 0.00 & -0.1 & \\
\hline \multicolumn{5}{|l|}{ Weather } \\
\hline $\begin{array}{l}\text { Wind Speed } \\
\text { Wind Dir. }\end{array}$ & 0.84 & 0.79 & 1.1 & \\
\hline Towards Shelter & -2.24 & 1.90 & -1.2 & \\
\hline Away from Shelter & & (ref & & \\
\hline With Traffic & -0.25 & 1.62 & -0.2 & \\
\hline Against Traffic & -2.44 & 1.23 & -2.0 & * \\
\hline Temperature & 0.22 & 0.48 & 0.5 & \\
\hline Relative Humidity & 0.50 & 0.14 & 3.5 & $* * *$ \\
\hline Adjusted $\mathrm{R}^{2}$ & \multicolumn{4}{|c|}{0.43} \\
\hline
\end{tabular}




\section{APPENDIX C - Shelter Orientation Time Series Plots}

\section{Morning Particulate Measurements}
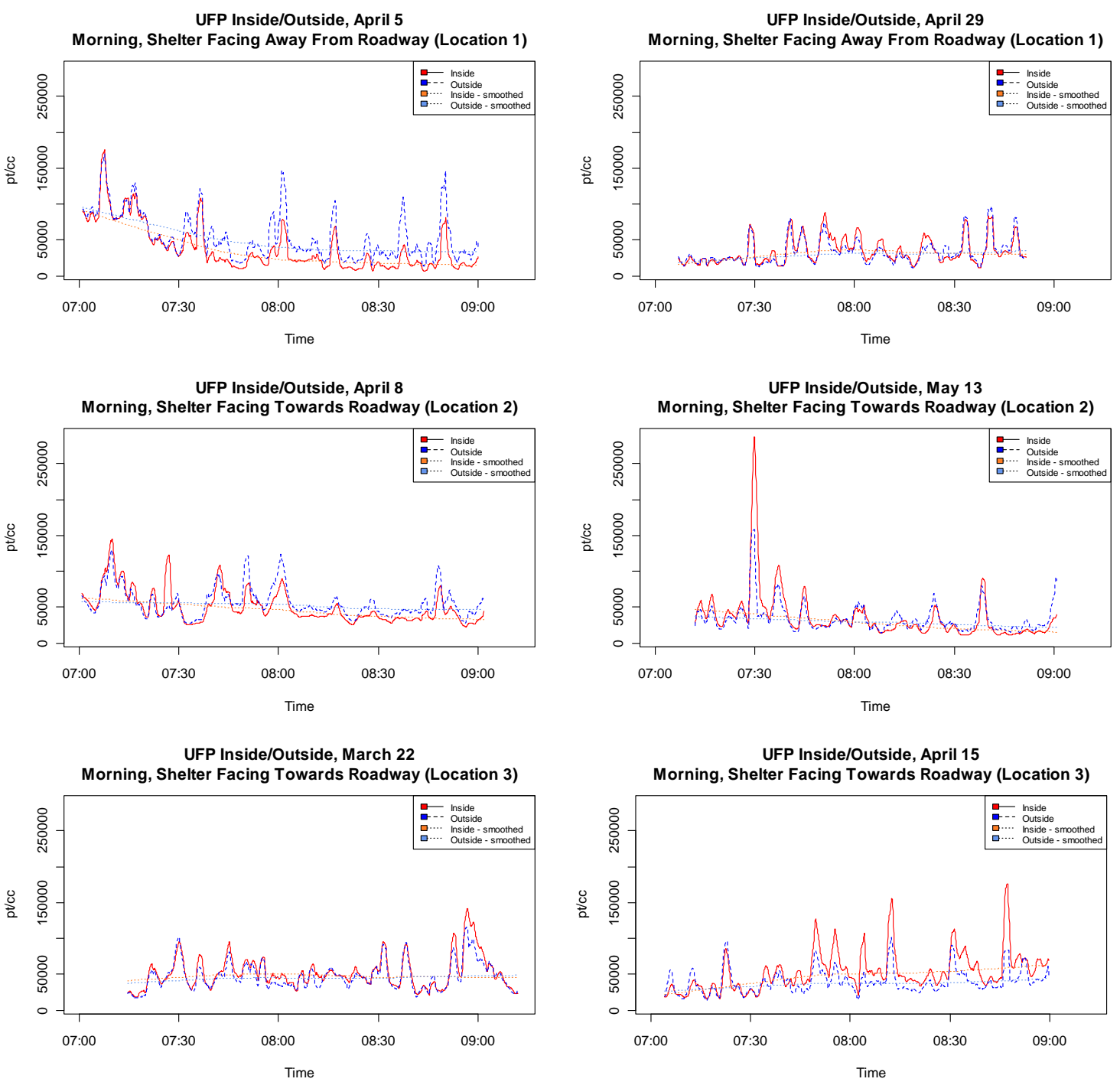

Figure 0.1: Morning UFP measurements and Loess-smoothed UFP measurements inside and outside each bus stop shelter per 5-second intervals. 

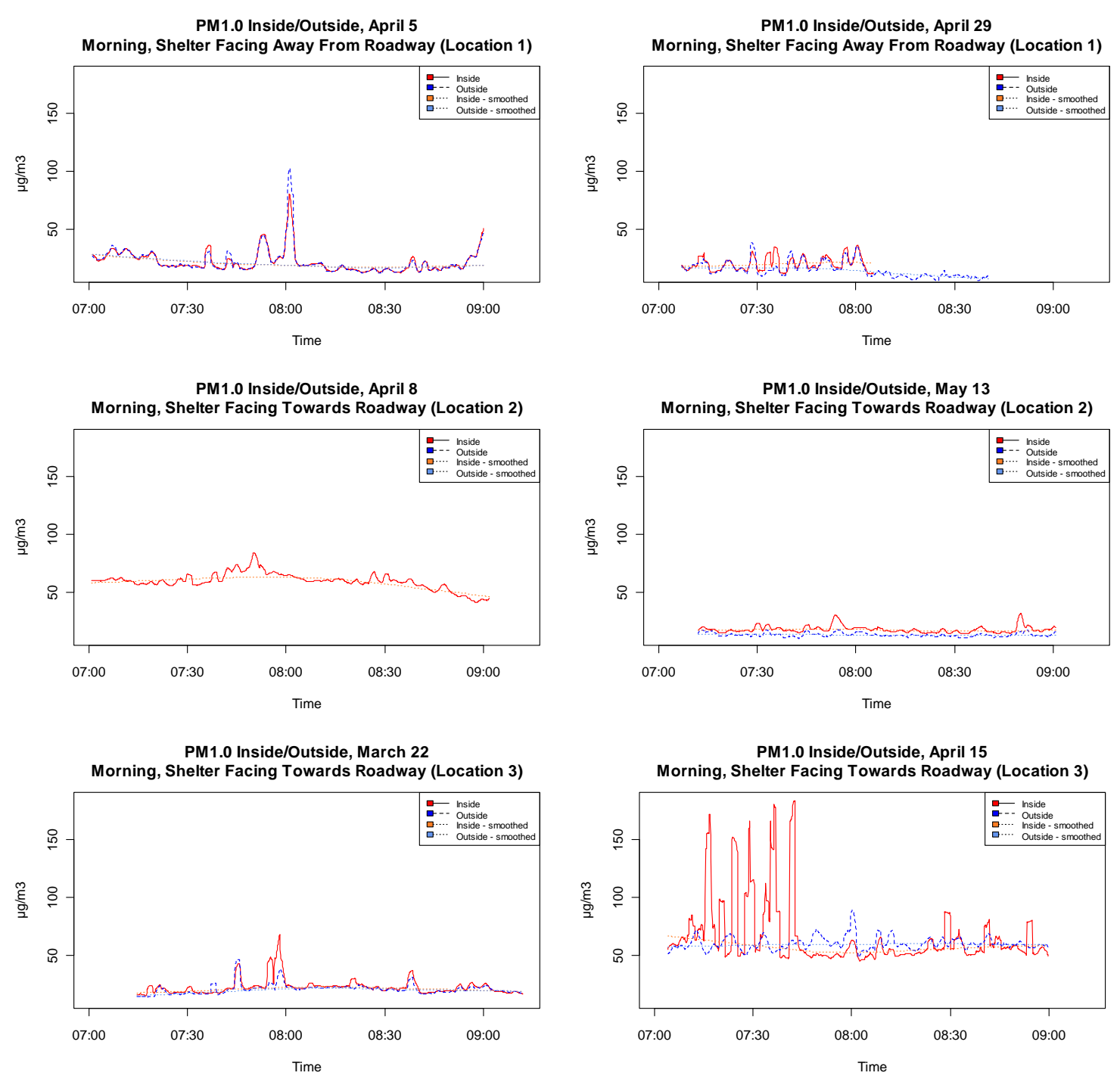

Figure 0.2: Morning $\mathrm{PM}_{1.0}$ measurements and Loess-smoothed $\mathbf{P M}_{1.0}$ measurements inside and outside each bus stop shelter per 5-second intervals. 

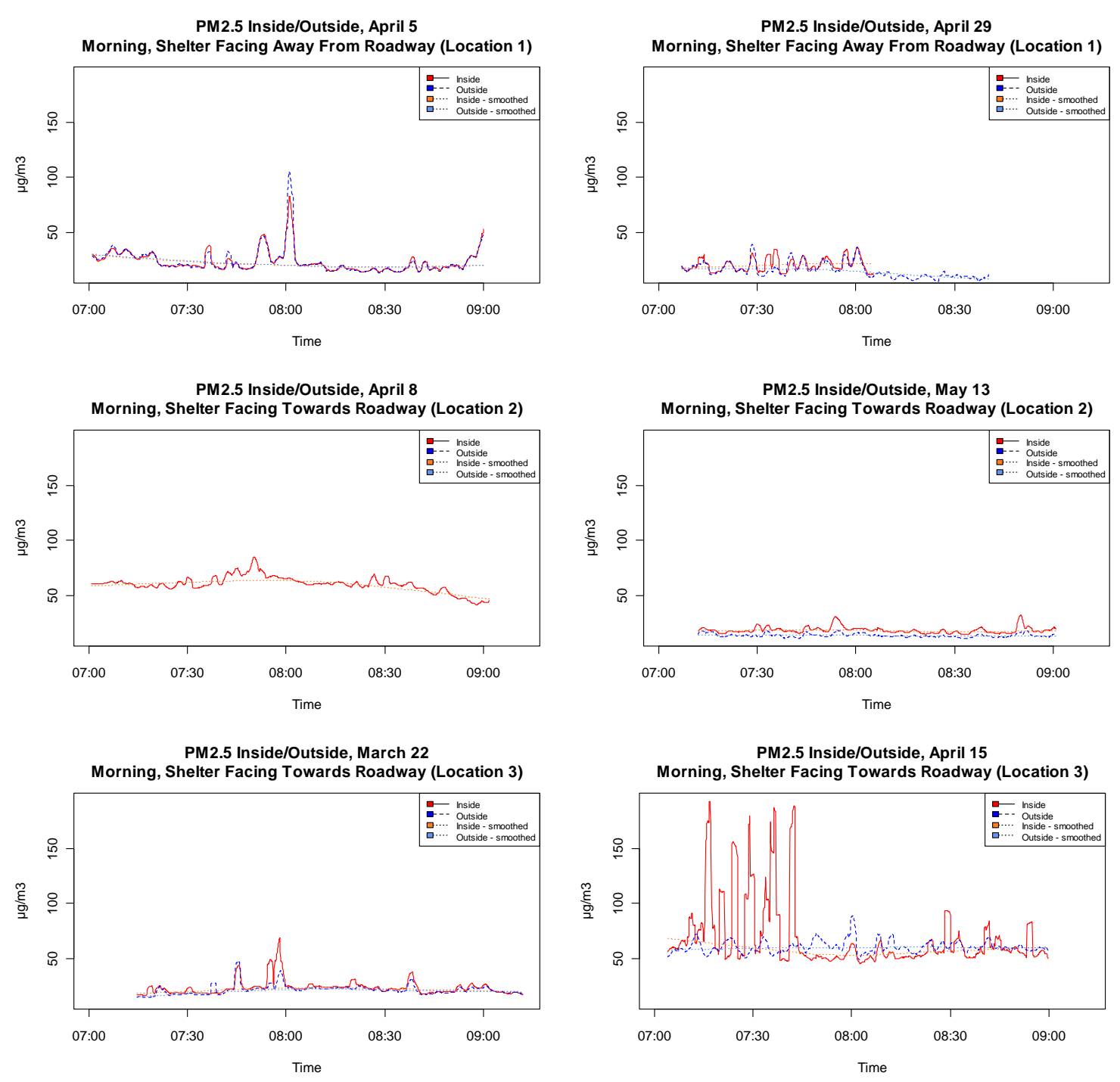

Figure 0.3: Morning $\mathrm{PM}_{2.5}$ measurements and Loess-smoothed $\mathbf{P M}_{2.5}$ measurements inside and outside each bus stop shelter per 5-second intervals. 

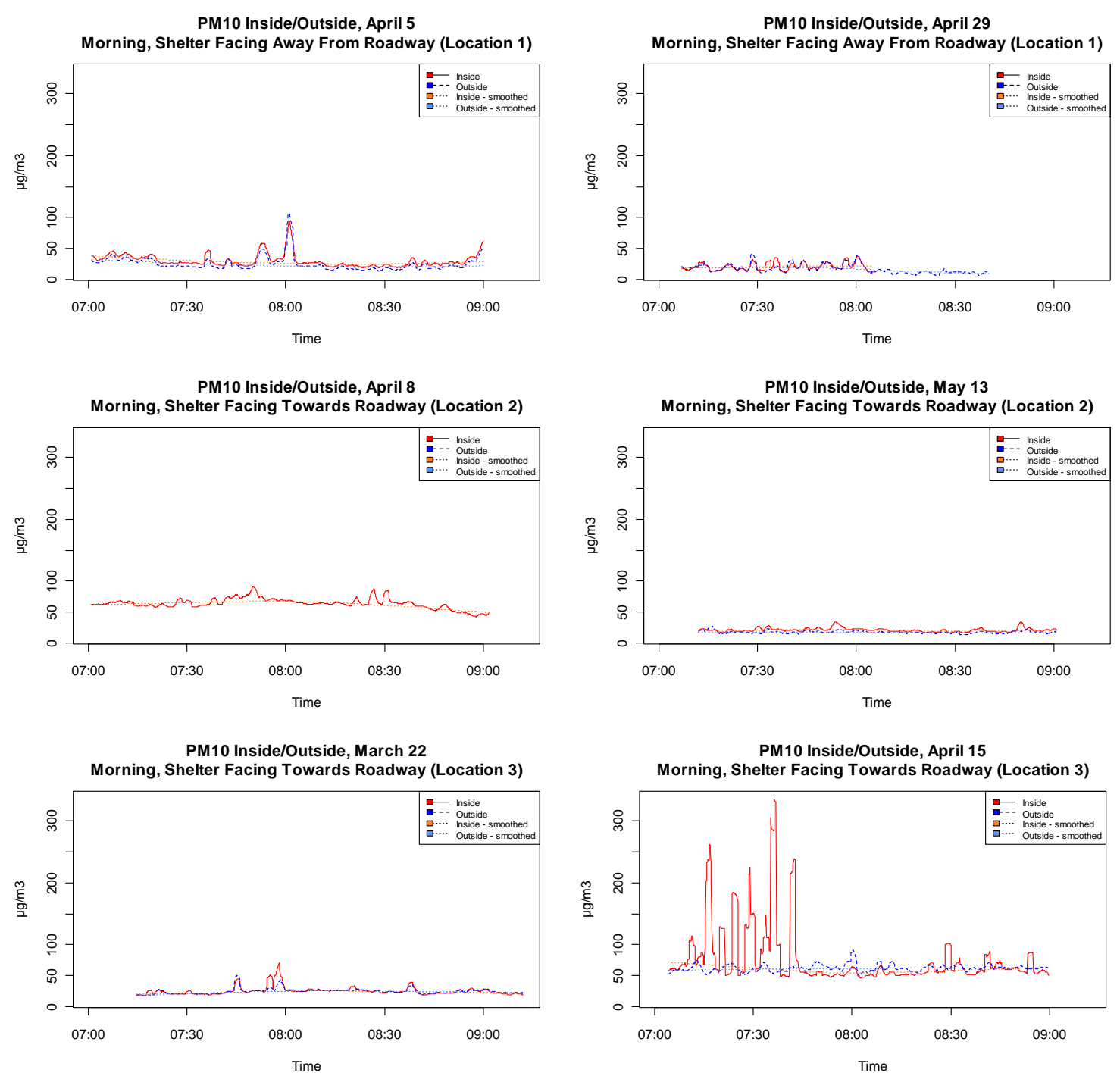

\section{Figure 0.4: Morning $P M_{10}$ measurements and Loess-smoothed $\mathrm{PM}_{10}$ measurements inside and outside each bus stop shelter per 5-second intervals.}



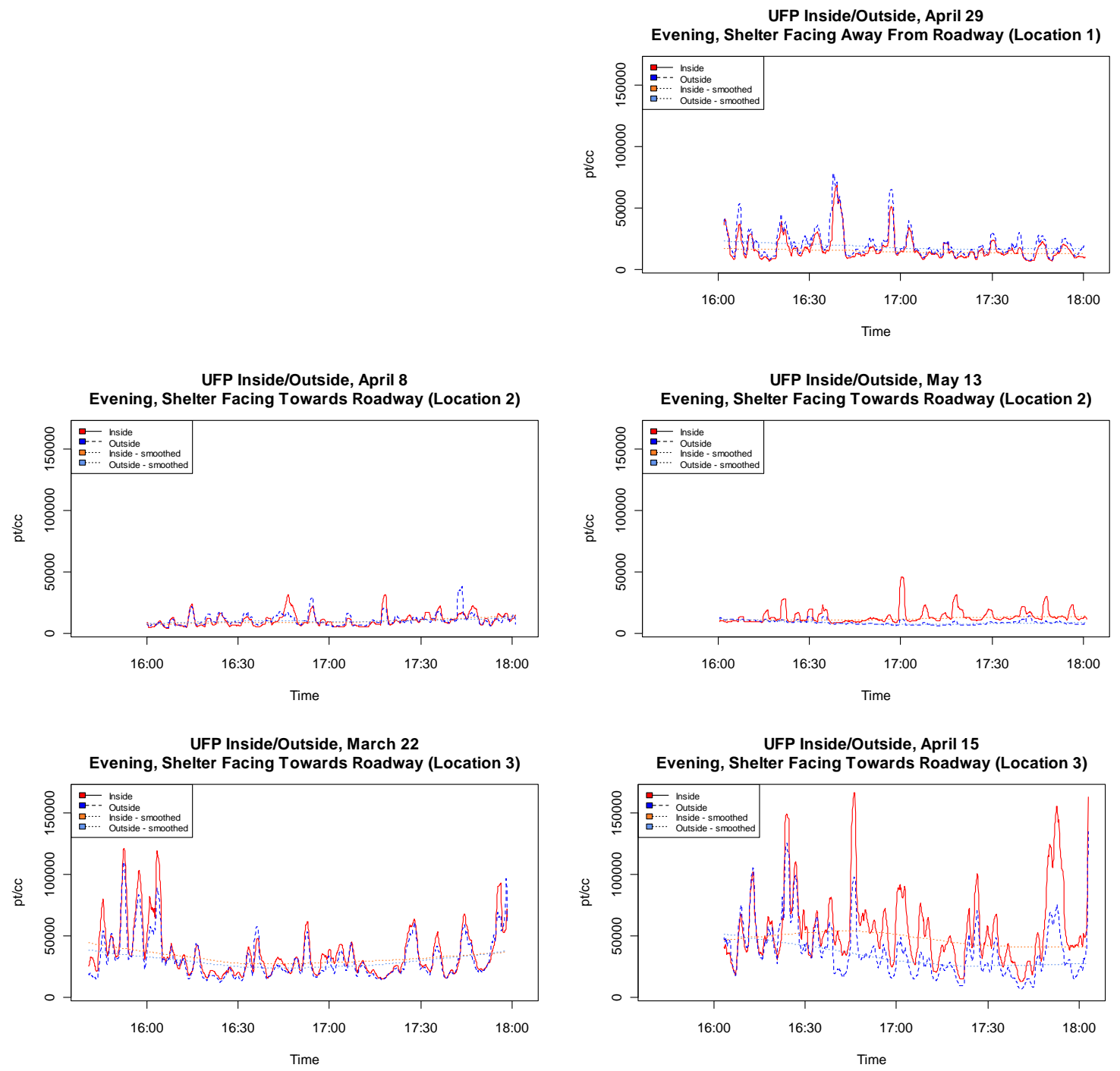

Figure 0.1: Evening UFP measurements and Loess-smoothed UFP measurements inside and outside each bus stop shelter per 5-second intervals. Note evening data are unavailable for Location 1 on April 5. 
Evening, Shelter Facing Away From Roadway (Location 1)

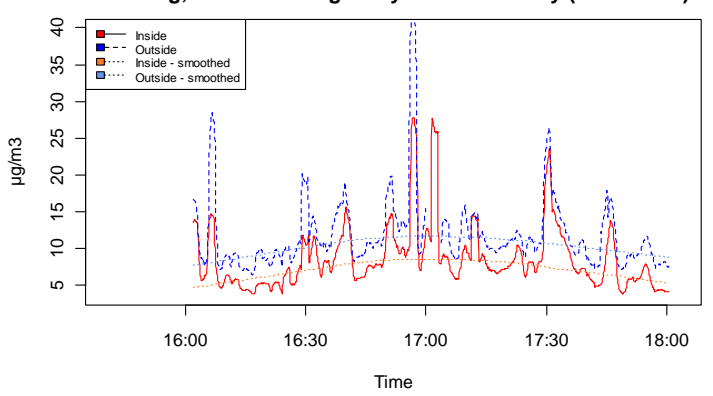

PM1.0 Inside/Outside, April 8

Evening, Shelter Facing Towards Roadway (Location 2)

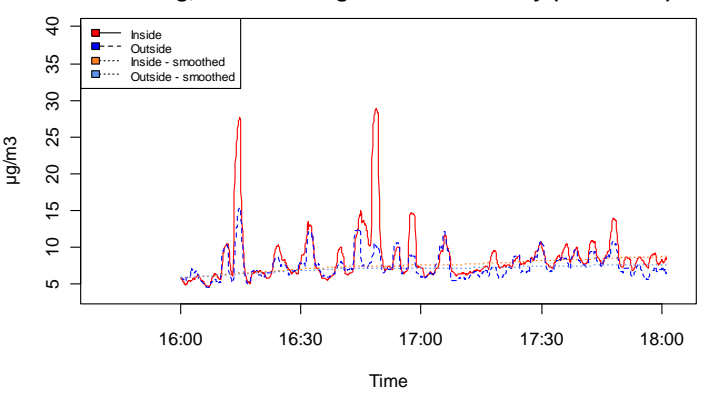

PM1.0 Inside/Outside, March 22

Evening, Shelter Facing Towards Roadway (Location 3)

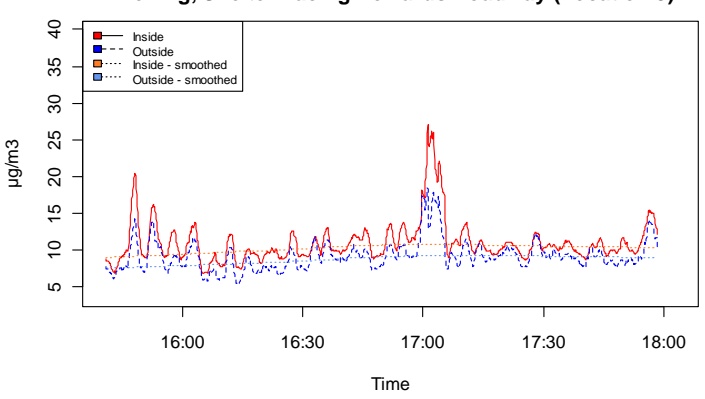

PM1.0 Inside/Outside, May 13

Evening, Shelter Facing Towards Roadway (Location 2)

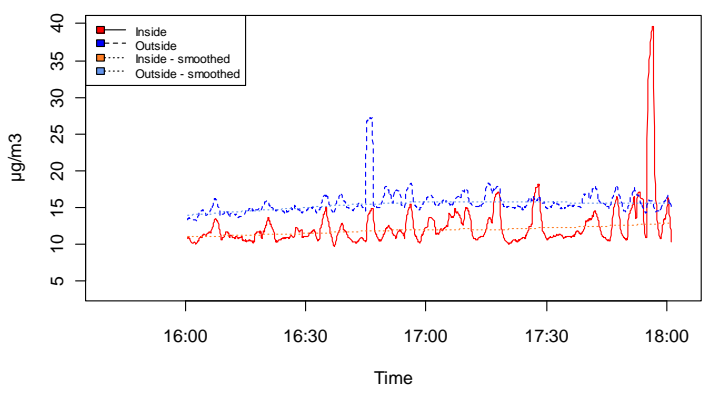

PM1.0 Inside/Outside, April 15

Evening, Shelter Facing Towards Roadway (Location 3)

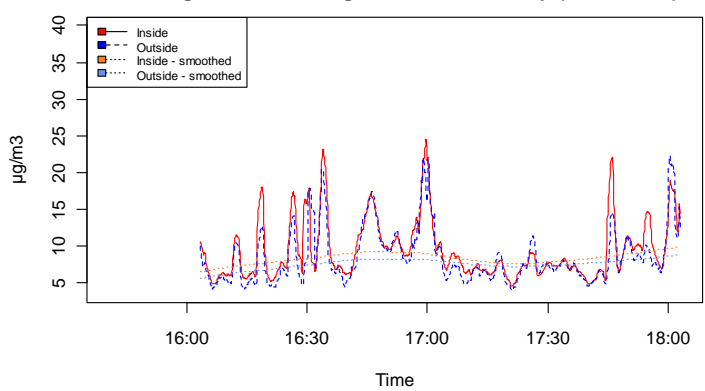

Figure 0.2: Evening $P M_{1.0}$ measurements and Loess-smoothed $\mathbf{P M}_{1.0}$ measurements inside and outside each bus stop shelter per 5-second intervals. Note evening data are unavailable for Location 1 on April 5. 

Evening, Shelter Facing Away From Roadway (Location 1)

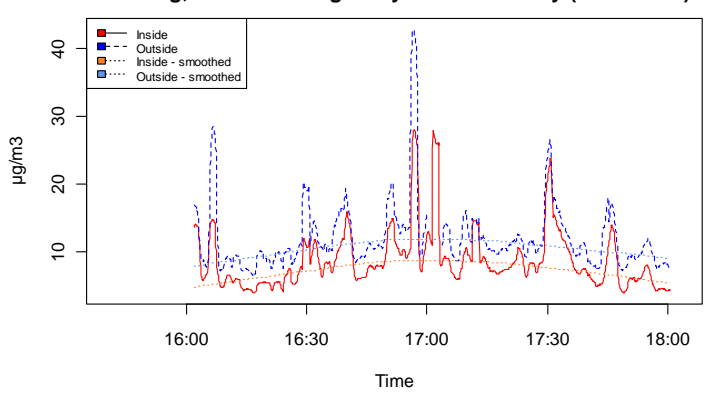

PM2.5 Inside/Outside, April 8

Evening, Shelter Facing Towards Roadway (Location 2)

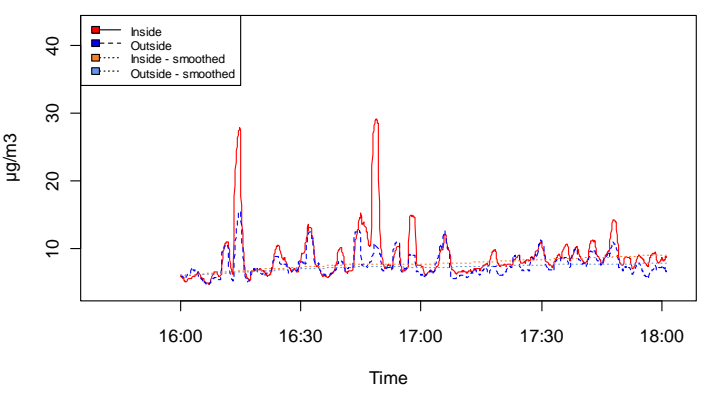

PM2.5 Inside/Outside, March 22

Evening, Shelter Facing Towards Roadway (Location 3)

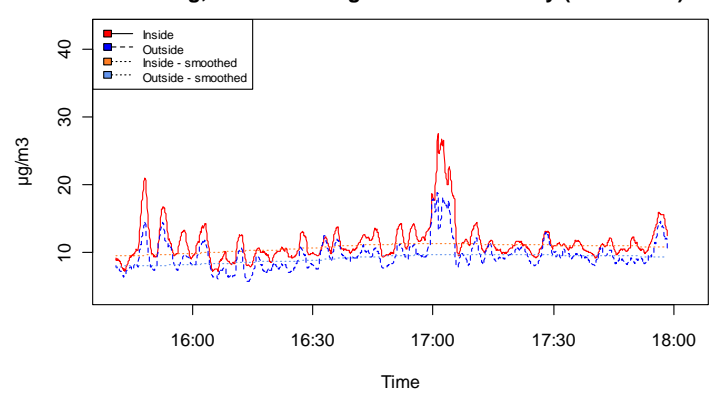

PM2.5 Inside/Outside, May 13 Evening, Shelter Facing Towards Roadway (Location 2)

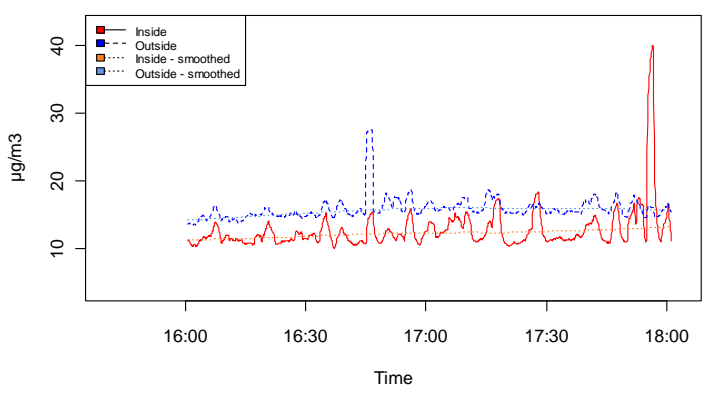

PM2.5 Inside/Outside, April 15

Evening, Shelter Facing Towards Roadway (Location 3)

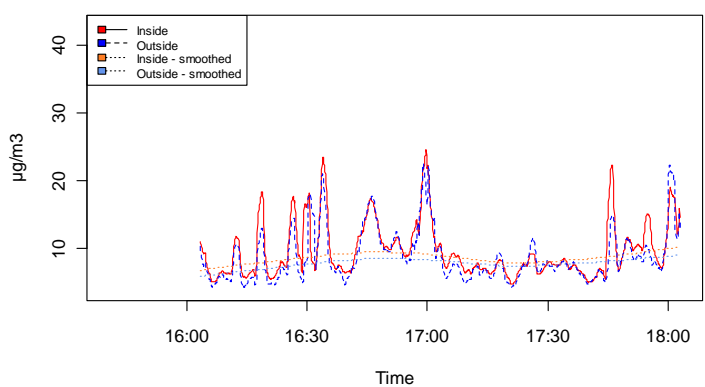

Figure 0.3: Evening $\mathbf{P M}_{2.5}$ measurements and Loess-smoothed $\mathbf{P M}_{2.5}$ measurements inside and outside each bus stop shelter per 5 -second intervals. Note evening data are unavailable for Location 1 on April 5. 


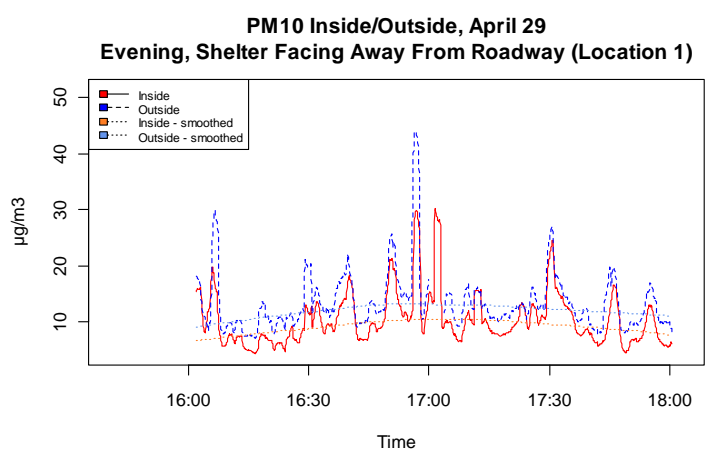

PM10 Inside/Outside, April 8

Evening, Shelter Facing Towards Roadway (Location 2)

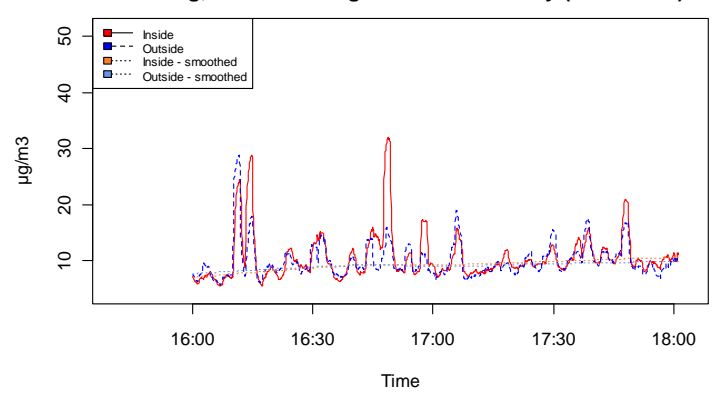

PM10 Inside/Outside, March 22

Evening, Shelter Facing Towards Roadway (Location 3)
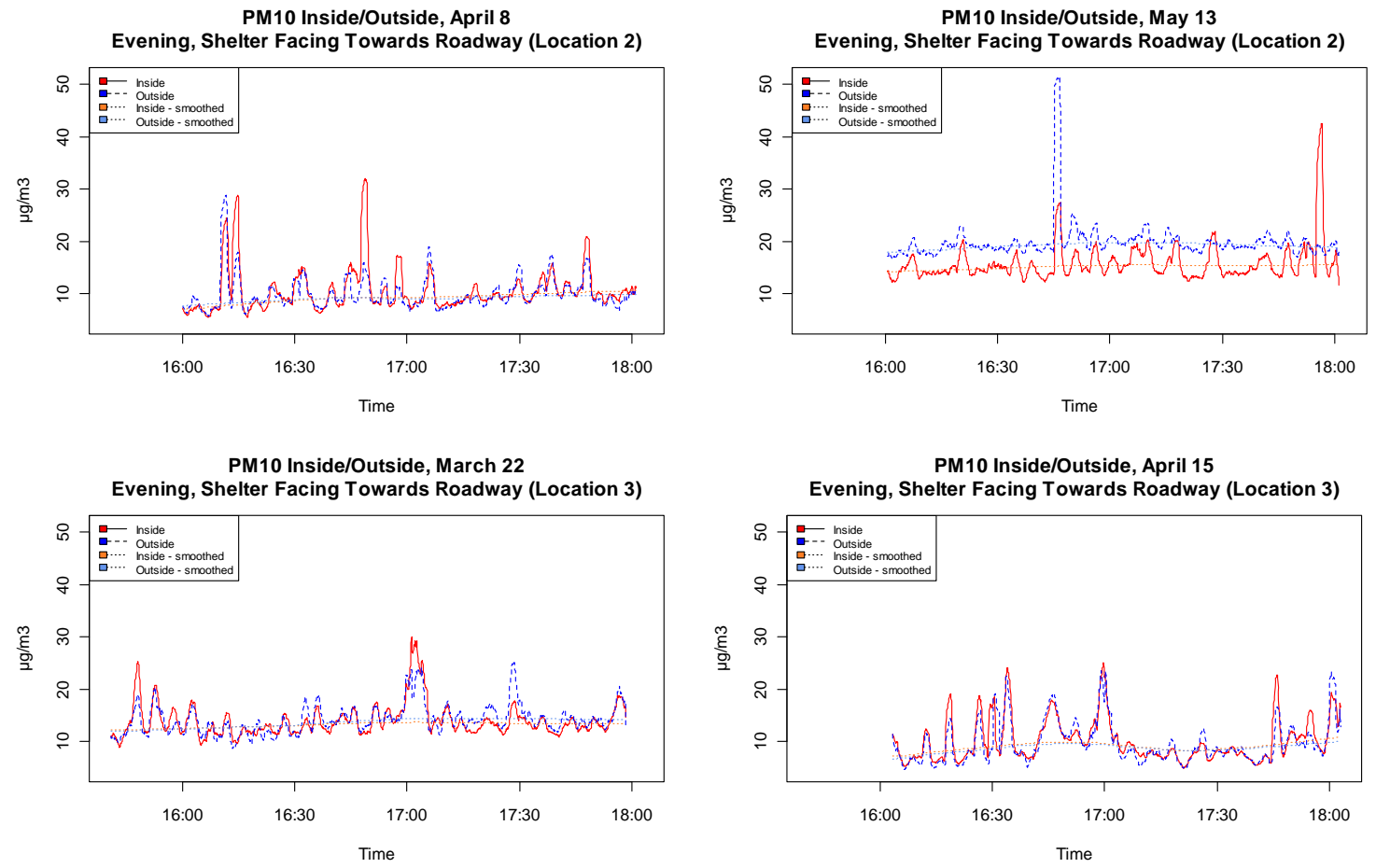

PM10 Inside/Outside, April 15

Evening, Shelter Facing Towards Roadway (Location 3)

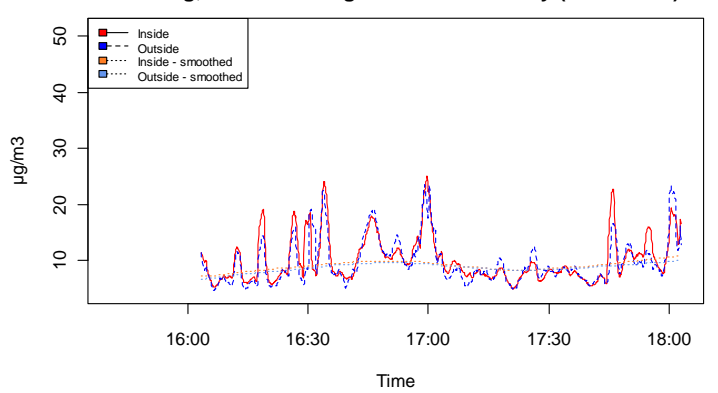

Figure 0.4: Evening $P M_{10}$ measurements and Loess-smoothed $\mathrm{PM}_{10}$ measurements inside and outside each bus stop shelter per 5-second intervals. Note evening data are unavailable for Location 1 on April 5. 


\section{APPENDIX D - Wind Effects on Particulate Concentration}

\section{UFP - Wind Measurements}
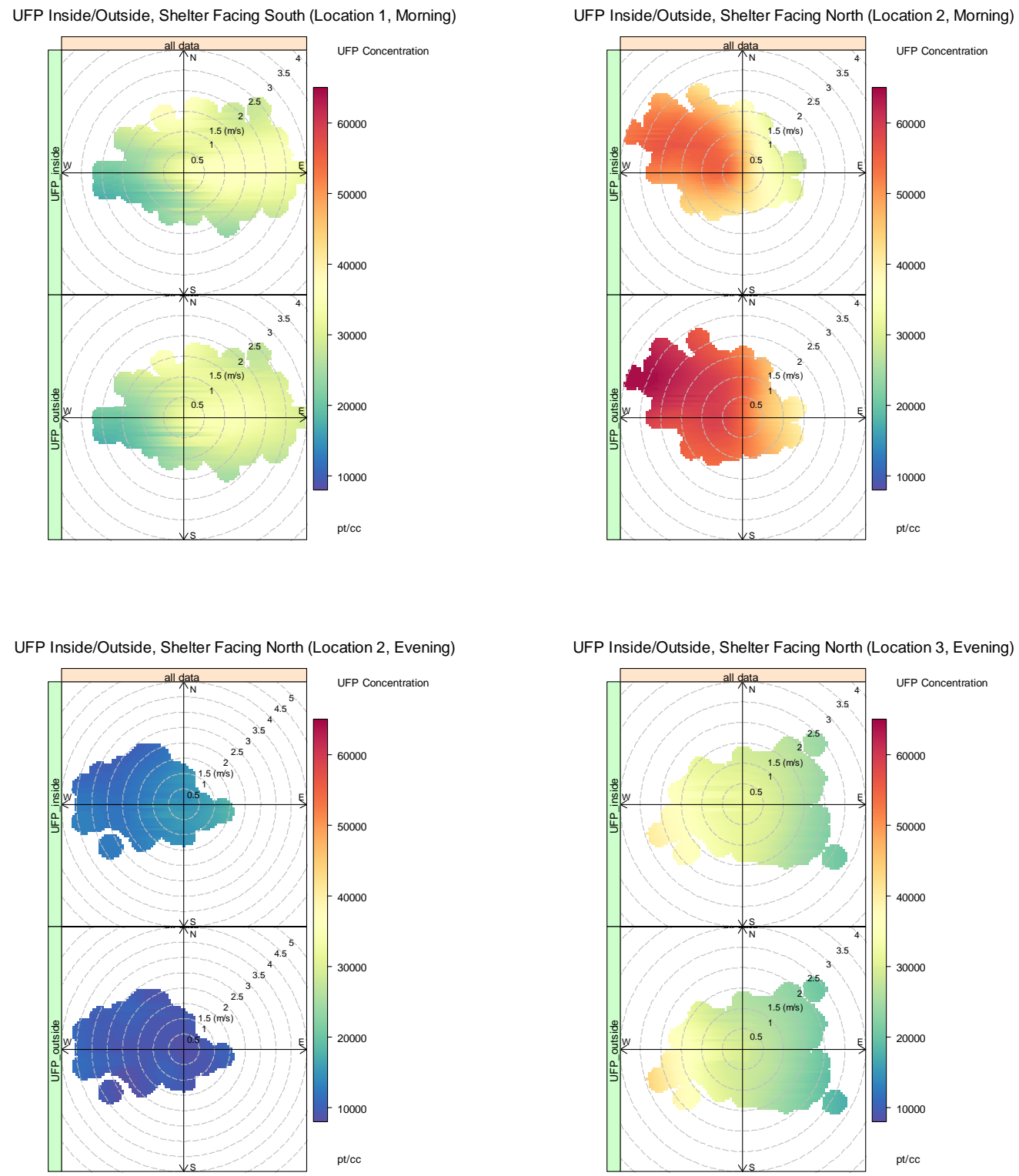

Figure 0.1: Bivariate polar plots illustrating wind speed and direction effects on UFP concentrations at each location. 
$P M_{1.0}-$ Wind Measurements

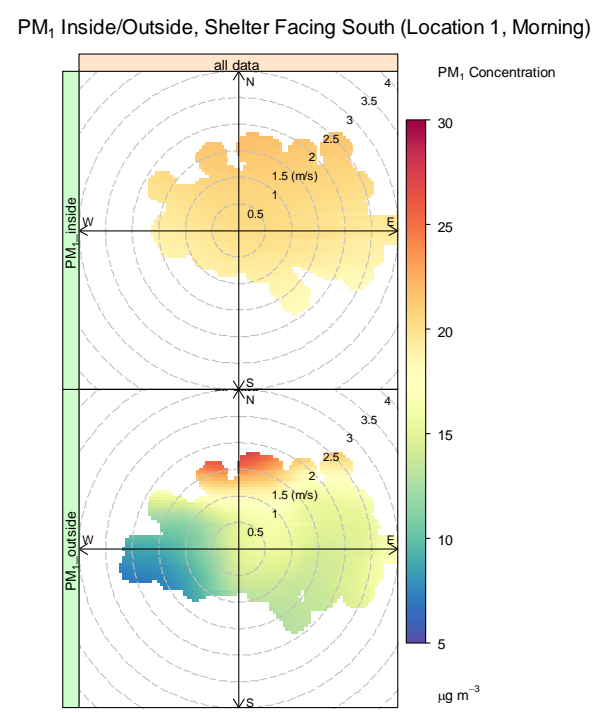

$\mathrm{PM}_{1}$ Inside/Outside, Shelter Facing North (Location 3, Evening)

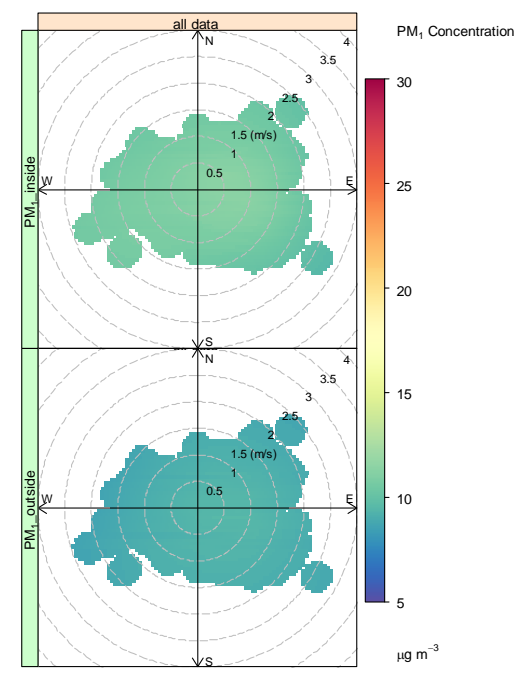

$\mathrm{PM}_{1}$ Inside/Outside, Shelter Facing North (Location 2, Evening)

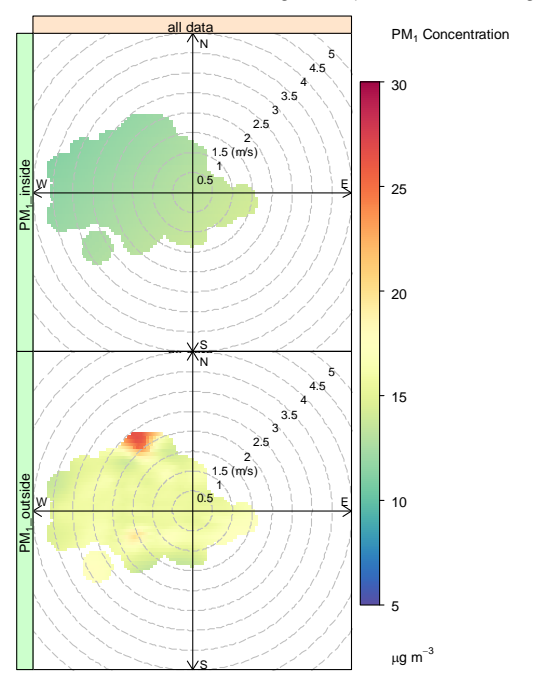

Figure 0.1: Bivariate polar plots illustrating wind speed and direction effects on $\mathbf{P M}_{1.0}$ concentrations at each location. 

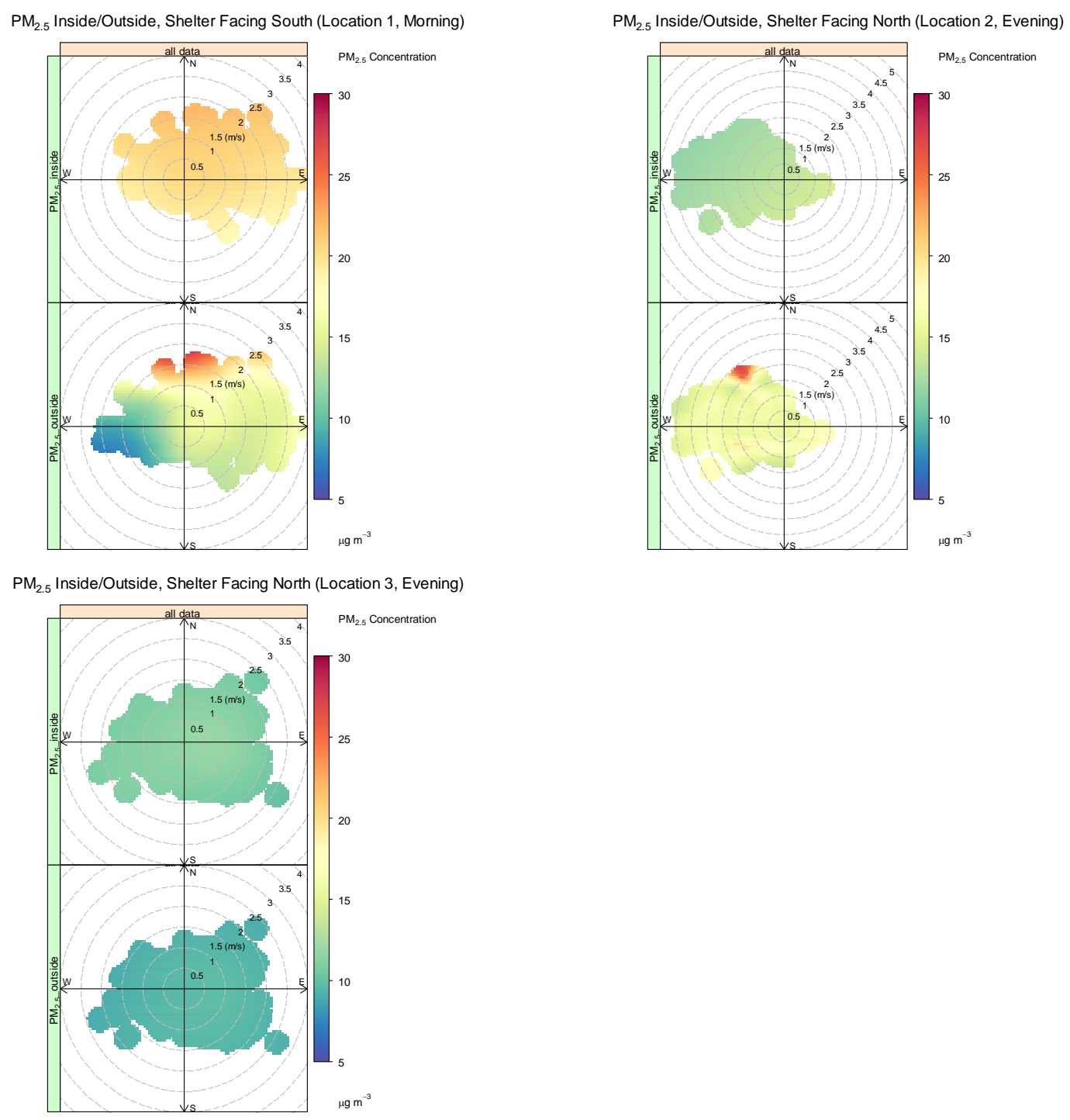

Figure 0.1: Bivariate polar plots illustrating wind speed and direction effects on $\mathrm{PM}_{2.5}$ concentrations at each location. 
$P M_{10}-$ Wind Measurements
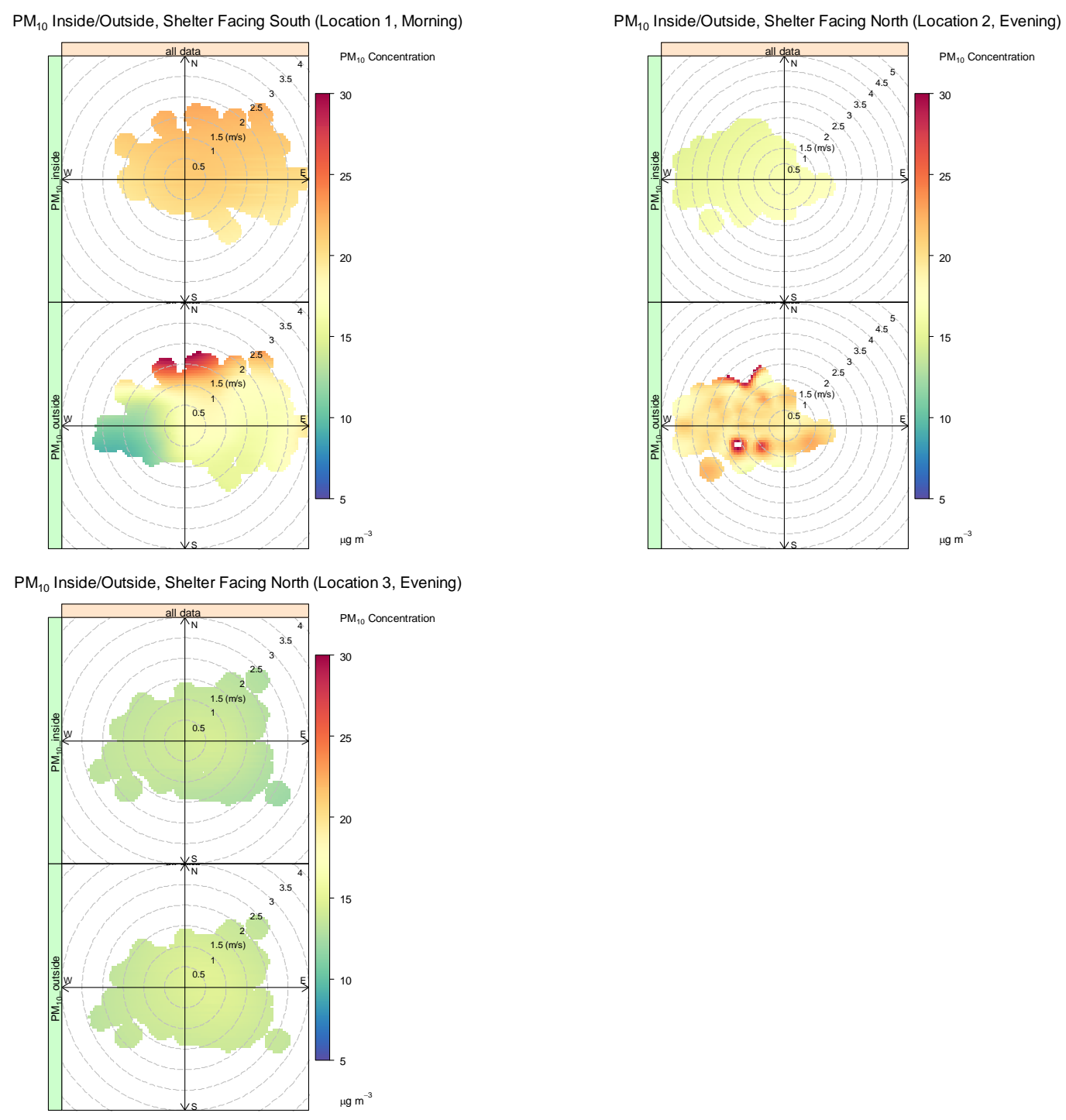

Figure 0.1: Bivariate polar plots illustrating wind speed and direction effects on $\mathbf{P M}_{10}$ concentrations at each location. 


\section{APPENDIX E - Vehicle and Particulate Interactions}

Morning Vehicle Measurements
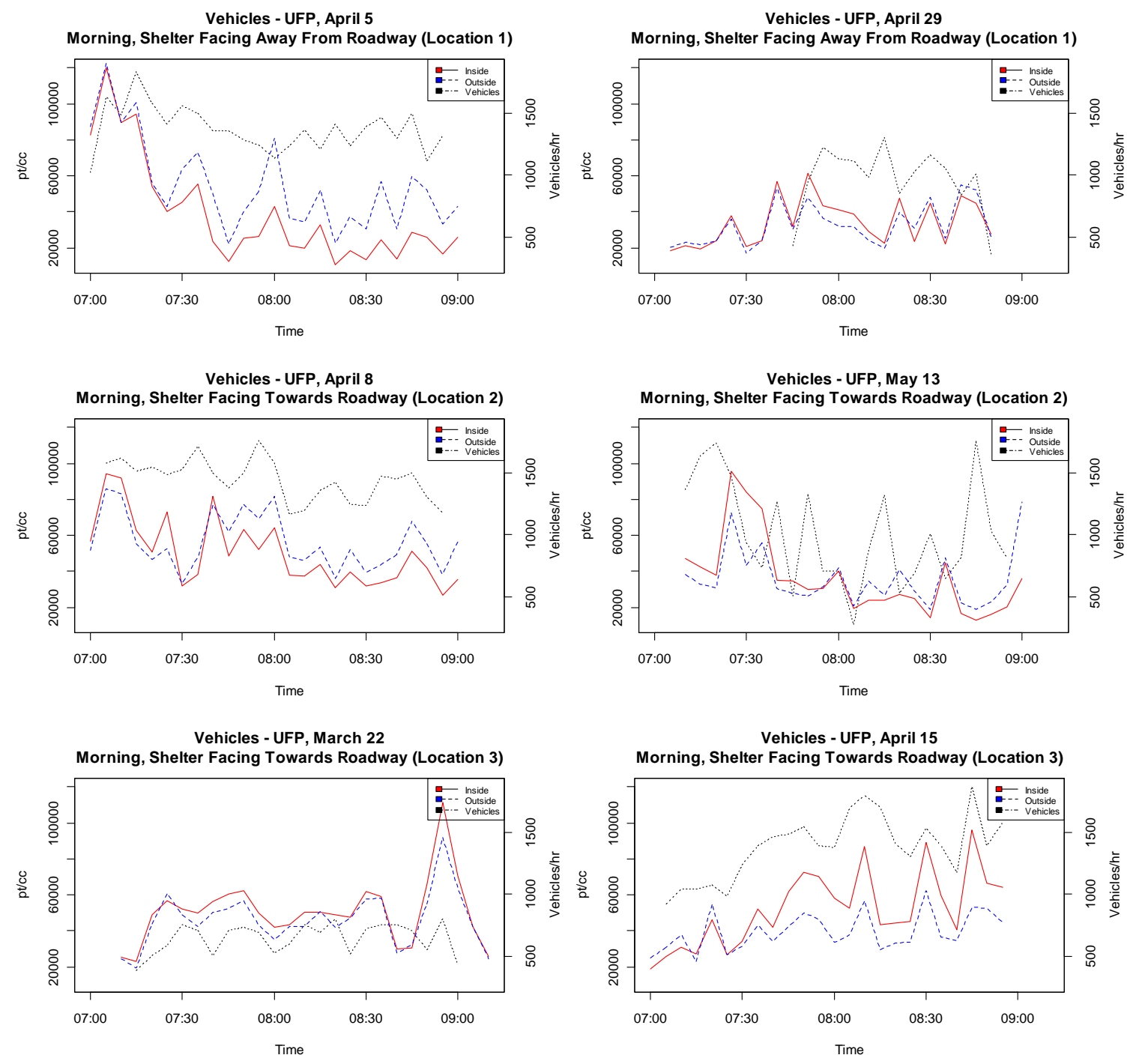

Figure 0.1: Morning UFP measurements inside and outside each bus stop shelter overlaid with vehicle counts per 5-minute time intervals. 

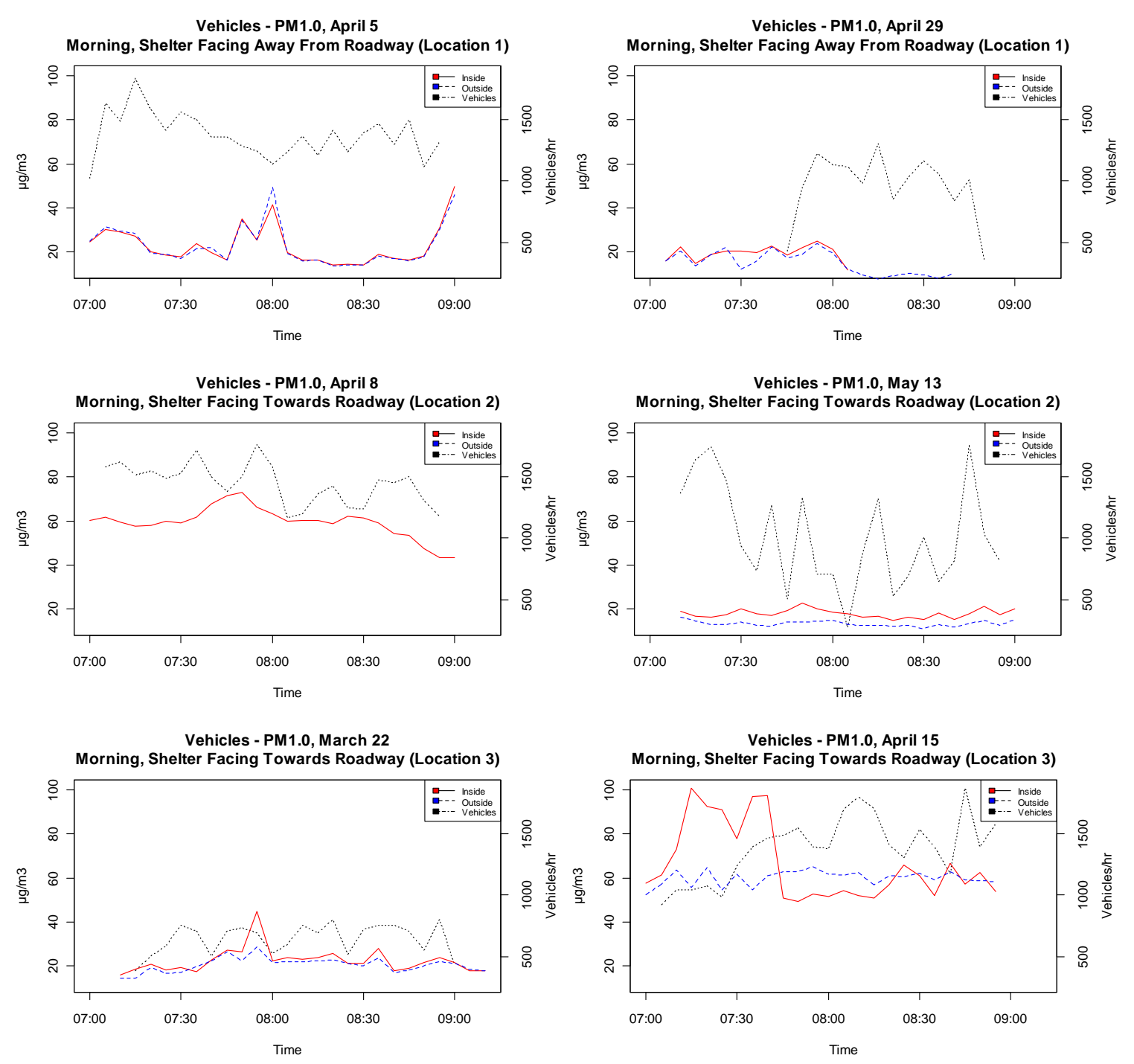

Figure 0.2: Morning $\mathrm{PM}_{1.0}$ measurements inside and outside each bus stop shelter overlaid with vehicle counts per 5-minute time intervals. 

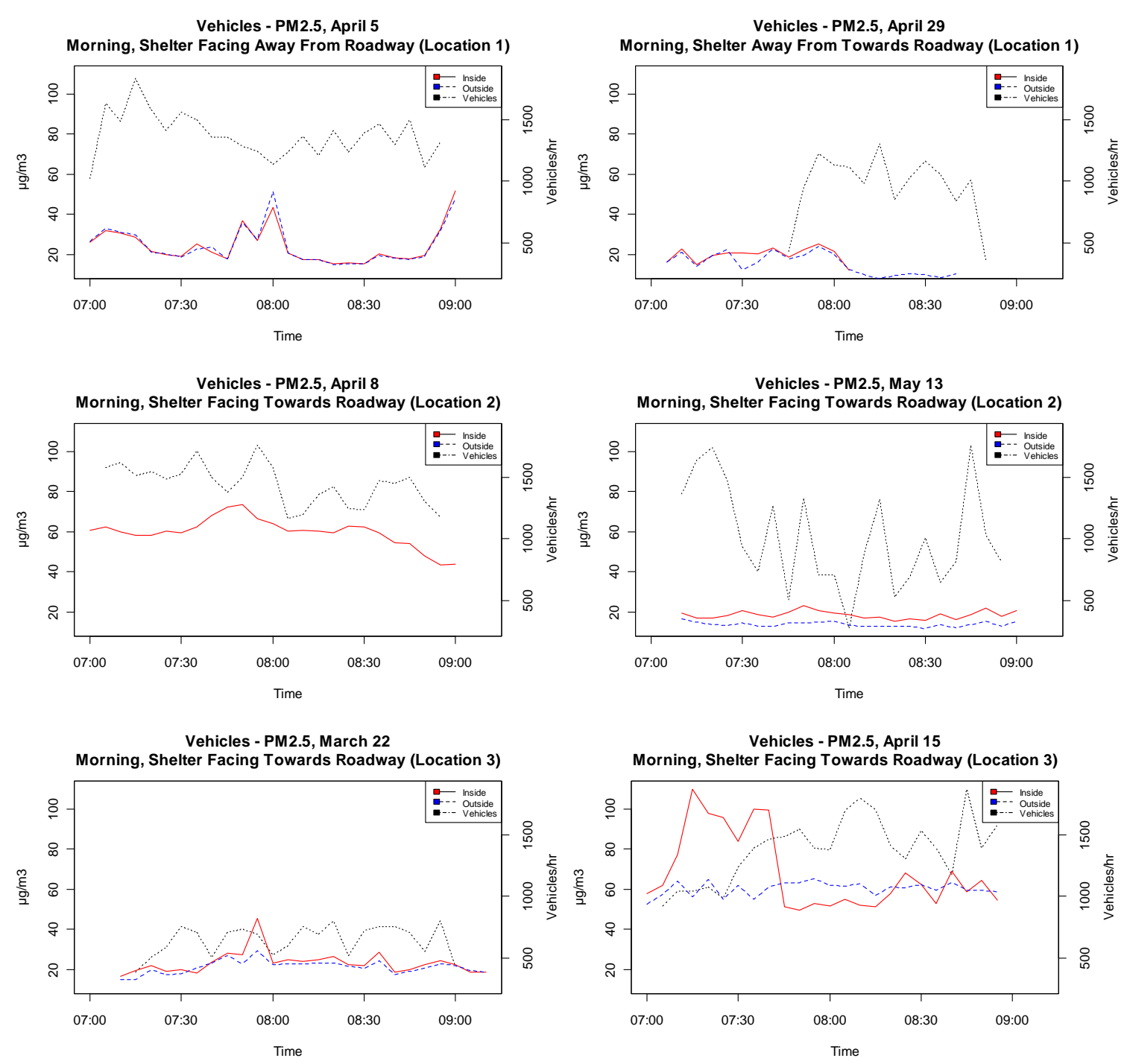

Figure 0.3: Morning $\mathrm{PM}_{2.5}$ measurements inside and outside each bus stop shelter overlaid with vehicle counts per 5-minute time intervals. 

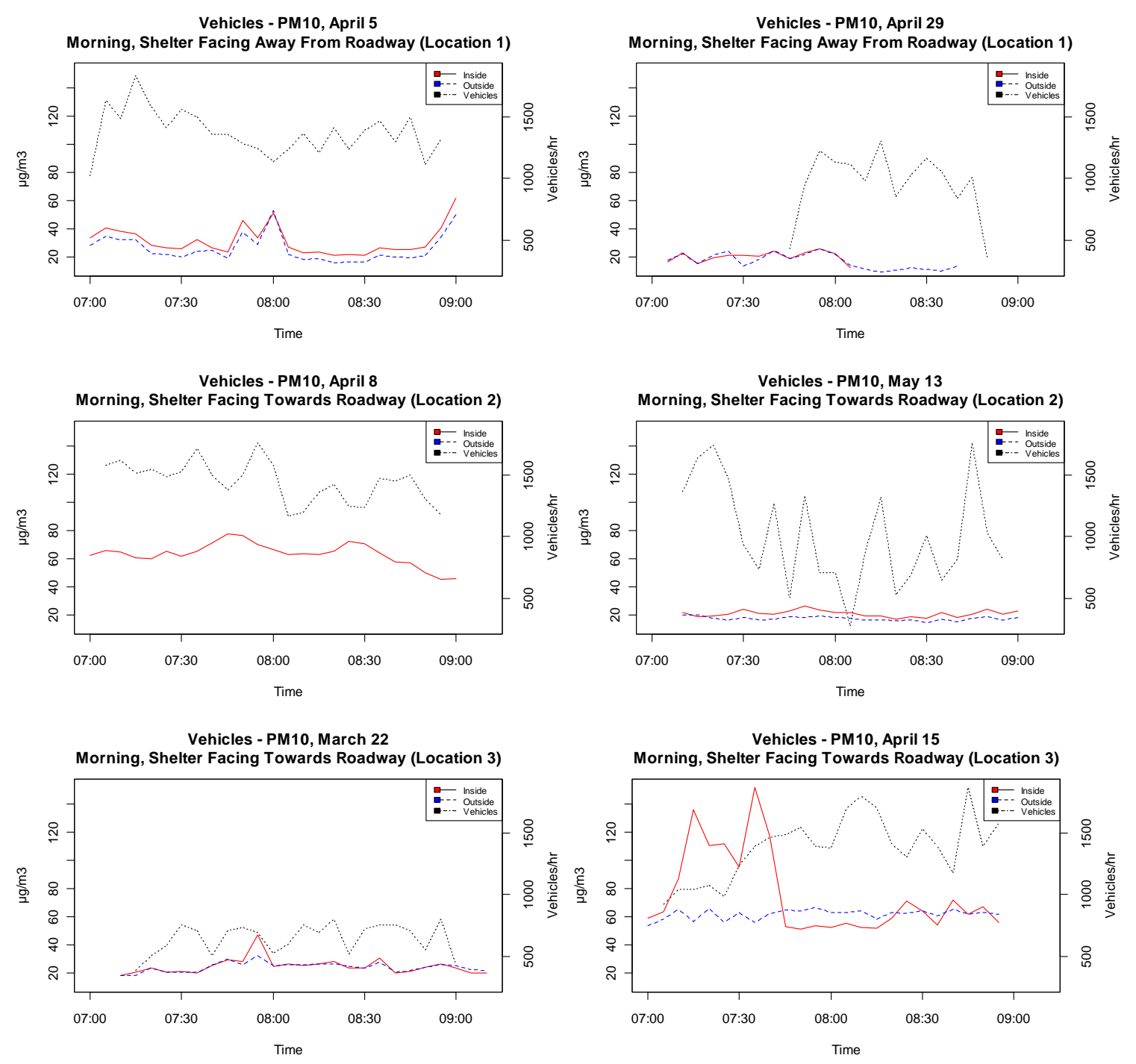

Figure 0.4: Morning $\mathrm{PM}_{10}$ measurements inside and outside each bus stop shelter
overlaid with vehicle counts per 5-minute time intervals. 
Evening Vehicle Measurements

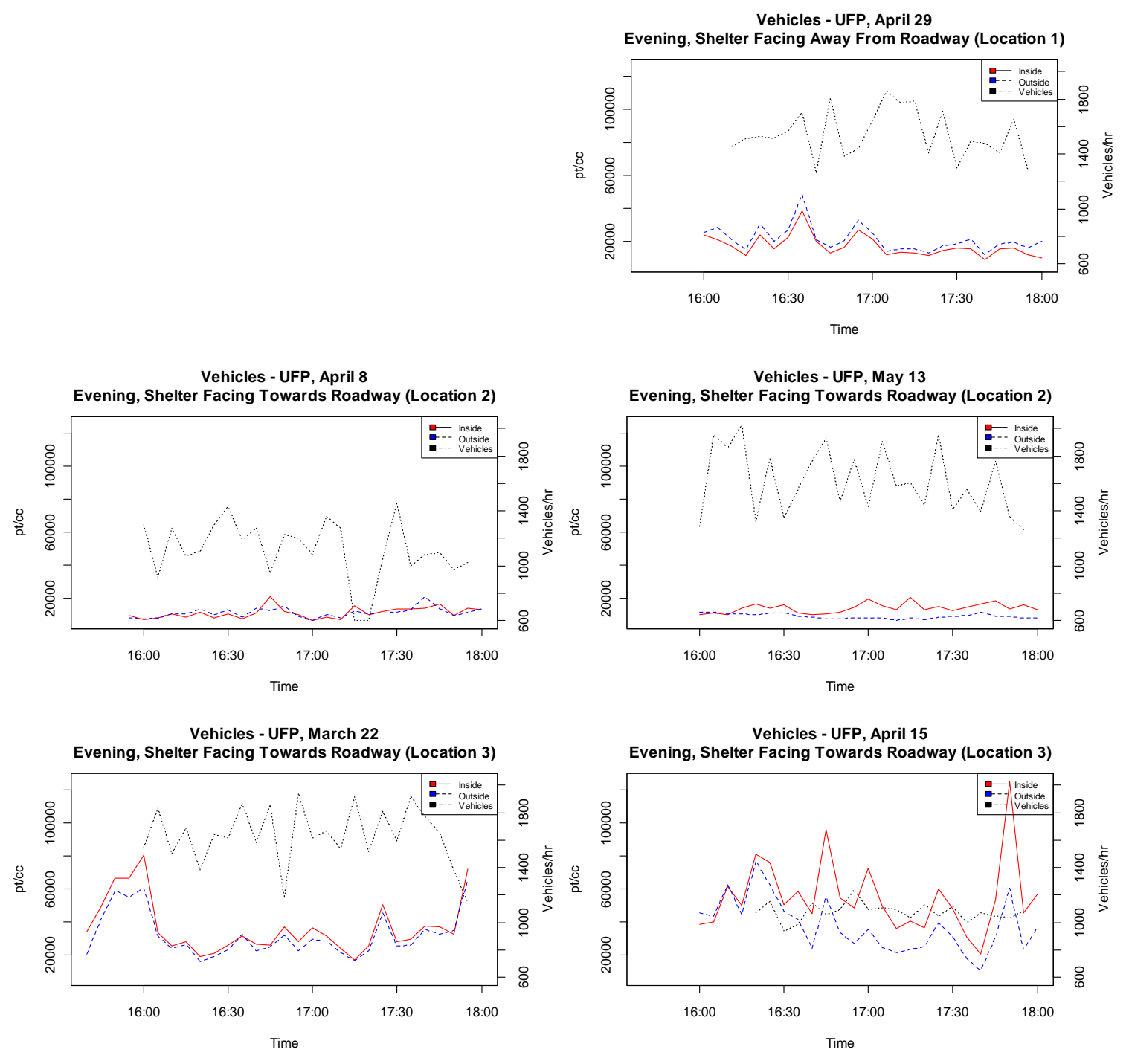

Figure 0.1: Evening UFP measurements inside and outside each bus stop shelter overlaid with vehicle counts per 5-minute time intervals. Note data are unavailable for Location 1 on April 5. 


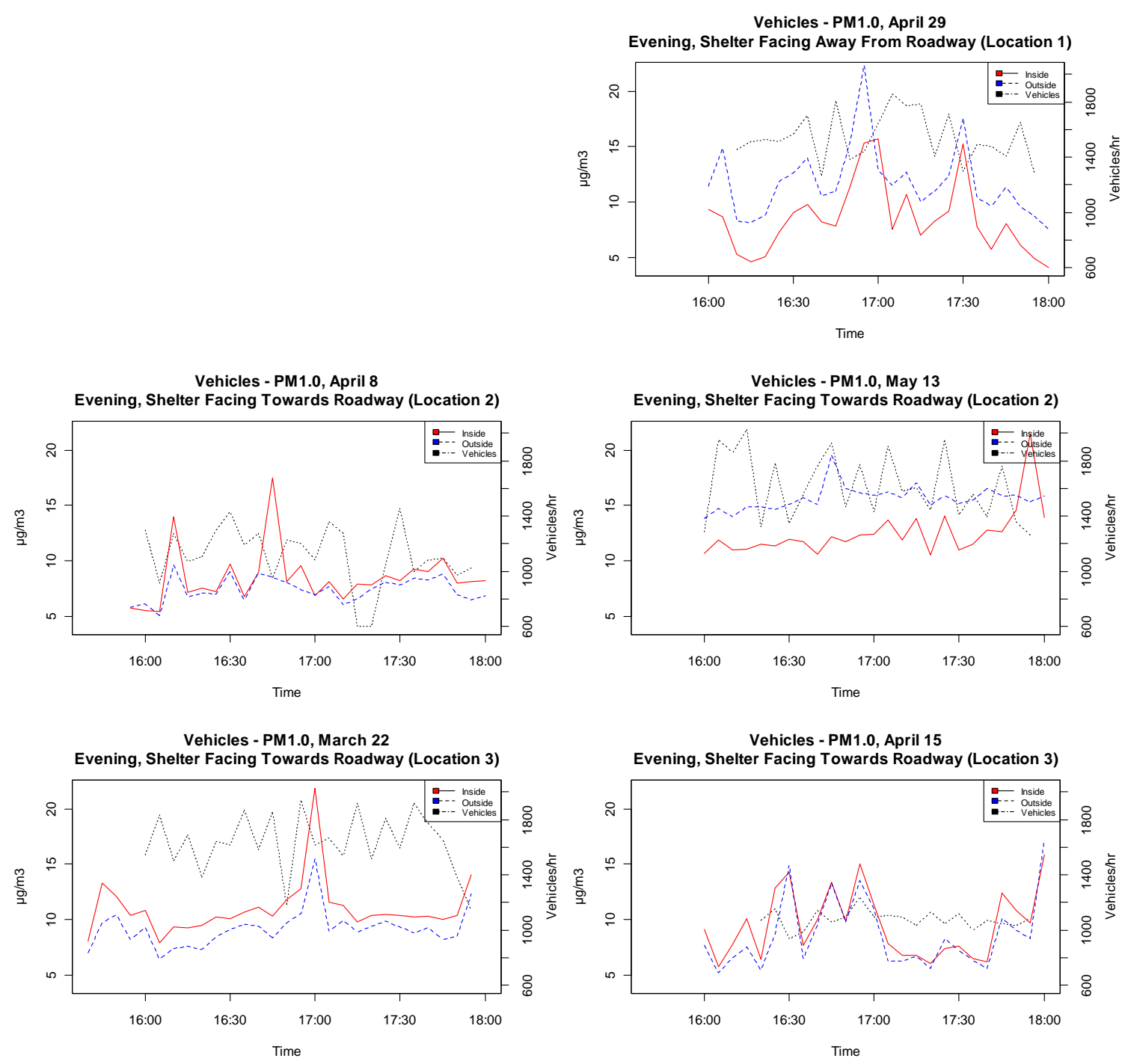

Figure 0.2: Evening $\mathrm{PM}_{1.0}$ measurements inside and outside each bus stop shelter overlaid with vehicle counts per 5-minute time intervals. Note data are unavailable for Location 1 on April 5. 


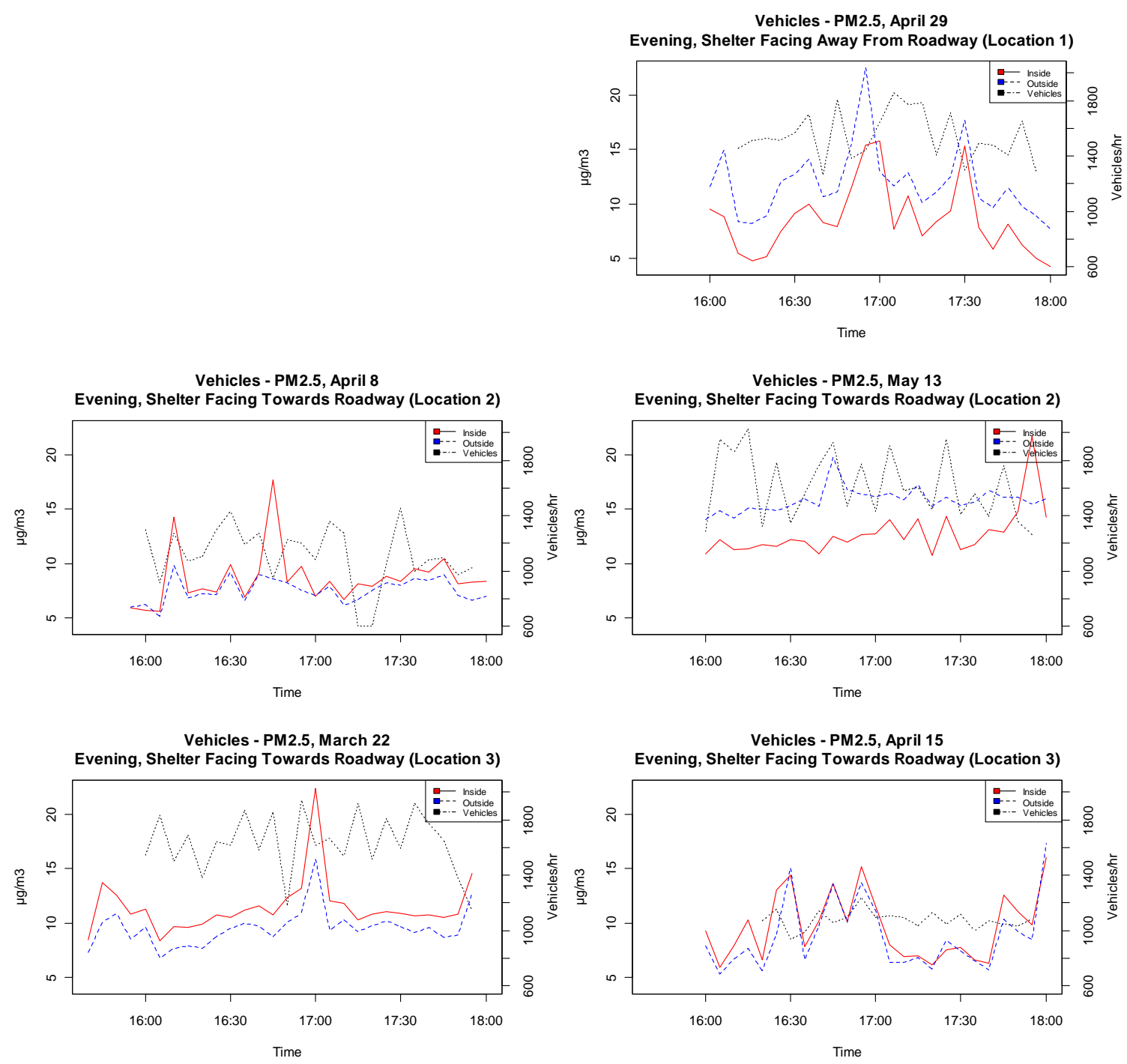

Figure 0.3: Evening $\mathbf{P M}_{2.5}$ measurements inside and outside each bus stop shelter overlaid with vehicle counts per 5-minute time intervals. Note data are unavailable for Location 1 on April 5. 

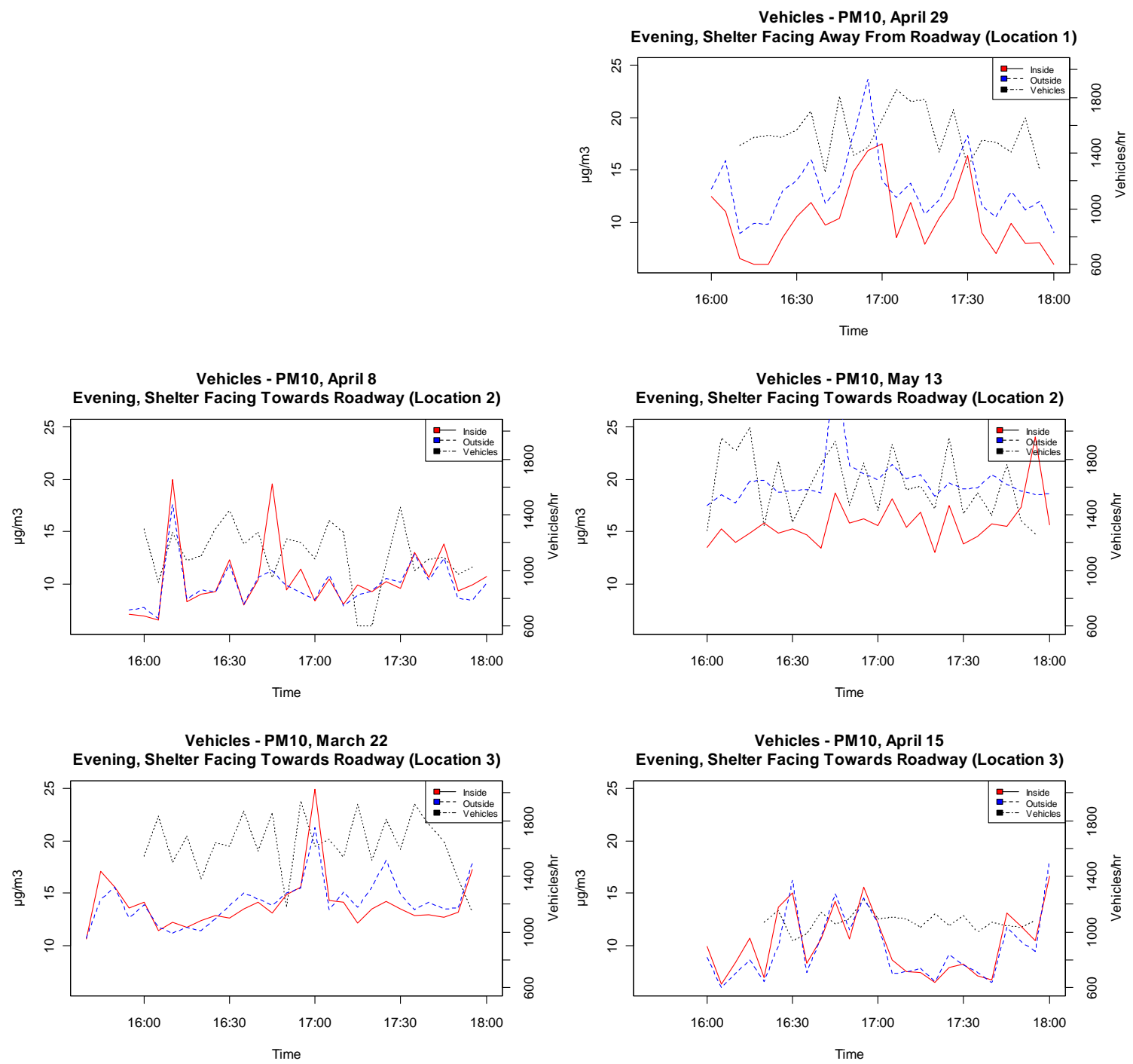

Figure 0.4: Evening $\mathrm{PM}_{10}$ measurements inside and outside each bus stop shelter overlaid with vehicle counts per 5-minute time intervals. Note data are unavailable for Location 1 on April 5. 